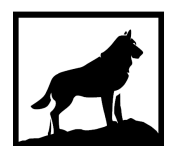

Michigan

Technological

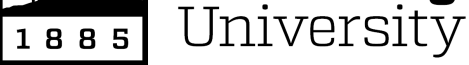

Michigan Technological University

Digital Commons @ Michigan Tech

DEVELOPMENT OF A HIGH-FIDELITY MODEL AND KALMAN FILTER BASED STATE ESTIMATOR FOR SIMULATION AND CONTROL OF NOX REDUCTION PERFORMANCE OF A SCR CATALYST ON A DPF

Venkata Rajesh Chundru

Michigan Technological University, vrchundr@mtu.edu

Copyright 2017 Venkata Rajesh Chundru

Recommended Citation

Chundru, Venkata Rajesh, "DEVELOPMENT OF A HIGH-FIDELITY MODEL AND KALMAN FILTER BASED STATE ESTIMATOR FOR SIMULATION AND CONTROL OF NOX REDUCTION PERFORMANCE OF A SCR CATALYST ON A DPF", Open Access Master's Report, Michigan Technological University, 2017.

https://doi.org/10.37099/mtu.dc.etdr/417

Follow this and additional works at: https://digitalcommons.mtu.edu/etdr

Part of the Acoustics, Dynamics, and Controls Commons, Automotive Engineering Commons, and the Energy Systems Commons 


\title{
DEVELOPMENT OF A HIGH-FIDELITY MODEL AND KALMAN FILTER BASED STATE ESTIMATOR FOR SIMULATION AND CONTROL OF NOX REDUCTION PERFORMANCE OF A SCR CATALYST ON A DPF
}

\author{
By \\ Venkata Rajesh Chundru
}

A REPORT

Submitted in partial fulfillment of the requirements for the degree

of

MASTER OF SCIENCE

in Mechanical Engineering

\section{MICHIGAN TECHNOLOICAL UNIVERSITY 2017}

(C) 2017 Venkata Rajesh Chundru 
This report has been approved in partial fulfillment of the requirements for the Degree of MASTER OF SCIENCE in Mechanical Engineering.

\section{Department of Mechanical Engineering - Engineering Mechanics}

Report Co-Advisor: Dr. Gordon G. Parker

Report Co-Advisor: Dr. John H. Johnson

Committee Member: Dr. Jeffery D. Naber

Committee Member: Dr. Sunil S. Mehendale

Department Chair: $\quad$ Dr. William Predebon 


\section{Table of Contents}

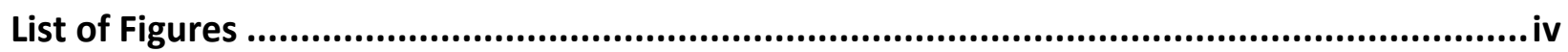

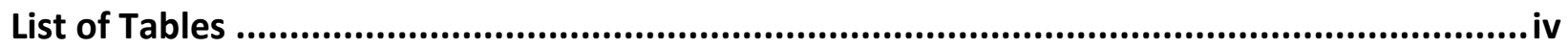

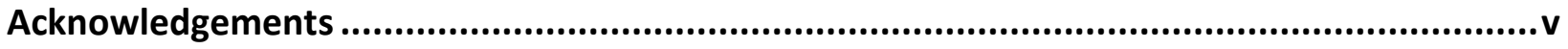

Nomenclature ................................................................................................................... vi

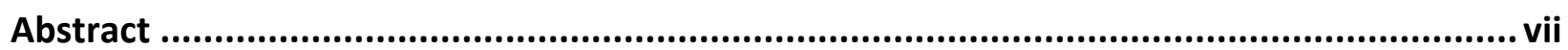

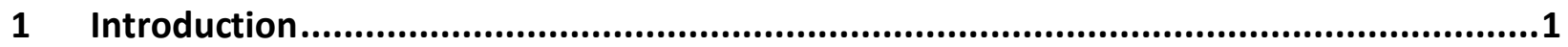

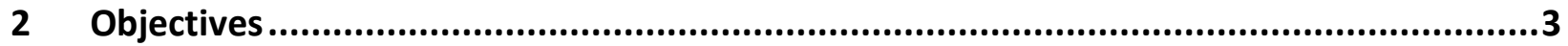

2.1 High fidelity model objectives ....................................................................................3

2.2 Reduced order model and estimator objectives..........................................................3

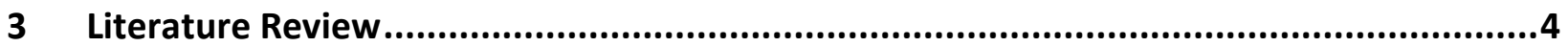

3.1 SCR-F high fidelity models....................................................................................4

3.2 SCR catalyst on an DPF experimental studies...........................................................10

3.3 SCR / SCR-F state estimator studies...................................................................13

3.4 Literature review overview ......................................................................................18

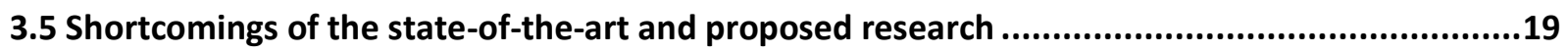

$4 \quad$ The SCRF ${ }^{\oplus}$ Experimental Data and the Approach to Modeling ........................................22

$4.1 \mathrm{SCRF}^{\circledast}$ configuration 1 experimental data ..............................................................................24

4.2 SCRF $^{\circledR}$ configuration 2 experimental data ...................................................................26

4.3 SCRF $^{\circledR}+$ SCR system configuration 3 experimental data .................................................26

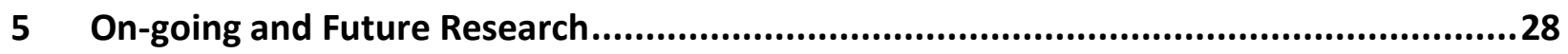

6 Main Contributions from Research ............................................................................32

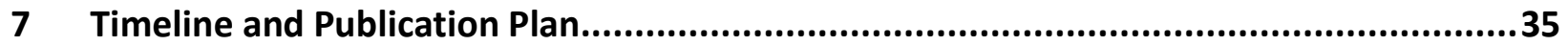

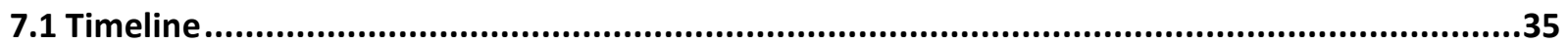

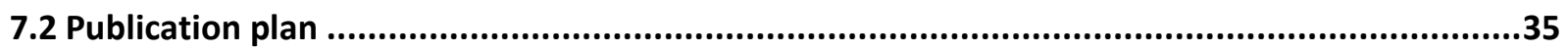

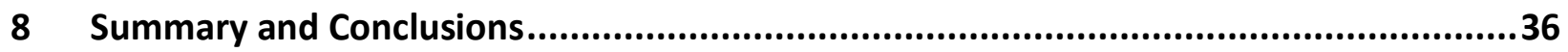

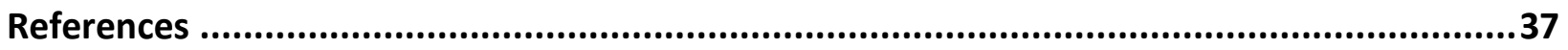

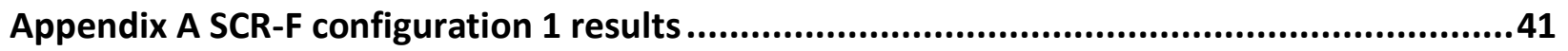

Appendix B SCRF ${ }^{\oplus}$ configuration 1,2 and 3 experimental data test points .............................44

Appendix C Reduced order model equations ......................................................................48

Appendix D State estimator equations ...........................................................................51 


\section{List of Figures}

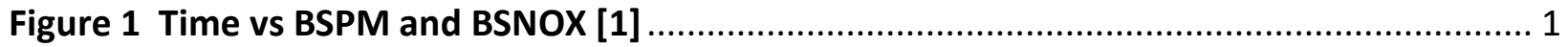

Figure 2 Inhibition of $\mathrm{NH}_{3}$ transport to active site due to $\mathrm{PM}$ in substrate wall [8] .................. 5

Figure 3 Change in $\mathrm{NO}_{2}$ concentration in radial and axial direction [12] ............................... 6

Figure 4 Competition for $\mathrm{NO}_{2}$ between PM oxidation and SCR reactions [12] ..................... 6

Figure $5 \mathrm{NH}_{3}$ adsorption and desorption for PM free filter with 250 ppm inlet $\mathbf{N H}_{3}$ [13]........ 7

Figure 6 Radial $\mathrm{NO} / \mathrm{NO}_{2}$ profiles (PM cake and substrate wall) with and without $\mathrm{NH}_{3}$ [16] ..... 8

Figure $7 \mathrm{NH}_{3}$ storage and $\mathrm{NO}_{2}$ consumption in PM cake and wall with and without PM [18] ... 9

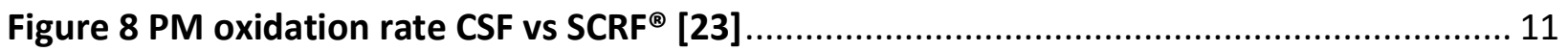

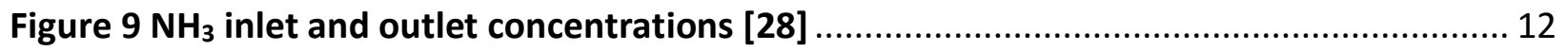

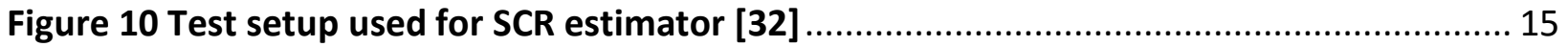

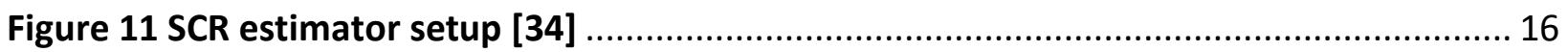

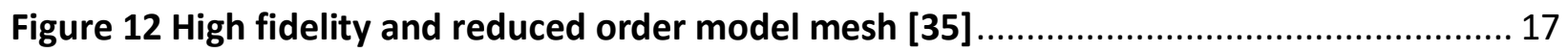

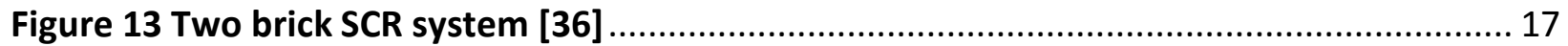

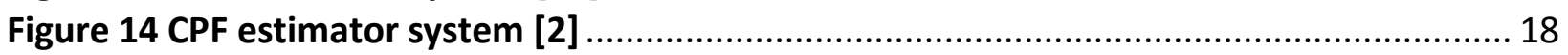

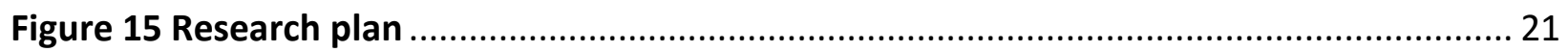

Figure 16 Mesh for SCR-F model v1.3 [2] ......................................................................... 22

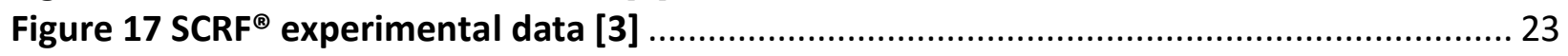

Figure 18 SCRF $^{\circledR}$ configuration 1 experimental test [3] ..................................................... 24

Figure 19 Arrhenius plot for configuration passive oxidation with and without $\mathrm{NH}_{3}$ [3]....... 25

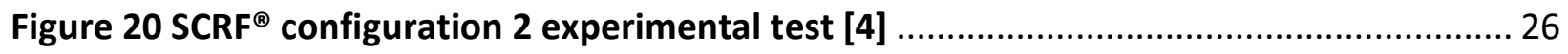

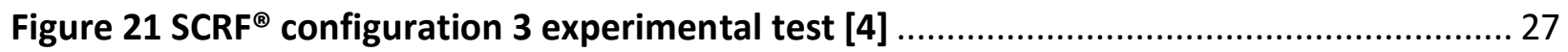

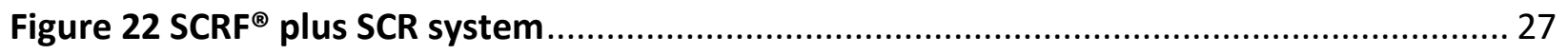

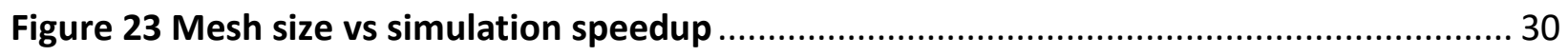

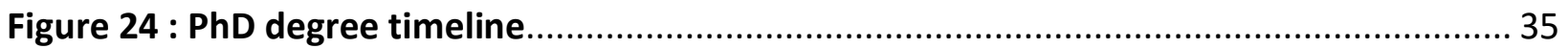

\section{List of Tables}

Table A 1 Pressure drop model vs experimental SCRF ${ }^{\circledR}$ configuration 1 .............................. 41

Table A 2 PM retained model vs experimental SCRF ${ }^{\circledR}$ configuration 1 ................................. 42

Table A 3 Outlet $\mathrm{NO}_{2}$ concentration model vs experimental SCRF ${ }^{\circledR}$ configuration 1 ............... 43

Table B 1 Engine condition for SCRF ${ }^{\circledR}$ configuration 1 without urea experiments [3] ............. 44

Table B 2 Engine condition for SCRF ${ }^{\circledR}$ configuration 1 with urea experiments [3] .................. 45

Table B 3 Engine condition for SCRF ${ }^{\circledR}$ configuration 3 experiments [41] ............................. 47 


\section{Acknowledgements}

I would like to thank my advisors Dr. Gordon G. Parker and Dr. John H. Johnson whose constant support and encouragement has helped me to pursue this research. I would also like to thank Dr.Jeffery D. Naber and Dr.Sunil S. Mehendale for spending time on my committee and reviewing my research.

I would also like to thank all the graduate students in my research group including Vaibhav Kadam, Krishnan Ragahavan, Erik Gustafson, Saksham Gupta and Sagar Sharma who collected the experimental data that has been used for this research work. Also I would like to thank Dr.Boopathi who helped me immensely in development of SCR-F model framework.

I would like to thank MTU Diesel Engine Aftertreatment Consortium (Cummins, John Deere, ISUZU, Daimler, Johnson Matthey, Tenneco and Corning) for supporting this project and providing financial support for the duration of this study.

I would like to thank my parents C.H. Surya Narayana Murthy and C.H. Sai Sudha without whom all of this effort wouldn't have been possible. Last but not the least, I would also like to thank my friends including Jaya, Yash, Nandu and Niranjan among others who have supported me during the course of this study. 


\section{Nomenclature}

SCR-F SCR catalyst on a DPF

$\mathrm{SCRF}^{\circledR}$ Selective catalytic reduction filter by Johnson Matthey

DOC Diesel oxidation catalyst

CPF Catalyzed particulate filter

DPF Diesel particulate filter

SCR Selective catalytic reduction catalyst on a flow though substrate

EPA Environmental Protection Agency

CARB California Air Resources Board

EFK Extended Kalman Filter

AR Active Regeneration

PO Passive Oxidation 


\section{Abstract}

Reduction of emissions and improving the fuel consumption are two prime research areas in Diesel engine development. The present after-treatment systems being used for emissions control include diesel oxidation catalyst (DOC) for NO, HC and $\mathrm{CO}$ oxidation along with catalyzed particulate filters for PM (particulate matter) and selective catalytic reduction (SCR) for controlling NOx emissions. Recently an after-treatment system called SCR catalyst on a DPF capable of simultaneously reducing both NOx and PM emissions has been developed in order to reduce the overall size of the after-treatment system.

The goal of this proposed research is to create a state estimator that is capable of estimating the internal states of temperature distribution, $\mathrm{PM}$ distribution, $\mathrm{NH}_{3}$ storage faction as well as pressure drop across the filter and outlet concentration of $\mathrm{NO}, \mathrm{NO}_{2}$ and $\mathrm{NH}_{3}$ for different operating conditions. This would help in achieving an optimal urea dosing strategy during $\mathrm{NO}_{\mathrm{x}}$ reduction as well as an optimum fuel dosing strategy during active regeneration for the SCR catalyst on a DPF. The motivation for this research comes from the desire to quantify the interaction of SCR reactions and PM oxidation in the SCR catalyst on a DPF and to use the mathematical model created in the process to develop a state estimator that can provide optimal control and onboard diagnostics of combined SCR catalyst on a DPF devices.

In the initial phase of the research a high-fidelity SCR-F model is being developed in MATLAB/Simulink which is capable of predicting the filtration efficiency, temperature distribution, PM distribution, pressure drop across the filter and outlet concentrations of NO, $\mathrm{NO}_{2}$ and $\mathrm{NH}_{3}$. This model will be calibrated using experimental data collected on a Cummins 2013 ISB SCRF ${ }^{\circledR}$. After the validation of the SCR-F model, the high-fidelity SCR-F model developed will be used with an existing 1D SCR model to perform $\mathrm{NO}_{x}$ reduction studies on a system consisting of $\mathrm{SCRF}^{\circledR}+\mathrm{SCR}$ using experimental data. This step will be followed by development of a reduced order SCR-F model using a coarser mesh (e.g. $5 \times 5$ vs 10x10) and simplified governing equations which will also be used as the mathematical model for the state estimator. SCR-F state estimator will be developed to accurately predict the internal states of $\mathrm{NH}_{3}$ coverage fraction, temperature distribution, PM distribution and pressure drop across the SCR catalyst on the DPF. The estimator will be validated using experimental data. 


\section{Introduction}

Diesel engines are used around the world in industrial, agricultural and transportation applications due to their reliability, fuel efficiency and high power output. Diesel engines, because of their lean combustion, also emit a wide variety of emissions including particulate matter, NOx, unburned $\mathrm{HC}$ and $\mathrm{CO}$. Typically these emissions are controlled using after-treatment systems to meet regulations set by various agencies around the world including EPA (Environmental Protection Agency), CARB (California Air Resources Board), Euro etc.

Over the last 30 years, EPA in the U.S. has set standards that require significant reduction of $\mathrm{NO}_{\mathrm{x}}$ and particulate matter emissions as shown in Figure 1. The most common after-treatment system being used for diesel engine emissions to meet the emission standards for particulate matter, $\mathrm{NO}_{x}, \mathrm{CO}$ and unburned $\mathrm{HC}$ includes a DOC (Diesel oxidation catalyst) plus a CPF (catalyzed particulate filter) plus a SCR (selective catalytic reduction) flow through substrate.

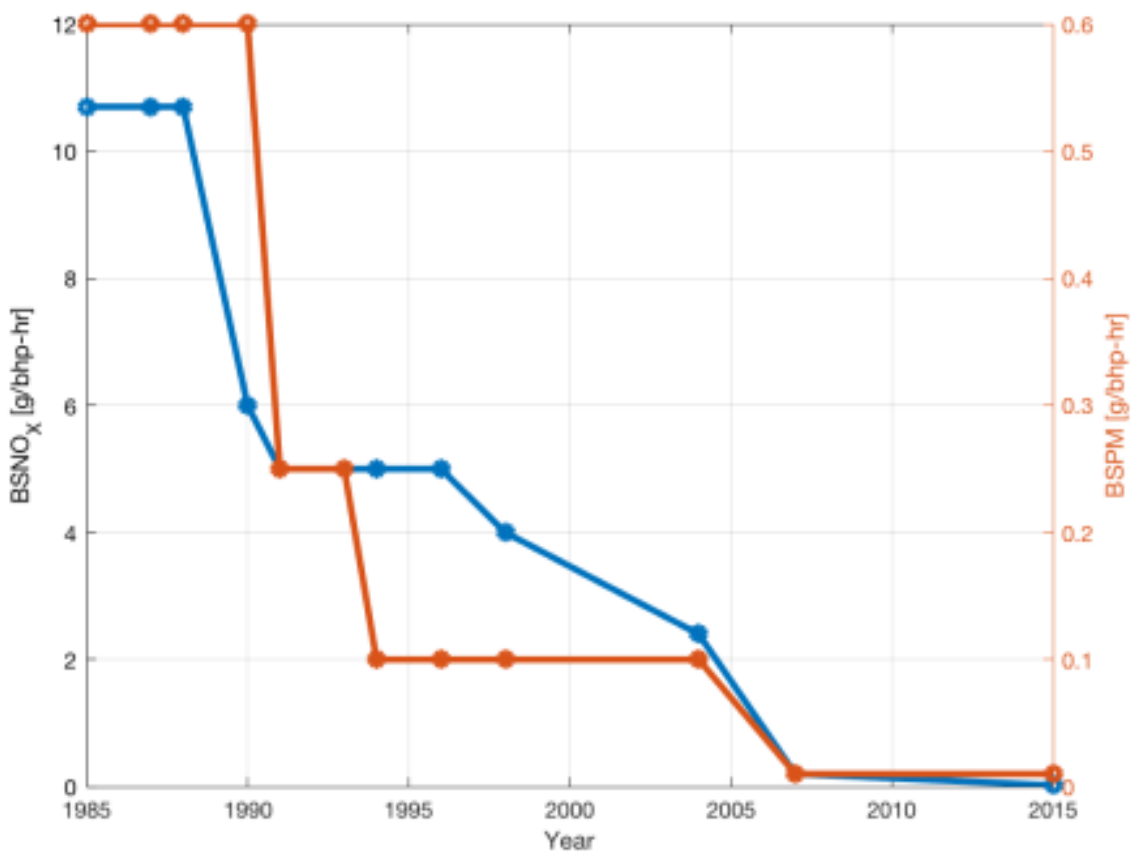

Figure 1 Time vs BSPM and BSNOX [1]

The system consisting of a DOC+CPF+SCR, although efficient at meeting the regulations, has several limitations: 1) large system volume 2) low NOx reduction efficiency at low temperatures during startup 3) lower NOx reduction efficiency and higher $\mathrm{NH}_{3}$ slip in SCR under mass transfer limitation condition. These limitations can be improved by using a SCR catalyst coated particulate filter such as the Johnson-Matthey SCRF ${ }^{\circledR}$.

The SCR catalyst on a DPF system has the following advantages compared to a CPF+SCR system 
1) Faster light off during cold start conditions due to placement of the SCR catalyst nearer to the engine out

2) Better performance in mass transfer limited conditions since the SCR catalyst is deposited on the substrate wall

3) Lower total SCR catalyst on a DPF volume which helps in reducing system costs and packaging volume.

Despite all these advantages, several key challenges remain in the design of the SCR catalyst on a DPF which include quantifying the interaction of SCR reactions with PM oxidation rate, low temperature NOx reduction performance, nitrate deposits formation, and impact of thermal regeneration on catalyst performance. Also, there is always a need for improved control strategies that minimize fuel dosing during DPF regeneration and minimize urea injection for SCR $\mathrm{NO}_{x}$ conversion.

In order to meet these requirements, this research will develop a high-fidelity model that captures the interaction of the SCR reactions with the $\mathrm{PM}$ oxidation and $\mathrm{NH}_{3}$ storage leading to a predictive state estimator. This constitutes a contribution that augments previous work in DPF modelling and state estimator design such as by Mahadevan, Boopathi et al. [2]. 


\section{Objectives}

The overall objective is to develop a high-fidelity SCR-F model using the SCRF ${ }^{\circledR}$ experimental data in references [3][4], followed by development of a reduced order SCR-F model which will be used to develop an SCR-F state estimator to predict to $\mathrm{NH}_{3}$ coverage fraction, temperature and PM distribution and the pressure drop.

The specific overall objectives include

- Develop a computationally efficient high fidelity SCR-F model to simulate

$>$ Temperature distribution,

$>\mathrm{PM}$ mass retained and distribution,

$>\mathrm{NH}_{3}$ storage,

$>\mathrm{NO}_{\mathrm{x}}$ emissions,

$>$ Pressure drop

- Develop a procedure to calibrate the model on the model's predictive performance to experimental engine data

- Develop a reduced order model by quantifying the impact of mesh size

- Develop a SCR-F state estimator validated using steady state and transient engine data

\subsection{High fidelity model objectives}

In order to meet the reduced order and state estimator goals, the high-fidelity model must be able to capture the following phenomena so that the reduced order model can be developed from an accurate model:

1) Competition for $\mathrm{NO}_{2}$ between selective catalytic reduction and $\mathrm{PM}$ oxidation reactions

2) Heat transfer in the radial and axial directions

3) Pressure drop and change in cake permeability

4) Filtration efficiency

\subsection{Reduced order model and estimator objectives}

Development of a reduced order model is needed to develop a mathematical model for the SCR-F estimator. The reduced order model would also help in determining the impact of several assumptions that will likely be used in the SCR-F reduced order model such as the impact of inhibition factors, intra layer diffusion and mass transfer from the exhaust gas stream to the catalyst coating surface inside the substrate wall pores.

Before designing any state estimator, it is important to identify the states of interest. Because the intended use of the state estimator is for dosing control and onboard diagnostics, the targeted states are:

1) $\mathrm{NH}_{3}$ storage distribution in the SCR catalyst on a DPF

2) Downstream $\mathrm{NO} / \mathrm{NO}_{2}$ emissions

3) Temperature distribution

4) PM distribution

5) Pressure drop across the SCR on a DPF 


\section{Literature Review}

The aim of this research is to develop a high-fidelity SCR-F model and SCR-F estimator capable of simulating the outlet concentrations of $\mathrm{NO}, \mathrm{NO}_{2}, \mathrm{NH}_{3}, \mathrm{CO}, \mathrm{CO}_{2}$ and $\mathrm{HC}$ along with pressure across the filter, filtration efficiency and PM mass retained. A literature review of previous research on SCR-F modelling and estimators has been conducted. To the best of the author's knowledge, there is no research of a SCR-F estimator in the open literature [5]. The literature review focused on the following aspects which would help in development of the SCR-F highfidelity model and the estimator: 1) SCR-F high fidelity models 2) experimental research performed on SCR catalyst on a DPF 3) SCR and SCR-F estimators.

Xiaobo song et al. [5] conducted a literature review on SCR catalyst on a DPF's relative to catalyst design, performance characterization and modelling which was carried out on under the MTU Diesel After-treatment Consortium program. The main conclusions from this paper were as follows

- $\quad$ SCR-F system leads to lower substrate volume and easier light off at lower temperatures

- Catalyst embedded inside the substrate wall is more effective compared to layer type catalyst

- The modelling of the competition for $\mathrm{NO}_{2}$ between PM oxidation reactions and SCR reactions is required to be considered

- Some of the models have multiple sites for $\mathrm{NH}_{3}$ storage

- Effect of PM on $\mathrm{NO}_{2}$ diffusion needs to be modeled

- Water adsorption and desorption needs to be modeled

The present literature review is an extension of this work with a focus on modelling and experimental data aspects of the SCR catalyst on DPF's with a focus on post 2014 publications.

\subsection{SCR-F high fidelity models}

SCR-F models reviewed in the literature all have a focus on the interaction of the SCR reactions with the PM oxidation reactions. The major focus of the modelling includes

- Effect of SCR reactions on PM oxidation rate

- Impact of PM loading on SCR reactions and deNOx performance of the SCR catalyst on a DPF

- Low temperature $\mathrm{NO}_{x}$ reduction performance and inhibition due to nitrate formation

- Change in local $\mathrm{NO}_{2} / \mathrm{NO}_{x}$ ratio in the substrate wall and its impact on the SCR reactions

- Inhibition in active sites by PM in the wall

- Change in $\mathrm{NH}_{3}$ storage capacity with PM loading

- Incomplete conversion of urea to $\mathrm{NH}_{3}$ at low temperatures $\left(\mathrm{T}<250{ }^{\circ} \mathrm{C}\right)$

Park et al. [8][9] developed a one-dimensional two way DPF/SCR model by combining the $1 \mathrm{D}$ physical model of a DPF with chemical reactions and kinetics from a SCR model with a focus on evaluating PM NOx interactions. This model found a correlation between PM loading and local 
$\mathrm{NO}_{2} / \mathrm{NO}_{x}$ ratio in the wall PM which impacts the NOx reduction activity by controlling the types of SCR reactions taking place in the wall. The study also found the inhibition of SCR reactions due to deep bed PM in the substrate wall. The decrease in the number of active sites as a result of the decrease in mass transfer of $\mathrm{NH}_{3}$ as well as a decrease in $\mathrm{NH}_{3}$ storage capacity was modeled. The model assumed that the SCR catalyst coating was present inside the substrate wall and considered forward diffusion of the chemical species between PM cake and the substrate wall. Figure 2 shows the PM deposited on substrate wall which blocks the active sites involved in $\mathrm{NH}_{3}$ storage.

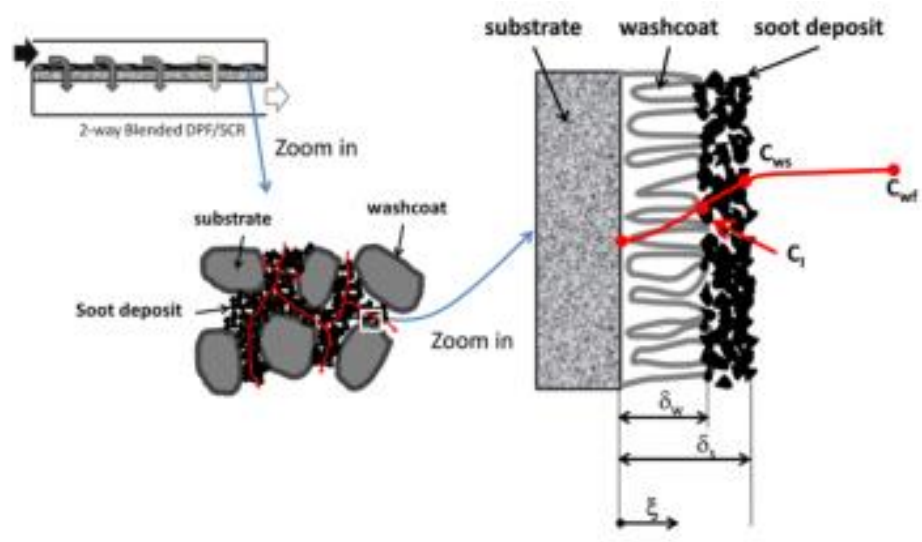

Figure 2 Inhibition of $\mathrm{NH}_{3}$ transport to active site due to PM in substrate wall [8]

Dosda et al. [10] developed a SCR catalyst on a DPF and SCR exhaust line model to simulate the SCR catalyst on a DPF with a downstream SCR. This model studied the deterioration of the catalyst due to thermal oxidation. The model found that $\mathrm{CuO}$ species aggregation in the $\mathrm{Cu}$-Ze catalyst was the reason behind the decrease in the number of active sites in an aged SCR catalyst on a DPF. This model also assumed one site for storage and consumption of $\mathrm{NH}_{3}$.

Lopez et. al [11] developed a Vanadium catalyst based SCRF ${ }^{\circledR}$ model. This study found that the fast SCR reaction did not affect the PM balance point. The maximum deNOx was found to be between $180-300^{\circ} \mathrm{C}$ with deNOx efficiency of $90 \%$. Higher temperatures led to $\mathrm{NH}_{3}$ oxidation which significantly decreased the deNOx performance. This model assumed that number of active sites is linearly proportional to the wash coat loading present on the $\mathrm{SCRF}^{\circledR}$.

Tronconi et.al [12] developed a multiscale SCR catalyst on a DPF model using Axisuite ${ }^{\circledR}$ with $\mathrm{NH}_{3}$ kinetics collected from fixed bed reactor based tests which were used for creating a physicochemical model. A decoupled calibration procedure was used for the calibration of the SCR reactions and $\mathrm{NO}_{2}$ assisted $\mathrm{PM}$ oxidation kinetics. The validity of kinetics found was then tested on model of a medium and heavy duty engine SCR catalyst on a DPF. Higher $\mathrm{CO} / \mathrm{CO}_{2}$ was found for cases with $\mathrm{NO}_{2}$ presence due to $\mathrm{NO}_{2}$ assisted $\mathrm{PM}$ oxidation till $400^{\circ} \mathrm{C}$. Studies on the filtration and pressure drop characteristics of the SCR catalyst on a DPF for different PM loading values was also conducted. It was found that with the presence of the SCR reactions, the available $\mathrm{NO}_{2}$ in the PM cake and thus PM oxidation rate reduced due to forward diffusion phenomena 
between PM cake and the substrate wall. As shown in Figure 3, significant decrease in the $\mathrm{NO}_{2}$ concentration across the PM cake was observed in the case with urea injection.
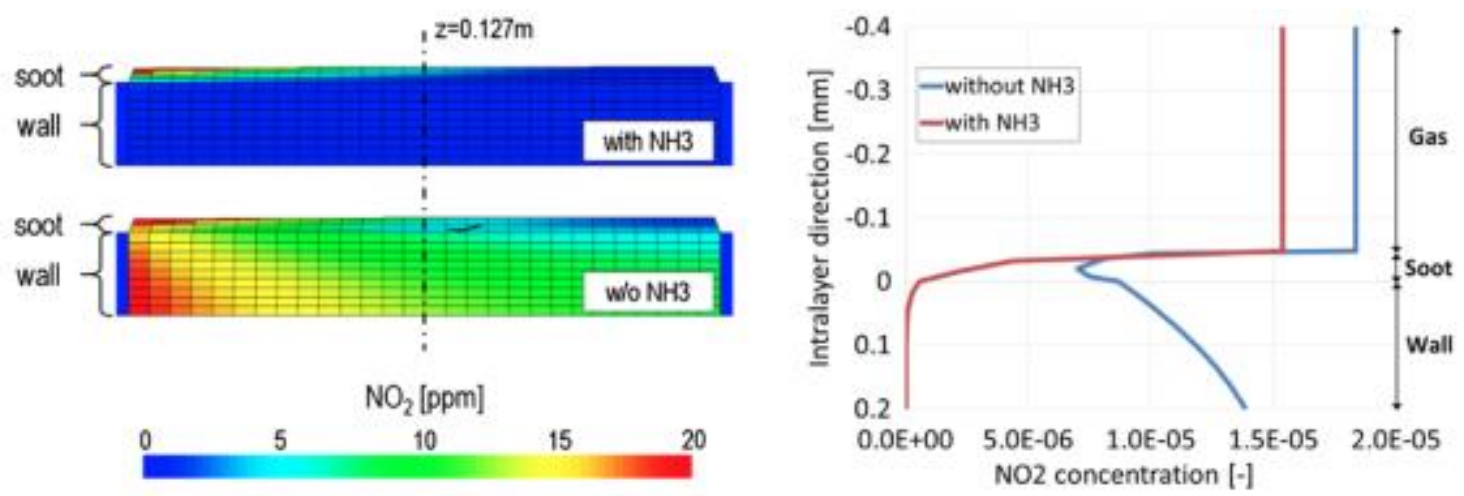

Figure 3 Change in $\mathrm{NO}_{2}$ concentration in radial and axial direction [12]

Figure 4 shows the competition for $\mathrm{NO}_{2}$ between SCR reactions and PM oxidation in the SCR catalyst on a DPF from reference [12] which is responsible for the decrease in the $\mathrm{NO}_{2}$ concentration in the PM cake.

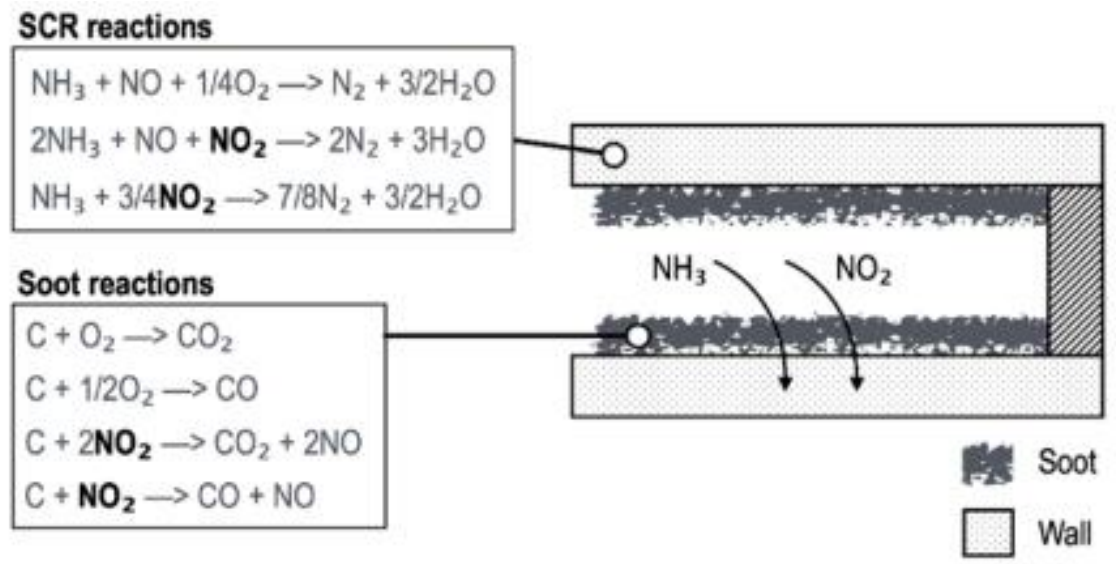

Figure 4 Competition for $\mathrm{NO}_{2}$ between PM oxidation and SCR reactions [12]

Schrade et.al [13] developed a phyisico-chemical model of the SCR on DPF based on fundamental principles for control strategies of a SCR catalyst on a DPF using AxiSuite ${ }^{\circledR}$. This model was calibrated with transient data from the NEDC cycle and from reactor data. The reactor data showed bimodal adsorption and desorption of $\mathrm{NH}_{3}$ which led to a two-site model development. The two sites represent weakly bonded $\mathrm{NH}_{3}$ at Lewis acid sites and strongly bonded $\mathrm{NH}_{3}$ by chemisorption at Bronstedt sites. Figure 5 shows the desorption pattern of a clean filter in this study which shows two distinct peaks for desorption which correspond to two different storage sites.

Also, a significant change in the amount of $\mathrm{NH}_{3}$ storage in the presence of the PM cake was found in this study which could lead to a third storage site present in the PM cake. Although the third site was neglected in the model as the storage variation is less than $5 \%$. The light off 
temperature for the SCR on a DPF was found to be above $200{ }^{\circ} \mathrm{C}$. $\mathrm{NH}_{4} \mathrm{NO}_{3}$ formation and the inhibition caused by these deposits was simulated for temperatures less than $250{ }^{\circ} \mathrm{C}$ and high $\mathrm{NO}_{2} / \mathrm{NO}_{\mathrm{x}}$ ratios using a third site for nitrates deposition. Water adsorption on zeolites was also considered in this model along with inhibition of active sites by wall PM.

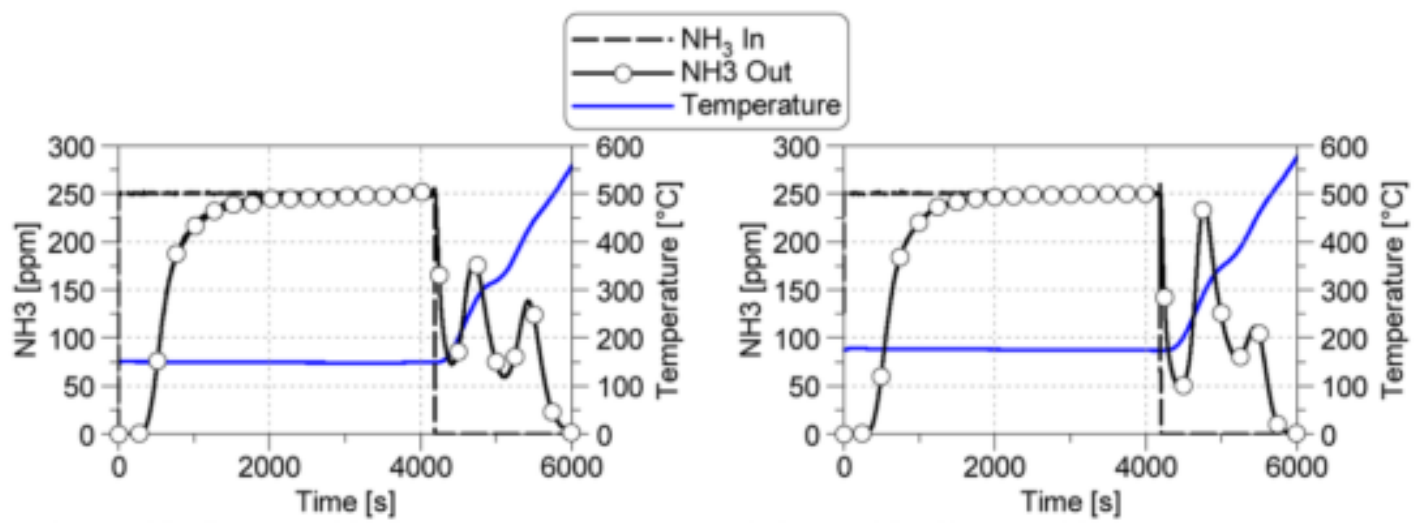

a) $\mathrm{T}=150^{\circ} \mathrm{C}, \mathrm{dT} / \mathrm{dt}=15^{\circ} \mathrm{C} / \mathrm{min}$

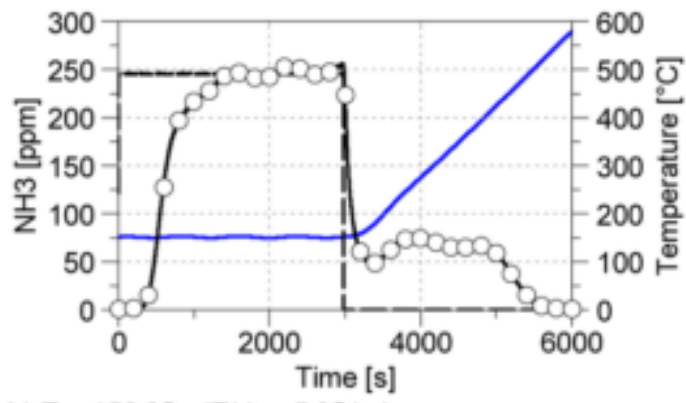

b) $\mathrm{T}=150^{\circ} \mathrm{C}, \mathrm{dT} / \mathrm{dt}=5^{\circ} \mathrm{C} / \mathrm{min}$ c) $\mathrm{T}=175^{\circ} \mathrm{C}, \mathrm{dT} / \mathrm{dt}=15^{\circ} \mathrm{C} / \mathrm{min}$

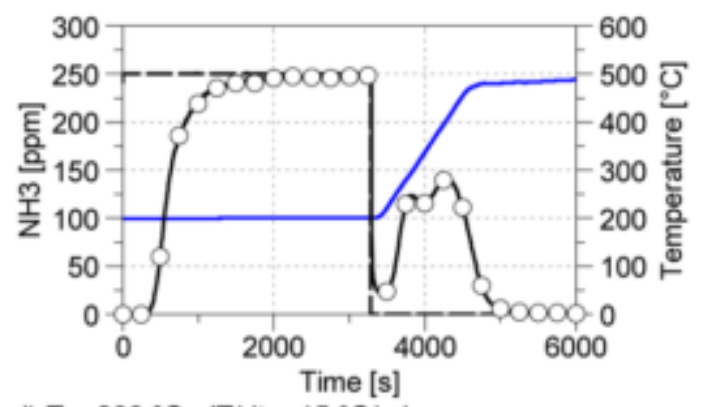

d) $\mathrm{T}=200^{\circ} \mathrm{C}, \mathrm{dT} / \mathrm{dt}=15^{\circ} \mathrm{C} / \mathrm{min}$

Figure $5 \mathrm{NH}_{3}$ adsorption and desorption for PM free filter with $250 \mathrm{ppm}$ inlet $\mathrm{NH}_{3}$ [13]

Watling al. [14] developed a 1D model of a SCR catalyst on a DPF using kinetics from lab reactor experiments. The model was able to predict outlet concentrations of $\mathrm{NO}, \mathrm{NO}_{2}$ and $\mathrm{NH}_{3}$ slip as well as $\mathrm{N}_{2} \mathrm{O}$ formation and $\mathrm{NH}_{3}$ storage. It was found that PM had minimal impact on SCR activity but had significant impact on $\mathrm{PM}$ oxidation rate by $\mathrm{NO}_{2}$ oxidation. An additional global reaction used in this model is the decomposition of $\mathrm{NO}_{2}$ to $\mathrm{NO}$ by adsorbed $\mathrm{NH}_{3}$ to simulate the excess $\mathrm{NO}$ which could not be explained by the reversible $\mathrm{NO}_{2}$ decomposition reaction.

$$
2 \mathrm{NH}_{3}(\text { ads })+3 \mathrm{NO}_{2} \longrightarrow 3 \mathrm{NO}+\mathrm{N}_{2}+3 \mathrm{H}_{2} \mathrm{O}
$$

Also, a exotherm of $5^{\circ} \mathrm{C}$ was observed due to SCR reactions which has a beneficial effect on PM oxidation at temperatures above $500^{\circ} \mathrm{C}$ where thermal PM oxidation is dominant.

Konstandopoulos, et al. [15] developed a two-layer SCR catalyst on a DPF model that studied the impact of thin coatings and variable porosity in the filter substrate wall on the pressure drop as well as deNOx performance of the SCR on a DPF. This model takes into account variation of PM oxidation rate based on PM contact variation. The effect of PM catalyst dynamics on the oxidation rate and SCR reaction rate as well as pressure drop across the filter were studied 
which is useful in developing efficient filter designs to find a proper tradeoff between pressure drop and filtration efficiency.

Colombo et al. [16] developed a SCR catalyst on a DPF model based on Axisuite ${ }^{\circledR}$ that focuses on coupling of diffusion and reaction mechanism which affect the interaction between $\mathrm{PM}$ oxidation and the SCR reactions. The study found a significant change in local $\mathrm{NO}_{2} / \mathrm{NO}_{x}$ ratio in the substrate wall due to the presence of PM which altered the NOx reduction performance either in the positive direction when $\mathrm{NO}_{2} / \mathrm{NO}_{\mathrm{x}}$ ratio is greater than 0.5 or decreased $\mathrm{NOx}$ reduction in the case of $\mathrm{NO}_{2} / \mathrm{NO}_{x}$ ratio less than or equal to 0.5 . Figure 6 shows the decrease in $\mathrm{NO}_{2}$ concentration through the PM cake layer that was observed in this work in the case with urea injection.

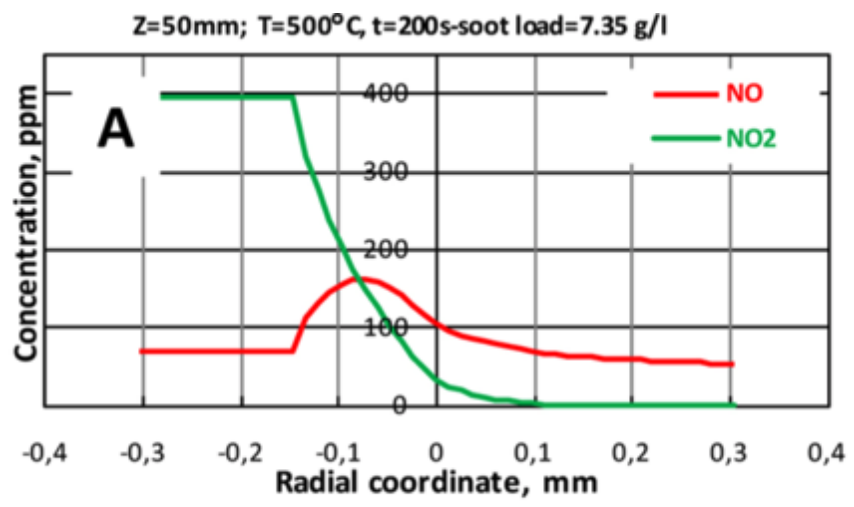

$\mathrm{Z}=50 \mathrm{~mm} ; \mathrm{T}=500^{\circ} \mathrm{C}, \mathrm{t}=200 \mathrm{~s}-$ soot load $=3.65 \mathrm{~g} / \mathrm{l}$

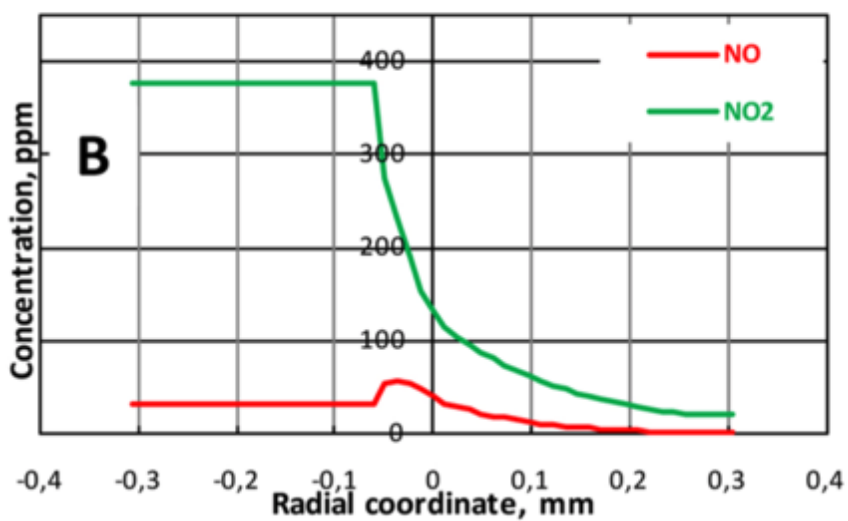

Figure 6 Radial NO/NO 2 profiles (PM cake and substrate wall) with and without $\mathrm{NH}_{3}$ [16]

Tan et al. [17] developed a 2-way SCR catalyst on a DPF model for a Cu-Ze based SCR on a DPF for HDD systems. This study found that up to 30\% reduction in overall SCR volume can be achieved using SCR catalyst on a DPF+SCR system compared to CDPF + SCR system while obtaining similar deNOx and PM filtration efficiency values. It was observed that a degreened SCR catalyst on a DPF showed a $30 \%$ decrease in $\mathrm{NH}_{3}$ storage with PM loading but an aged SCR catalyst on a DPF showed no change in storage with PM. Also, it was concluded that with a $20-$ $30^{\circ} \mathrm{C}$ increase in the temperature profile, the PM oxidation rate can be increased to the levels observed in a CDPF. 
Yang et al. [18] developed a 1D model for Cu-Ze SCR on a DPF. This study focused on effects of space velocity, temperature and local $\mathrm{NO}_{2} / \mathrm{NO}_{x}$ ratio on clean and PM loaded filters. The variation in space velocity was found to have a $2 \%$ change in the NOx reduction performance. Wall PM on the other hand played an important role in decreasing NOx reduction performance. Unlike previous studies, the effect of wall PM and cake PM was studied separately in this work and it was found that wall PM is the main reason for blocking the active sites of $\mathrm{NH}_{3}$ storage. The inhibition of $\mathrm{NH}_{3}$ storage caused by wall PM was simulated. Also, energy release by the SCR reactions and their impact on wall PM oxidation rate were simulated. Figure 7 shows the variation of $\mathrm{NH}_{3}$ storage and $\mathrm{NO}_{2}$ consumption rate through the $\mathrm{PM}$ cake and substrate wall observed in this study.
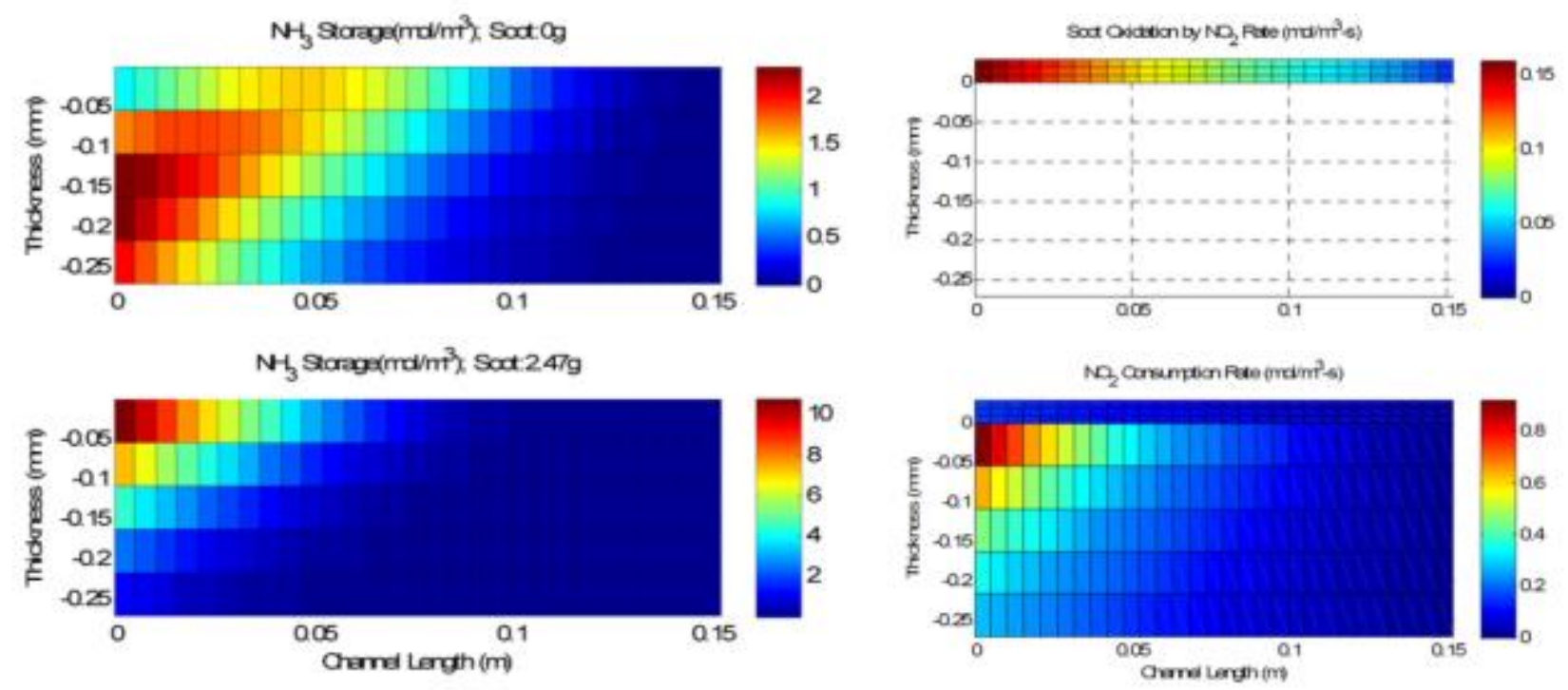

Figure $7 \mathrm{NH}_{3}$ storage and $\mathrm{NO}_{2}$ consumption in PM cake and wall with and without PM [18]

Strots et.al [19] performed a comparative study on a DOC+CDPF+SCR system and DOC+SCRF+SCR system on a HDD engine with WHTC cycle data and 1D SCR/DPF model using AxiSuite ${ }^{\circledR}$. The SCR-F based system was found to have faster light off at $200{ }^{\circ} \mathrm{C}$.

Overall the major trends that were observed from the literature review of the SCR-F modelling are as follows

- PM loading does not significantly affect the SCR reactions

- $\mathrm{PM}$ in the substrate wall is responsible for a decrease in the SCR storage

- Significant change in local $\mathrm{NO}_{2} / \mathrm{NO}_{x}$ ratio is observed across the PM cake and substrate wall for PM loaded filters which affects NOx reduction performance

- Some studies found an increase in storage of the $\mathrm{NH}_{3}$ with $\mathrm{PM}$ loading which needs to be studied further

- SCR reactions have significant impact on PM oxidation rate due to forward diffusion of $\mathrm{NO}_{2}$ caused by competition for $\mathrm{NO}_{2}$ between PM oxidation and SCR reactions 
- Inhibition of SCR reactions by the presence of nitrate deposits in the substrate wall below $250^{\circ} \mathrm{C}$ was observed in some studies

- An exotherm of about $5^{\circ} \mathrm{C}$ caused by SCR reactions was reported in some of the studies but a quantitative modelling study of temperature change caused by the SCR reactions needs to be developed.

Some of the new trends that were observed in this literature review compared to earlier work by Xiaobo et al. [5] are as follows

- Forward diffusion phenomena govern the competition for $\mathrm{NO}_{2}$ between SCR and PM oxidation reactions

- $\mathrm{PM}$ in the substrate is responsible for a decrease in $\mathrm{NH}_{3}$ storage

- Inhibition of the SCR reactions occurs due to the nitrate deposits at temperatures below $250^{\circ} \mathrm{C}$

- There is an increase in $\mathrm{NH}_{3}$ storage due to PM loading

- Exotherm of $5^{\circ} \mathrm{C}$ caused by the SCR reactions was observed in the experimental data

\subsection{SCR catalyst on an DPF experimental studies}

Experimental studies of a SCR catalyst on a DPF have been performed by multiple groups to study the effect of PM loading on SCR activity and the effect of SCR reactions on PM oxidation rate. Studies on $\mathrm{N}_{2} \mathrm{O}$ formation and $\mathrm{NH}_{4} \mathrm{NO}_{3}$ deposits at temperatures below $250{ }^{\circ} \mathrm{C}$ have also been conducted. Comparison studies of production after-treatment systems consisting of a $\mathrm{DOC}+\mathrm{CDPF}+\mathrm{SCR}$ as compared to a $\mathrm{DOC}+\mathrm{SCR}-\mathrm{F}+\mathrm{SCR}$ have been performed to determine the quantitative decrease in SCR catalyst volume, system level deNOx performance and PM oxidation rate. The major classification of the catalysts used in the SCR on a DPF are Fe-Ze, Cu-Ze and Vandia with each having its advantages and disadvantages. The following paragraphs give a brief explanation of the experimental studies performed on SCR catalysts on DPF's.

Mihai et al. [20] [21] has conducted experimental studies on a Cu-Ze based SCR coated DPF which has been hydrothermally aged to $850^{\circ} \mathrm{C}$ for $12 \mathrm{hrs}$. The filter was loaded with PM and cut into sections which were then subjected to reactor tests. NOx reduction performance decreased with increase in $\mathrm{PM}$ loading with the largest $\mathrm{CO} / \mathrm{CO}_{2}$ formation at $540^{\circ} \mathrm{C}$. The standard $\mathrm{SCR}$ reaction rate increased slightly when $\mathrm{PM}$ is removed. The presence of $\mathrm{PM}$ reduced the formation of $\mathrm{NH}_{4} \mathrm{NO}_{3}$ which increased the fast $\mathrm{SCR}$ reaction rate at $150^{\circ} \mathrm{C}$. The authors proposed that PM reacts with $\mathrm{NH}_{4} \mathrm{NO}_{3}$ present on $\mathrm{CuO}$ species outside the zeolite leading to less number of blocked sites and higher standard SCR reaction rate at low temperatures $\left(<250{ }^{\circ} \mathrm{C}\right)$. Maximum $\mathrm{NO}_{\mathrm{x}}$ reduction was observed between $250-400^{\circ} \mathrm{C}$. Cu particles are susptible to NO oxidation so less $\mathrm{NO}$ oxidation was observed with $\mathrm{PM}$ loading. $\mathrm{NH}_{3}$ oxidation increases with an increase in PM loading at high temperature. 
Lasitha et al. [22] [23] conducted a comparative study on PM oxidation efficiency of a SCRF ${ }^{\circledR}$ vs a CSF during active regeneration. It was found that for $\mathrm{T}>270{ }^{\circ} \mathrm{C}$, CSF had a higher passive oxidation rate compared to the $\mathrm{SCRF}^{\circledR}$. For the same inlet temperature, the $\mathrm{SCRF}^{\circledR}$ had $5-45 \%$ lower PM oxidation rate compared to the CSF. Also, a significant amount of $\mathrm{NO}_{2}$ was formed in the CSF compared to the $\mathrm{SCRF}^{\circledR}$ during passive oxidation e.g. $6-12 \%$ vs $1 \%$. The location of PM was found to have minimal effect on PM oxidation rate. Also, for the CSF, it was found that PM oxidation rate increased with increase in Pt catalyst loading with $40 \mathrm{~g} / \mathrm{ft}^{3}$ filter having higher PM oxidation rate than $10 \mathrm{~g} / \mathrm{ft}^{3}$. Pt was found to not catalyze the $\mathrm{NO}_{2}$ based $\mathrm{PM}$ oxidation but instead caused an increase in the $\mathrm{NO}_{2}$ available in the PM cake by oxidizing $\mathrm{NO}$ to $\mathrm{NO}_{2}$ unlike the catalyst $\mathrm{Cu}-\mathrm{Ze}$ in the $\mathrm{SCRF}^{\circledR}$ which did not oxidize a significant amount of $\mathrm{NO}$ to $\mathrm{NO}_{2}$.

During active regeneration, the $\mathrm{PM}$ oxidation rate remained the same for the $\mathrm{SCRF}^{\circledR}$ with and without $\mathrm{NH}_{3}$. The $\mathrm{CSF}$ had higher $\mathrm{PM}$ oxidation rate during active regeneration compared to the $\mathrm{SCRF}^{\circledR}$ due to the higher $\mathrm{NO}_{2}$ produced by the Pt catalyst which back diffused into the PM cake at the cake wall boundary. Figure 8 shows the comparison of the PM oxidation rate between the $\mathrm{CSF}$ and $\mathrm{SCRF}^{\circledR}$ for temperatures greater than $550^{\circ} \mathrm{C}$.

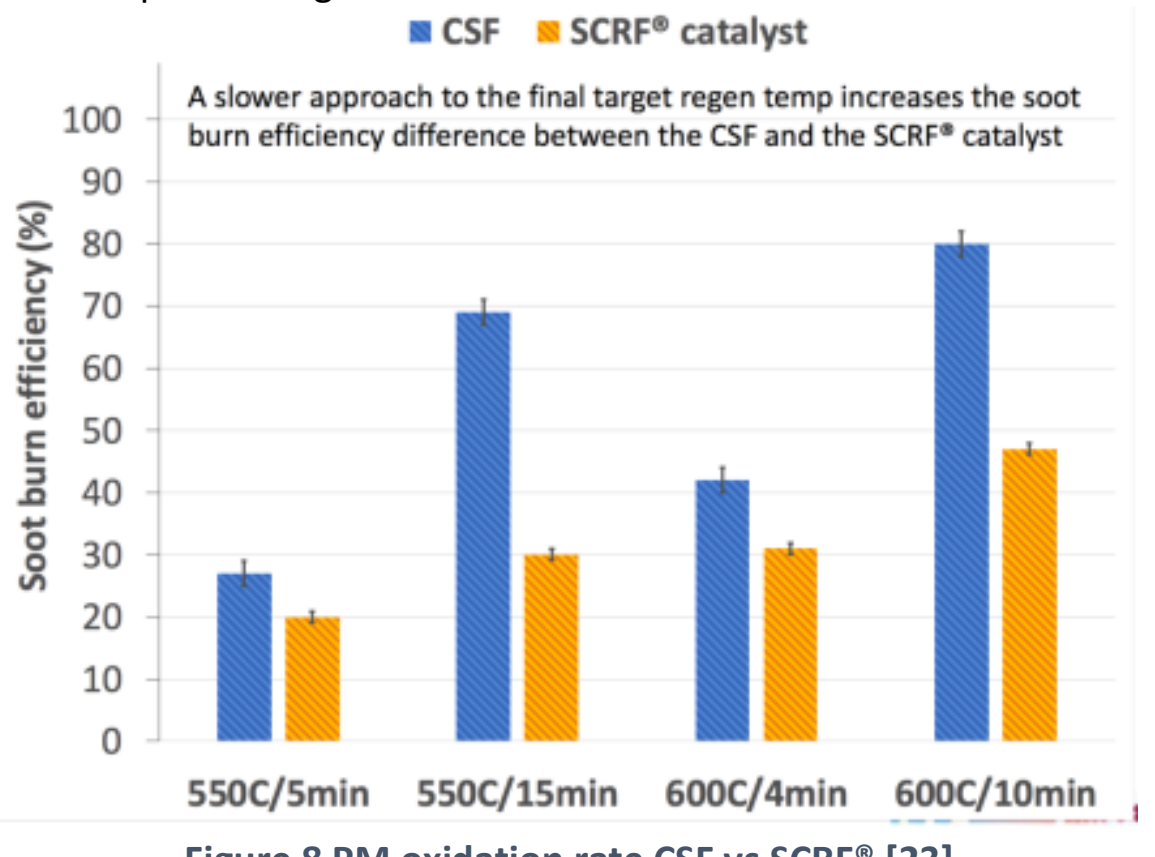

Figure 8 PM oxidation rate $\mathrm{CSF}_{\text {vs }} \mathrm{SCRF}^{\circledR}[23]$

Lee et al. [24] conducted experiments on Cu-Ze SCR/DPF using USO6 and cold FTP cycles to evaluate transient performance of the SCR/DPF. It was found that NOx reduction performance of the SCR/DPF decreased from $84 \%$ to $82 \%$ with increase in mileage. Back pressure did not affect the NOx reduction performance of the SCR/DPF.

The SCR/DPF was found to have $96 \% \mathrm{NO}_{x}$ reduction efficiency for US06 cycle with PM loading up to $5 \mathrm{~g} / \mathrm{l}$ having minimal impact on $\mathrm{NO}_{\mathrm{x}}$ reduction performance. The $\mathrm{NO}_{\mathrm{x}}$ reduction efficiency reduced to $53 \%$ at temperatures above $400^{\circ} \mathrm{C}$ due to $\mathrm{NH}_{3}$ oxidation. Also, oxidation of about 5 $\%$ of the $\mathrm{NH}_{3}$ to $\mathrm{NO}_{x}$ in the mixer was observed at high temperatures. Catalyst deactivation was 
also studied and it was found that the number of active sites on the $\mathrm{Cu}$-Ze catalyst and thus $\mathrm{NH}_{3}$ storage capacity reduced after the filter was subjected to thermal regeneration above $550^{\circ} \mathrm{C}$.

Tang et.al. [25] performed experiments on a Cu-Ze SCR on filters (SCRoF) to study DeNOx and $\mathrm{NH}_{3}$ slip characteristics for steady state and transient conditions. The study also focused on the effect of sulphur content in the fuel on the Cu-Ze catalyst. The SCRoF was exposed to fuel containing $395 \mathrm{ppm}$ of sulphur which led to degradation of catalyst performance. The desulfication process was conducted at $500^{\circ} \mathrm{C}$ for $0.5 \mathrm{hrs}$ which led to complete recovery of the $\mathrm{NH}_{3}$ storage capacity and $\mathrm{NO}_{x}$ reducing performance of the SCRoF. SCR reaction rates were found to be significantly faster than PM oxidation reactions leading to a decrease in PM oxidation rate due to forward diffusion of $\mathrm{NO}_{2}$. $\mathrm{A} \mathrm{NO}_{2} / \mathrm{NO}_{x}$ ratio of 0.74 was found to be suitable for a loaded filter to achieve a $\mathrm{NO}_{x}$ reduction performance of $84 \%$.

Naseri et.al. and Cavataio et.al. [26] [27] performed SCR catalyst on a DPF experiments to compare the performance of the CSF to a SCR catalyst on a DPF. They found higher NOx reduction performance in the SCR catalyst on a DPF compared to a CSF+SCR system for both transient and steady state conditions.

Mihani et al. [28] conducted experiments to study the effects of ammonia nitrate on the low temperature performance of a Cu-Ze SCR on a DPF. The study found that there is a significant increase in ammonia storage with PM loaded filters compared to a clean filter ( $493 \mu \mathrm{mol}$ for PM loaded filter vs $424 \mu \mathrm{mol}$ for filter without PM). Figure 9 shows the change in outlet $\mathrm{NH}_{3}$ concentration between filter with and without PM loading.

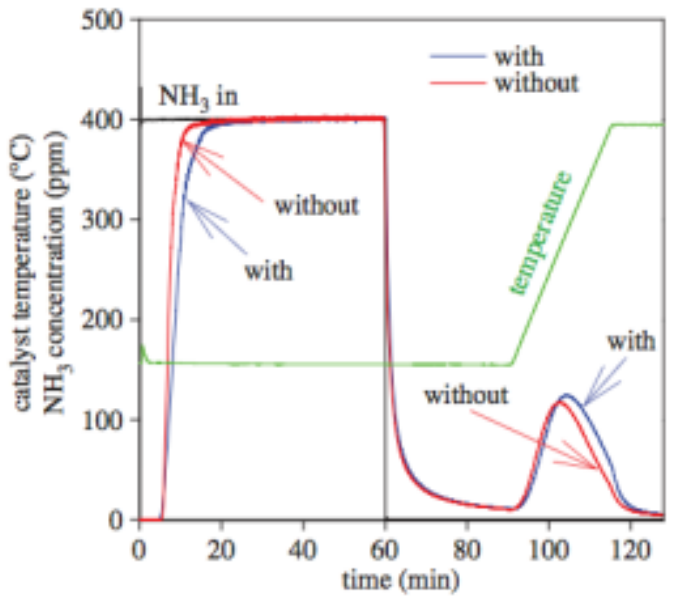

Figure $9 \mathrm{NH}_{3}$ inlet and outlet concentrations [28]

The study also found that $\mathrm{PM}$ reduced the formation of $\mathrm{NH}_{4} \mathrm{NO}_{3}$ at low temperatures which led to a decrease in $\mathrm{N}_{2} \mathrm{O}$ formation at $\mathrm{T}>400^{\circ} \mathrm{C}$ as well as increasing the $\mathrm{NO}_{2} \mathrm{SCR}$ reaction at low temperatures. In the case of a clean filter, the nitrate deposits block the active sites reducing the $\mathrm{NH}_{3}$ storage and deNOx performance but in the case of PM loaded filters the PM reacts with nitrates keeping the active sites free leading to higher NOx reduction performance. Also, two types of nitrates were observed in the filter based on outlet $\mathrm{N}_{2} \mathrm{O}$ values at high temperatures. 
Upon analysis of the PM, the authors propose that the hydrothermal aging of filters leads to the formation of $\mathrm{CuO}$ species which are coated on top of zeolite particles. The PM reacts with $\mathrm{NH}_{4} \mathrm{NO}_{3}$ undergoing oxidation over these $\mathrm{CuO}$ species which reduces the nitrate deposits and thus keeps the active sites free for $\mathrm{NH}_{3}$ storage.

\subsection{SCR / SCR-F state estimator studies}

A SCR catalyst on a DPF estimator can be used to estimate the outlet temperature, pressure drop across filter PM mass retained along with outlet concentrations of $\mathrm{NO}, \mathrm{NO}_{2}, \mathrm{NH}_{3}$ and the $\mathrm{NH}_{3}$ storage. Such an estimator would need a mathematical model that would combine the functionalities of a SCR estimator plant model with functionalities of the DPF to estimate the required quantities. A literature review on SCR estimators capable of estimating outlet $\mathrm{NO}, \mathrm{NO}_{2}$, $\mathrm{NH}_{3}$ and coverage fraction was conducted since there is no mention of a SCR-F estimator in the open literature. The major trends in the research directions observed in the SCR literature are as follows:

1) Modelling of the cross-sensitivity factor for the outlet $\mathrm{NO}_{\mathrm{x}}$ sensor to enable better estimation and control of $\mathrm{NO}_{x}$

2) Reduction of the number of sensors used with estimators capable of predicting downstream $\mathrm{NO} / \mathrm{NO}_{2}$ and $\mathrm{NH}_{3}$ concentrations

3) The ability to estimate the inlet $\mathrm{NH}_{3}$ for low temperature conditions

4) Estimation of coverage fraction of $\mathrm{NH}_{3}$ stored inside the $\mathrm{SCR}$

5) Estimation of outlet $\mathrm{NO}, \mathrm{NO}_{2}$ and $\mathrm{NH}_{3}$ concentrations

Upadhyay et al. [29] developed a model based SCR control using a 3-state control oriented lumped model to investigate the observability and the controllability of SCR plant properties. Sliding mode framework was used for the control algorithm. In order to take into account the two competing objectives of high $\mathrm{NO}_{x}$ conversion and low $\mathrm{NH}_{3}$ slip, an alternate definition of conversion efficiency combining both these factors was used in this study. The observability model is based on the $\mathrm{NH}_{3}$ surface fraction. The observability matrix was found to have the required rank of 3 for all the normal engine operating conditions. An analysis based on a linear and non-linear version of the model was made and it was found that nonlinear version was more stable since its harder to make the observability matrix unstable ( rank < 3) compared to the linear version since the non-linear model depends on trends in the properties whereas the linear version depends on values of the properties at the given point. A FTP75 cycle based test was used to evaluate the estimator.

Devarkonda et al. [30] developed a model based linear estimator and nonlinear controller law for a Fe-Ze catalyst urea with a flow through SCR. The plant model consists of 4 states consisting of $\mathrm{NO}, \mathrm{NO}_{2}, \mathrm{NH}_{3}$ and coverage fraction thus controlling $\mathrm{NO}, \mathrm{NO}_{2}$ independently. The system was found to be observable and controllable for all the operating conditions. In order to quantify the accuracy of the 4 state model, a 3-state version of the plant model was developed and both of these models were compared in terms of accuracy of states predicted and stability. It was found that $\mathrm{NO}, \mathrm{NO}_{2}$ based 4 state approach was more accurate at predicting the states and controlling 
the system compared to $\mathrm{NO}_{\mathrm{x}}$ based 3 state approach. Some of the assumptions made for this model are mass transfer limitations were neglected i.e. surface phase is neglected. Reactions are a function of the concentration of gases and stored $\mathrm{NH}_{3}$ in the catalyst. Full state feedback nonlinear control law was used for controlling the SCR. The linear estimator used is of the following form

$$
X_{e s t}=f(\theta, u, t)+L 1\left(C_{N O_{x}}-C_{N O_{x, e s t}}\right)
$$

The downstream $\mathrm{NO}_{\mathrm{x}}$ sensor is used for the estimator and control law. Cross sensitivity is not considered.

Hsieh et al. [31] developed an EKF based SCR estimator to estimate $\mathrm{NO}_{x}$ concentration from the downstream $\mathrm{NO}_{x}$ sensor eliminating error because of $\mathrm{NH}_{3}$ slip by computing a $\mathrm{NO}_{x} / \mathrm{NH}_{3}$ cross sensitivity factor. $\mathrm{NH}_{3}$ slip can cause a significant error in control of the $\mathrm{SCR}$ as $\mathrm{NH}_{3}$ slip leads to an error in $\mathrm{NO}_{x}$ sensor reading due to cross sensitivity. In production systems, a manufacturer supplied cross sensitivity factor is used to estimate the $\mathrm{NO}_{\mathrm{x}}$ reading but the cross sensitivity is a function of catalyst deterioration, sensor aging, temperature, etc. To avoid these issues, the EKF estimator with plant model based on the continuous stirred tank reactor approach is used. The equation used for calculating the cross sensitivity is as follows

Where $\mathrm{K}_{\mathrm{cs}}=$ cross sensitivity factor (-)

$$
C_{N O, \text { sen }}=C_{N O}+K_{C S} C_{N H_{3}}(2)
$$

The EKF used in the study has the following form

$$
\begin{gathered}
x(k)=f(x(k-1), u(k))+w(k) \\
z(k)=h(x(k))+v(k)
\end{gathered}
$$

Where, $\mathrm{w}(\mathrm{k}) \mathrm{v}(\mathrm{k})$ are process and observation noise

$Q(k) R(k)$ are covariance

Hsieh et al. [32] has further developed an EKF for estimation of $\mathrm{NO}_{x}$ concentration at the outlet of the SCR using a EKF consisting of downstream NOx sensor and SCR plant model using the setup used in Figure 10. 


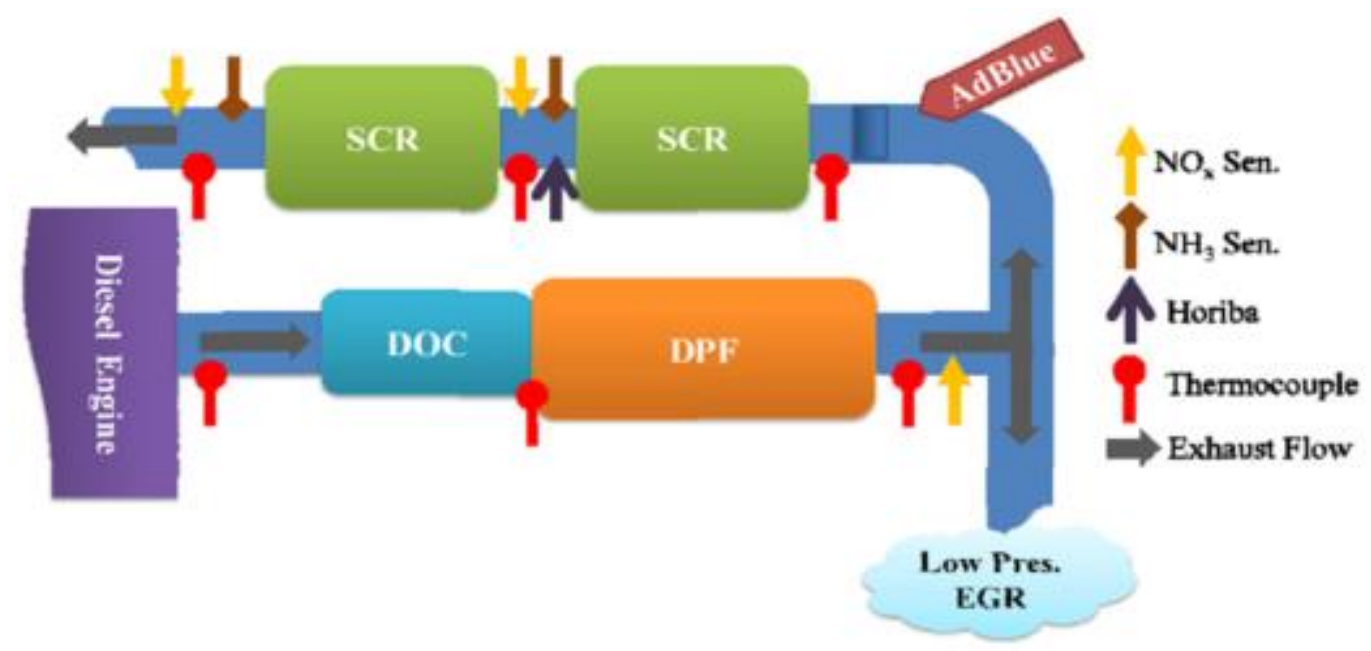

Figure 10 Test setup used for SCR estimator [32]

It was found that for $\mathrm{T}>300 \mathrm{~K}_{\mathrm{cs}}=2, \mathrm{~T}<250 \mathrm{~K}_{\mathrm{cs}}=0.5$. A simplified plant model with lumped $\mathrm{NO}_{\mathrm{x}}$ concentration is used for the estimator and more trust is placed on the sensor reading to track the changes in cross sensitivity which is considered constant in the SCR plant model.

Zhou et al. [33] developed state estimators based on both ordinary and extended Kalman filters based on the plant model consisting of 4 state and 3 state approaches. Both the plant models were based on the first principles and were used to predict the $\mathrm{NH}_{3}$ storage and outlet $\mathrm{NO}_{\mathrm{x}}$ concentrations. The system used tank in series approach for creation of the plant models. Feedback control law was used for SCR control. Varying flow rates, temperatures and $\mathrm{NO}, \mathrm{NO}_{2}$ and $\mathrm{NH}_{3}$ concentrations were used with WHTC data to validate the estimators. The study consisted of two cases. In case 1 where an accurate 4 state model was used with EKF, it was found to be more accurate in terms of estimation of states for a wider range of operating conditions compared to ordinary Kalman filter. In the case 2, a simplified plant model was used and in this case EKF over predicted the storage compared to the model with 4 axial zones.

Chen et al. [34] developed an SCR estimator to estimate $\mathrm{NO}_{x}$ concentrations at low exhaust gas temperatures. Since low temperatures leads to incomplete conversion of urea to $\mathrm{NH}_{3}$ and incomplete hydrolysis of Isocyanic acid, estimation of inlet $\mathrm{NH}_{3}$ is important in this case. Two observers were developed for this approach. The first observer is used to estimate the coverage ratio and the $\mathrm{SCR}$ out $\mathrm{NH}_{3}$ sensors measurement. A second-high gain observer is used to estimate the actual ammonia input and the ammonia slip for the SCR at low temperatures. The setup used is shown in Figure 11. 


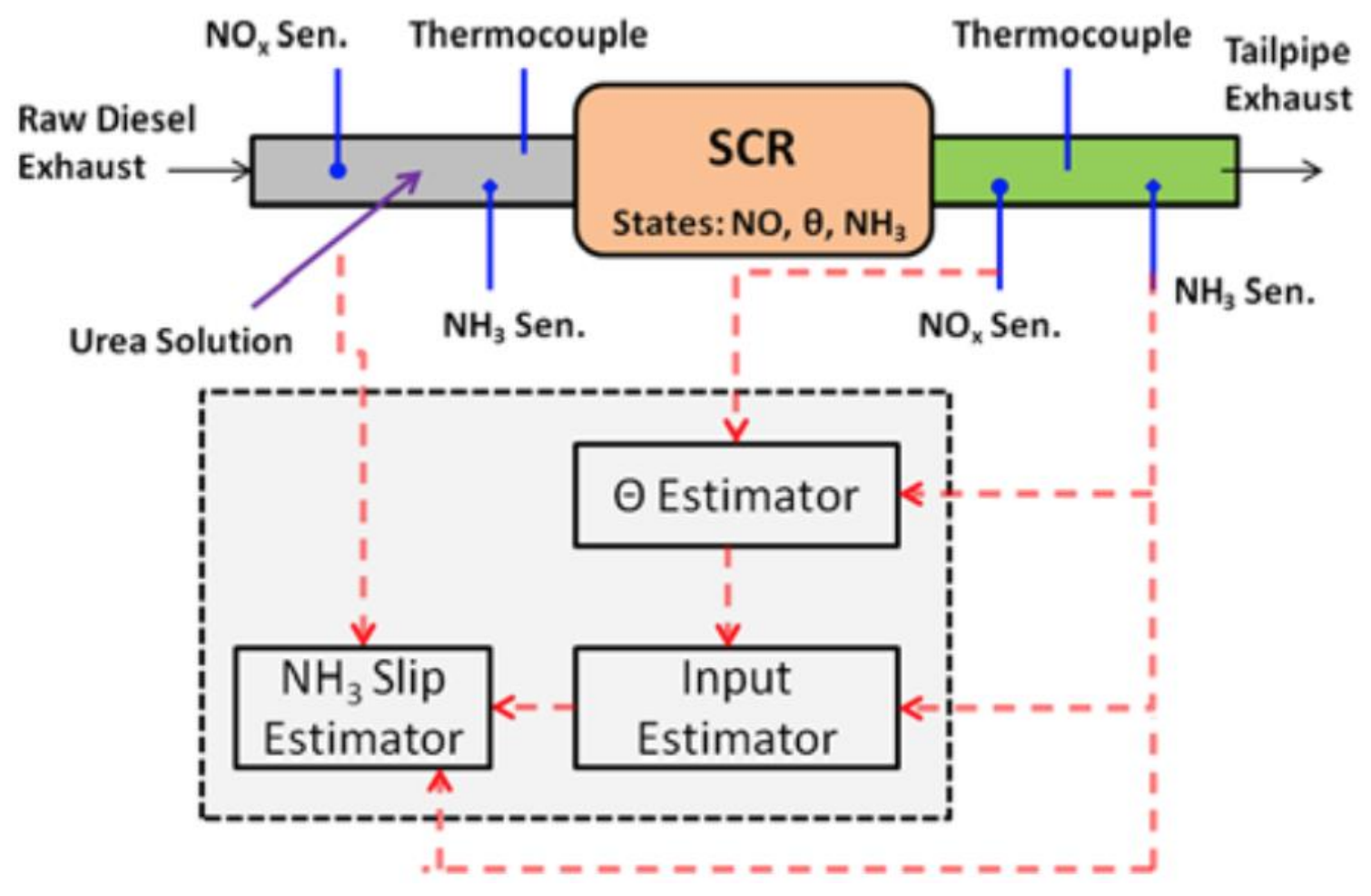

Figure 11 SCR estimator setup [34]

Surenhalli et.al [35] developed an SCR estimator using the EKF to estimate $\mathrm{NH}_{3}$ storage, outlet $\mathrm{NO}, \mathrm{NO}_{2}$ and $\mathrm{NH}_{3}$ concentrations. The estimator is capable of estimating internal states of species and coverage fraction values. This knowledge is useful for OBD purposes and to improve the SCR control strategy when used with a closed loop urea controller. A comparative study of different sensor setups was performed to determine the importance of each sensor in the system. The three systems consisted of $\mathrm{NO}_{x}$ sensor only, $\mathrm{NH}_{3}$ sensor only and $\mathrm{NH}_{3}+\mathrm{NO}_{x}$ sensors. As expected, the system with $\mathrm{NH}_{3}+\mathrm{NO}_{x}$ sensor had the best performance followed by only $\mathrm{NH}_{3}$ and only $\mathrm{NO}_{x}$ sensor based systems.

A reduced order model was used for the estimator. The model was calibrated to within +/$40 \mathrm{ppm}$ for $\mathrm{NO} / \mathrm{NO}_{2}$ and +/- $1 \mathrm{ppm}$ for $\mathrm{NH}_{3}$ compared to the high-fidelity model. The plant model used in this study uses a two-site storage model for $\mathrm{NH}_{3}$ storage with standard, fast and slow SCR reactions.

The major assumptions made in this work are

- Instantaneous reactions

- Mass transport limitations are not considered

- Energy release by SCR reactions are not considered

The estimator was validated with both steady state and transient data. Figure 12 shows the mesh used for high fidelity and reduced order model in this study 

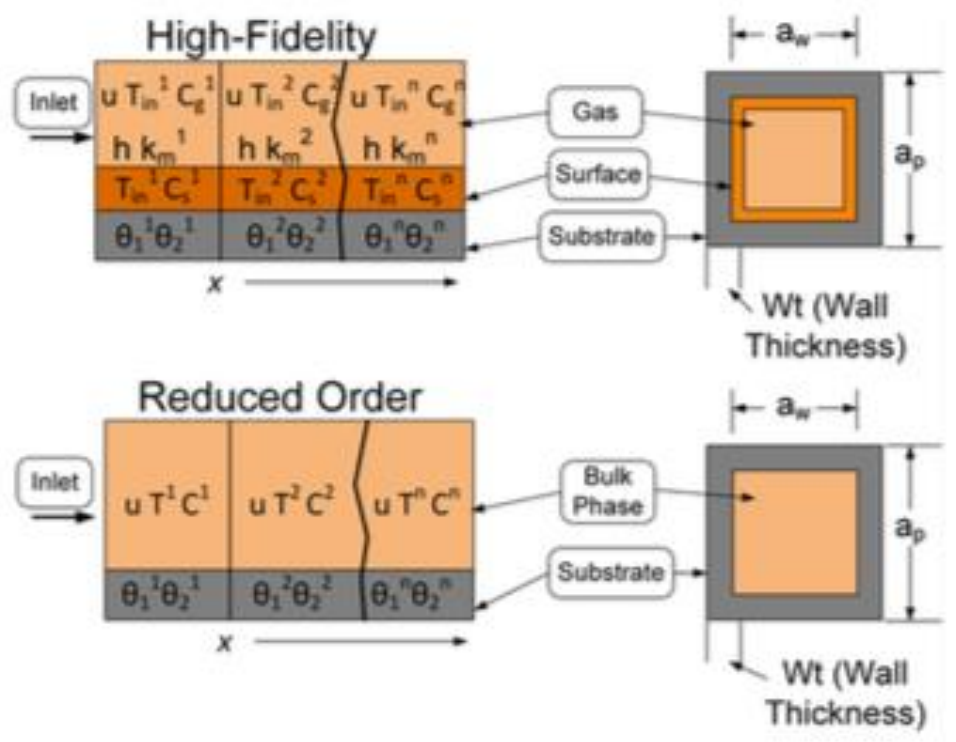

Figure 12 High fidelity and reduced order model mesh [35]

Zhang et al. [36] developed a SCR estimator to estimate outlet $\mathrm{NO}_{x}$ concentrations in a two brick SCR with an aim of reducing the number of sensors in the system with estimators. Figure 13 shows the arrangement of sensors in the original system.

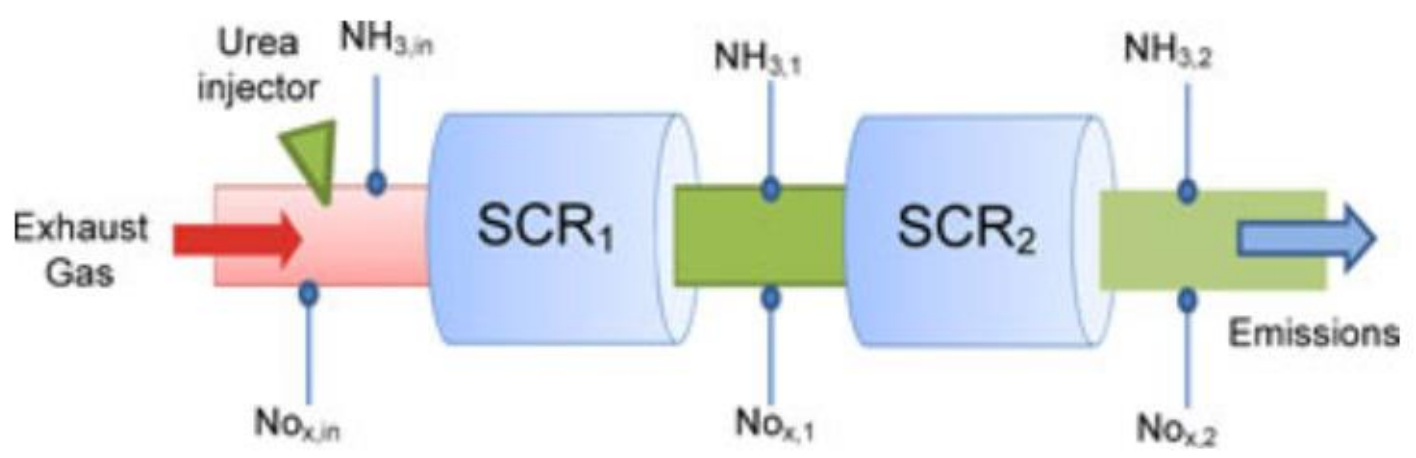

Figure 13 Two brick SCR system [36]

The original system implemented a feedback loop for urea injection with readings from $3 \mathrm{NH}_{3}$ sensors and $3 \mathrm{NO}_{\mathrm{x}}$ sensors. The aim of the work was to reduce the system to 3 sensors and 2 observers. The first observer was developed to estimate the inlet $\mathrm{NH}_{3}$ and coverage fraction inside the first SCR brick thus replacing the $\mathrm{NH}_{3}$ sensor at the inlet of the first SCR brick. The second observer was developed using Luenberger observer approach to estimate $\mathrm{NO}_{\mathrm{x}}$ concentration and $\mathrm{NH}_{3}$ coverage fraction in the second SCR brick.

Boopathi et.al [2] recently developed an CPF estimator to estimate the outlet temperature, pressure drop across the filter and PM mass retained in a CPF which is a first attempt of its kind for particulate wall flow devices. This work consisted of a EKF for estimation of temperature and 
PM loading distribution and a linear Kalman filter (LKF) for estimation of pressure drop across the filter. Figure 14 shows the setup used in this work.

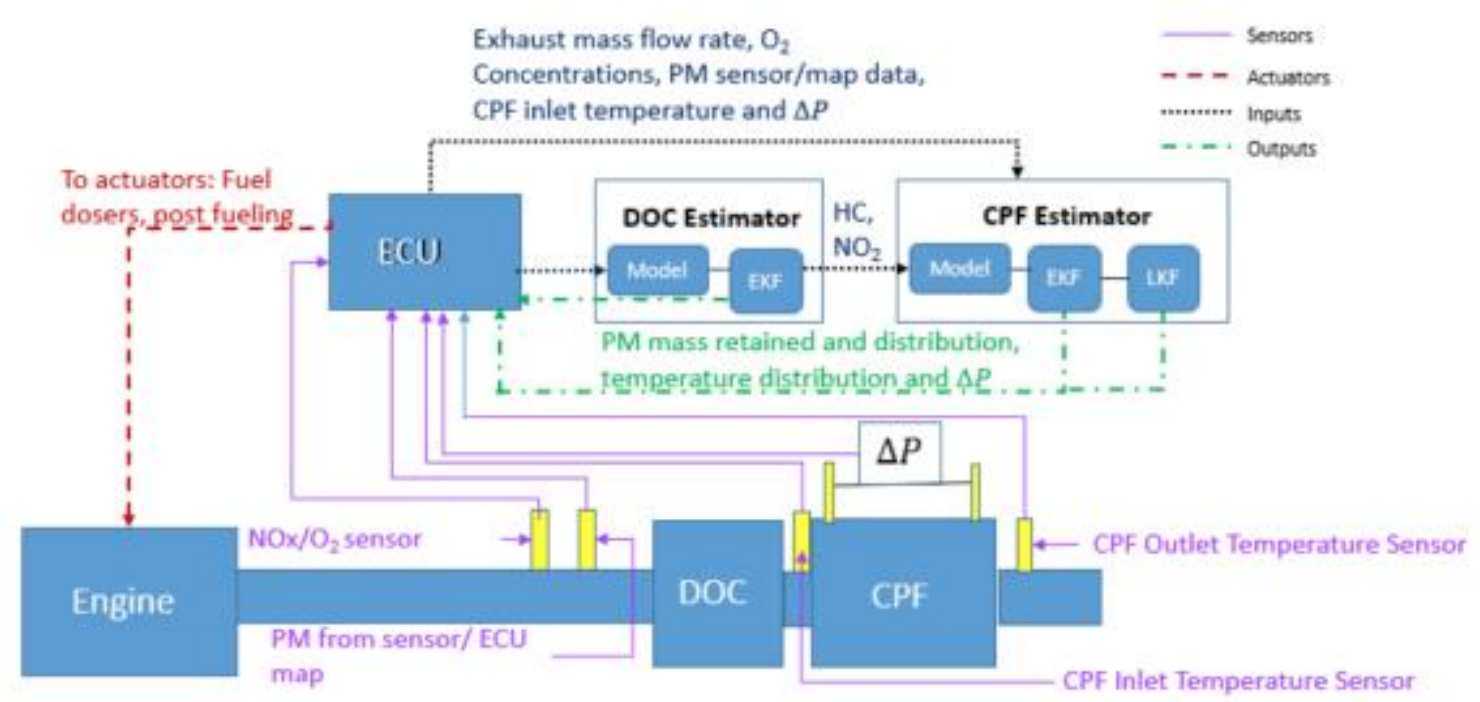

Figure 14 CPF estimator system [2]

A 2D CPF model was used as the plant model for this work. The pressure drop estimate was computed based on the pressure drop sensor reading along with the internal states of temperature and PM distribution values at every time step. The estimator was able to estimate temperature to within $5^{\circ} \mathrm{C}$ and pressure drop to within $0.5 \mathrm{kPa}$ of experimental values.

\subsection{Literature review overview}

The literature on SCR catalyst on a DPF's modeling, experimental data and estimators led to the following observations that needs to be studied as part of the research

1) The formation of $\mathrm{NH}_{4} \mathrm{NO}_{3}$ deposits at low temperatures $\left(\mathrm{T}<250{ }^{\circ} \mathrm{C}\right)$

2) The interaction of nitrates with PM

3) The impact of the SCR reactions on PM oxidation rate and amount of forward diffusion of $\mathrm{NO}_{2}$ from cake to substrate wall

4) The requirement for one or two sites for storage of $\mathrm{NH}_{3}$ in the substrate wall

5) The interaction of $\mathrm{PM}$ with $\mathrm{NH}_{3}$ in terms of storage

6) The impact of PM in the wall on SCR reactions in terms of temperature and inhibition of active sites

7) The impact of $\mathrm{PM}$ loading on local $\mathrm{NO}_{2} / \mathrm{NO}_{x}$ ratio in the substrate wall which affects the $\mathrm{NO}_{x}$ reduction performance of the $\mathrm{SCRF}^{\circledR}$

8) The requirements for a state estimator that can estimate the PM mass retained, temperature, and pressure drop as well as outlet chemical species concentrations of NO, $\mathrm{NO}_{2}$ and $\mathrm{NH}_{3}$ 
So far only one implementation of a CPF state estimator has been found in the open literature. The framework developed in this CPF estimator can be combined with EKF estimator implementations found in the literature to develop a SCR-F estimator capable of meeting all the requirements discussed earlier.

\subsection{Shortcomings of the state-of-the-art and proposed research}

Work that needs to be done on SCR-F modelling of the SCRF ${ }^{\circledR}$ and controls

1) 2-D temperature distribution studies during SCR reactions

2) Local $\mathrm{NO}_{2} / \mathrm{NOx}$ ratio for different $A N R$ 's and PM loading values

3) Change in storage capacity of the catalyst as a function of PM deposition in the wall

4) Quantitative study of $\mathrm{NO}_{2}$ consumption between $\mathrm{NO}_{2}$ based $\mathrm{PM}$ oxidation and $\mathrm{SCR}$ reactions for different $\mathrm{PM}$ loading conditions

5) Study of forward diffusion phenomena between PM cake and substrate wall during SCR reactions

6) Estimation of $\mathrm{NH}_{3}$ storage and $\mathrm{NO}_{x}$ reduction performance during $\mathrm{PM}$ oxidation as a function of temperature and PM cake thickness

7) Modeling of pressure drop across the $\mathrm{SCRF}^{\circledR}$

Steps to be followed in the proposed research:

High fidelity SCR-F model

- Develop a computationally efficient high fidelity SCR-F model - A $10 \times 10$ model of the $\mathrm{SCRF}^{\circledR}$ will be created that's capable of simulating the temperature and PM distribution along with pressure drop across the filter

- Quantify the temperature distribution and deNOx performance of the SCRF ${ }^{\circledR}-\mathrm{SCR}$ reactions have been added to the SCR-F high fidelity model and NOx reduction performance of $\mathrm{SCRF}^{\circledR}$ will be quantified along with energy release by the SCR reactions

- Calibrate the SCR-F model with experimental data - Experimental data collected from 2013 Cummins ISB engine SCRF ${ }^{\circledR}$ will be used to calibrate the model (Configuration 1 and 2)

\section{SCRF $^{\circledR}$ Configuration 3 calibration}

- $\quad \mathrm{NO}_{\mathrm{x}}$ reduction performance studies on $\mathrm{SCRF}^{\circledR}+\mathrm{SCR}$ system using configuration 3 data The experimental data collected on 2013 Cummins ISB engine SCRF ${ }^{\circledR}+$ SCR will be used to calibrate the SCR-F high fidelity and SCR high fidelity models used as a system 


\section{$\mathrm{SCRF}^{\circledR}$ reduced order model development}

- Evaluate the optimum mesh size to obtain reasonable model accuracy vs simulation time for a SCR-F reduced order model - the mesh size will be reduced from $10 \times 10$ to $7 \times 7$, $5 \times 5$ and $4 \times 4$. The accuracy of the model and change in simulation time will be evaluated to find a mesh size that is more suitable for the SCR-F reduced order model.

- Simplify the governing equations to reduce the runtime for the SCR-F reduced order model - The governing equations for the temperature distribution and species concentration will be simplified to reduce simulation time. The impact of these simplifications will be quantified by their impact on temperature, pressure drop, and species concentration differences between the detailed and simplified models.

\section{SCR-F state estimator}

- Develop SCR-F state estimator to estimate the downstream concentration of $\mathrm{NO}, \mathrm{NO}_{2}$ and $\mathrm{NH}_{3}$ values as well as pressure drop, $\mathrm{NH}_{3}$ storage fraction and temperature and $\mathrm{PM}$ distribution of the SCR-F

- Add DOC reduced order model and estimator to the SCR-F reduced order model

- Calibrate the model against engine data - Data from Configuration 1 with urea injection will be used for SCR-F estimator calibration

Figure 15 shows the research plan for the proposed research 


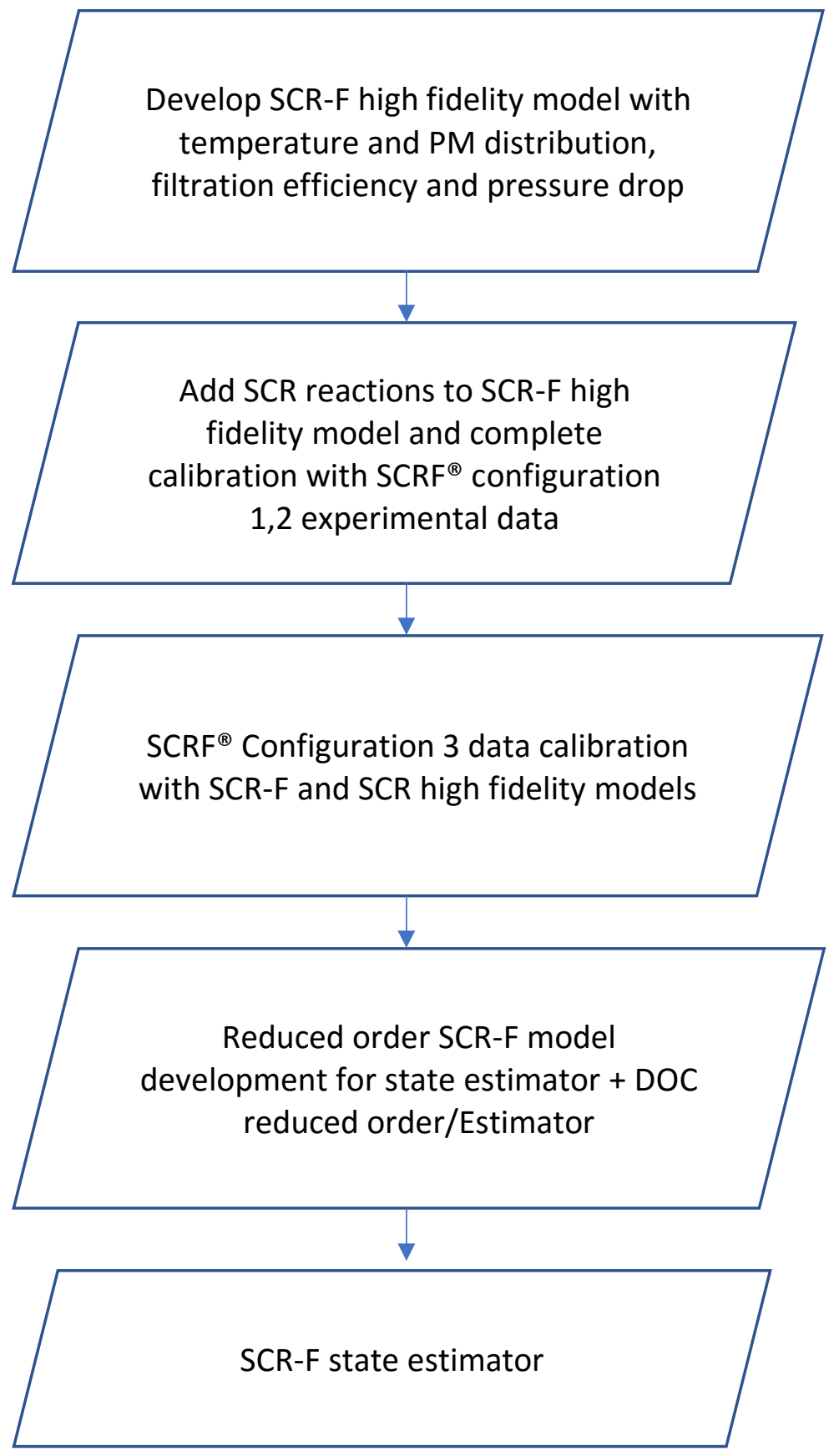

Figure 15 Research plan 


\section{The SCRF ${ }^{\circledR}$ Experimental Data and the Approach to Modeling}

The primary objective of the research is to develop a high-fidelity SCR-F model and a SCR-F reduced order estimator model.

Development of the high-fidelity SCR-F/CPF model applied to a CPF was first the high-fidelity SCR-F model developed and it is capable of simulating the temperature and PM distribution in the filter along with filtration efficiency and pressure drop. A detailed description of the literature outlining the background for the model can be found in reference [2] [35] [36] [37]. This version of the model will be referred to as v1.3 of the SCR-F model. The model was used for a CPF and was calibrated to experimental data from the 2007 ISL engine and a CPF by Boopathi [2]. The model was calibrated to within $3 \mathrm{~g}$ of the experimental PM mass retained for all 18 runs that were present in the dataset. Also, the model was able to simulate the temperature distribution to within $5^{\circ} \mathrm{C}$, pressure drop to within $0.3 \mathrm{kPa}, \mathrm{NO}$ and $\mathrm{NO}_{2}$ outlet concentrations to within 20 ppm and filtration efficiency to within $1 \%$ of the experimental data. Details about the calibration process and results for a CPF are described in reference [2]. The development of the high-fidelity model with SCR reactions is described in reference [6] that is now being written.

The main states in the version 1.3 of the model were

1) Temperature in each of the axial and radial zones (10 radial $\times 10$ axial)

2) PM mass retained in PM cake and wall of each axial and radial zones ( 2 states $\times 10$ radial x10 axial)

The filtration efficiency, pressure drop and outlet chemical species concentrations are treated as outputs of the model computed at each time step based on inlet data and states. Figure 16 shows the mesh used for the model.

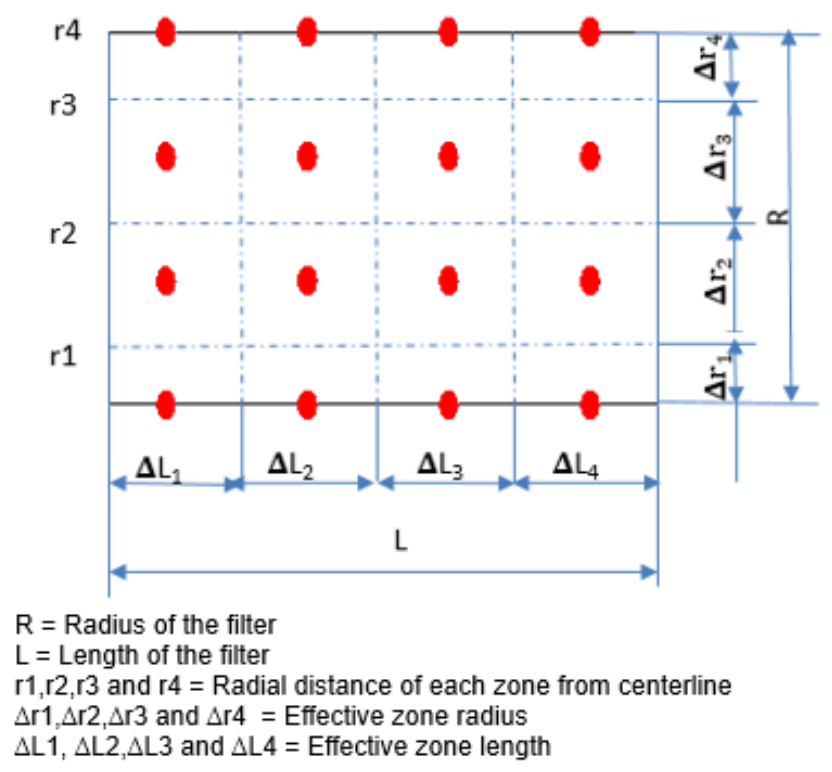

Figure 16 Mesh for SCR-F model v1.3 [2] 
Equations 5 to 9 show the equations used for computing the temperature distribution and species outlet concentrations in the model. Details about the remaining equations used in the model can be found in reference [2].

$$
\begin{aligned}
& \frac{\mathrm{d}}{\mathrm{dt}}\left(\rho_{\mathrm{p}} \mathrm{c}_{\mathrm{p}} \mathrm{A}_{\mathrm{p}} \Delta \mathrm{x}+\rho_{\mathrm{s}} \mathrm{c}_{\mathrm{p}, \mathrm{s}} \mathrm{w}_{\mathrm{s}} \mathrm{a} \Delta \mathrm{x}\right) \mathrm{T}_{\mathrm{w}}=\dot{\mathrm{q}}_{\text {conv }, 1-\mathrm{w}}+\dot{\mathrm{q}}_{\text {conv }, 2-\mathrm{w}}+\dot{\mathrm{q}}_{\text {cond,radial }}+\dot{\mathrm{q}}_{\text {axial }}+\dot{\mathrm{q}}_{\mathrm{amb}}+ \\
& \dot{\mathrm{q}}_{\mathrm{rxn}} \\
& a v_{w} \frac{d Y_{i}}{d y}-\frac{d}{d y}\left(D_{i} a \frac{d Y_{i}}{d y}\right)=-\frac{\bar{a}}{\left(\bar{\rho}_{\text {exh }}\right)_{w}} \sum_{j} \xi_{i, j} R_{j} \\
& \dot{m}_{\text {ox,cake }}=m_{\text {cake }}\left[(-1) R_{\text {th,cake }}+(-1) R_{\mathrm{NO}_{2}, \text { cake }}\right] \\
& R_{\text {th,cake }}=S_{p} A_{\text {th, cake }} C_{O_{2}}\left(T_{w}\right)^{x_{\text {th,cake }}} e^{-\frac{E a_{\text {th }, \text { cake }}}{R T_{w}}} \\
& R_{\mathrm{NO}_{2}, \text { cake }}=S_{p} A_{\mathrm{NO}_{2}, \text { cake }} C_{\mathrm{NO}_{2}}\left(T_{w}\right)^{x_{N O_{2}, \text { cake }}} e^{-\frac{E a_{\mathrm{NO}_{2}, \text { cake }}}{R T_{w}}}
\end{aligned}
$$

The v1.3 of the model also had a cake permeability model which is capable of simulating the change in the cake permeability during oxidation stage due to cracks formed in the cake. This part of the model for a CPF is described in reference [39] and has been modified to simulate the $\mathrm{SCRF}^{\circledR}$ experimental data.

The SCR-F model was further developed to simulate the SCR reactions during urea injection leading to development of v3.0 of the model with all the required SCR reactions [4]. In order to calibrate the SCR-F model, three sets of experimental data have been collected on the Cummins 2013 ISB engine SCRF $^{\circledR}$ [3][4]. To date, calibrating the configuration 1 data without urea has been completed and calibration of configuration 2 data without PM has been started. Figure 17 shows the overview of the datasets that have been collected for this effort.

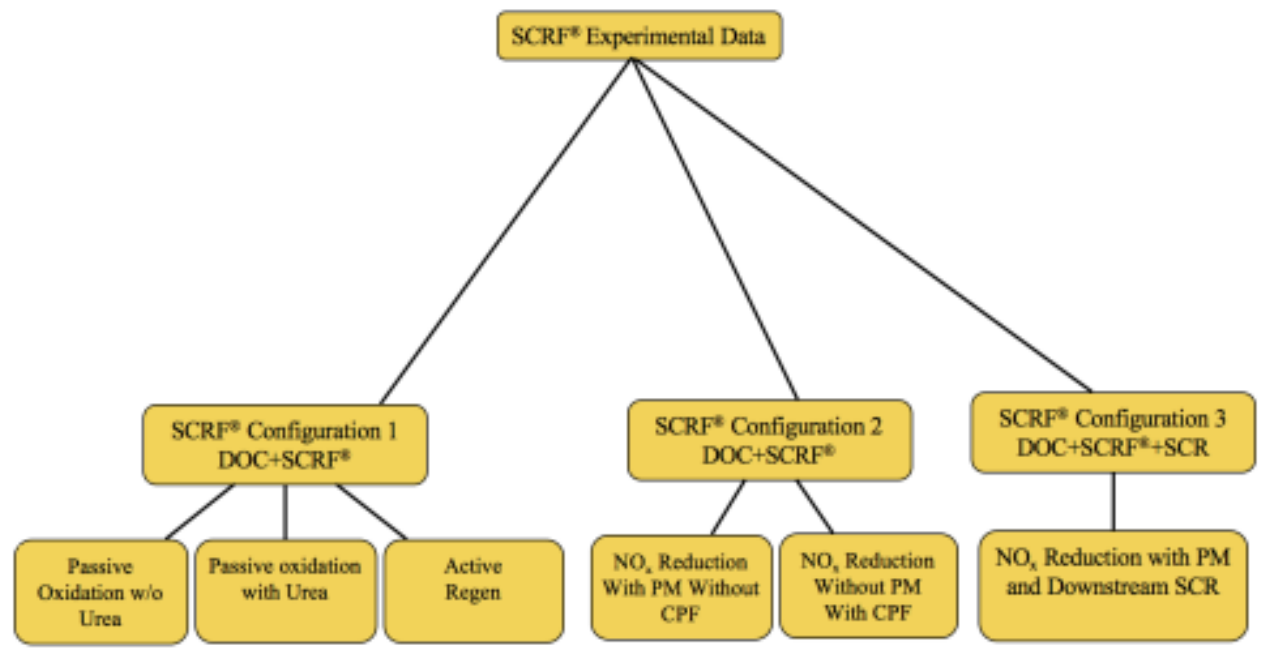

Figure $17 \mathrm{SCRF}^{\oplus}$ experimental data [3] 


\section{1 $\mathrm{SCRF}^{\circledast}$ configuration 1 experimental data}

The configuration 1 dataset has 7 passive oxidation and 4 active regeneration experiments without urea experiments and 7 passive oxidation experiments with urea injection. The experiments without urea injection were collected to determine the PM oxidation kinetics and pressure drop parameters of the $\mathrm{SCRF}^{\oplus}$ along with temperature and pressure drop characteristics. These test points were selected to represent the range of inlet temperature and $\mathrm{NO}_{2}$ concentration values for different engine speed and load conditions. Also, the active regeneration experiments are used to determine the thermal oxidation kinetics and thermal characteristics of the $\mathrm{SCRF}^{\oplus}$ at temperatures greater than $500{ }^{\circ} \mathrm{C}$. Table $\mathrm{B} 1$ and $\mathrm{B} 2$ show the engine conditions for all the experiments with and without urea injection in configuration 1. Figure 18 shows the test used for the configuration 1 experiments with urea dosing. The test is divided into following stages.

S1: In stage 1 the filter is loaded with PM without any urea dosing. This stage is used to load the substrate wall with PM and form PM cake. At the end of this stage the filter is weighed.

S2: In this stage, the loading of the filter with PM is continued until the target loading value is reached which in the case of configuration 1 is $1.8+/-0.2 \mathrm{~g} / \mathrm{l}$. The filter is weighed to determine the PM mass retained at the end of loading.

Ramp UP: In this stage the engine is run at same speed and load condition as the loading stage in order to stabilize the substrate temperature before changing the engine condition

PO Stage: In this stage, the engine condition is changed to a higher NOx and temperature condition where passive oxidation of PM is dominant. Also, urea dosing at constant ANR of 1 is performed.

Stage 3: At the end of the PO stage the engine condition is changed to the loading condition and run for some time till the system is stabilized. At the end of this stage the PM mass retained is measured

Stage 4: This stage has the same engine condition as loading. This stage is used to study the post loading pressure drop characteristics of the filter. At the end of this stage the final PM mass retained value is measured.

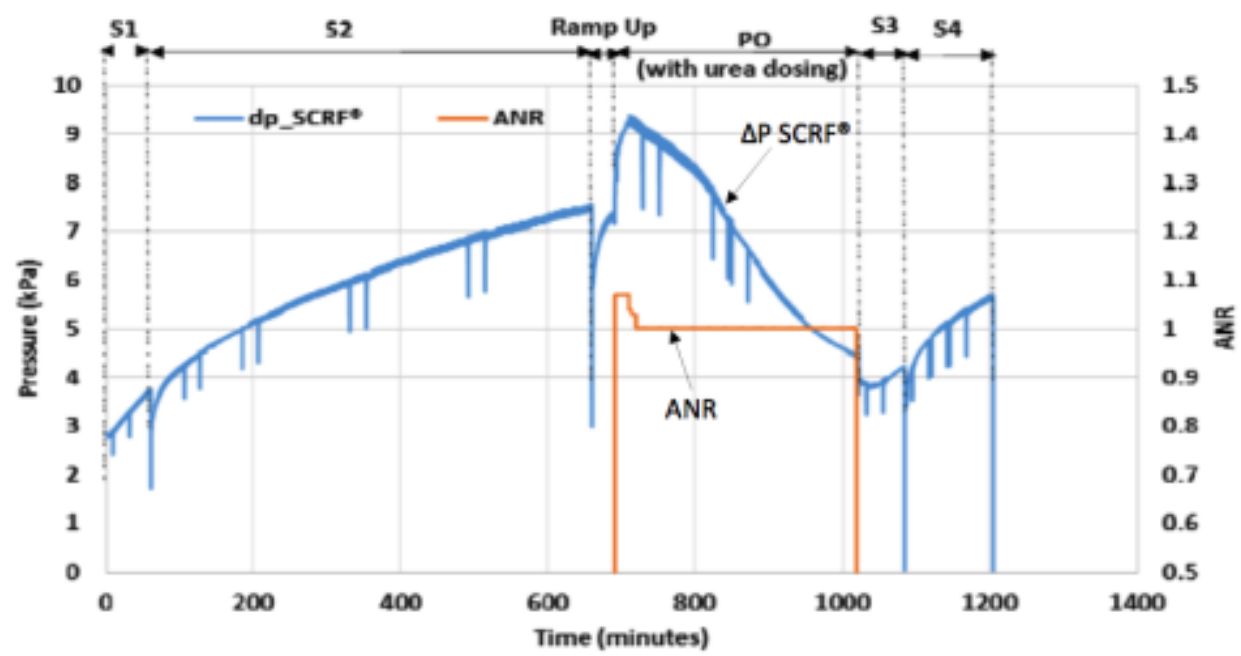

Figure $18 \mathrm{SCRF}^{\oplus}$ configuration 1 experimental test [3] 
The data from these experiments were used to calibrate the SCR-F model and find the PM oxidation kinetics without urea. The results from this calibration process have been described in Appendix A. The details of the calibration process and several results can be found in the reference [6].

The following conclusions were made based on the results of the SCR-F model calibration with configuration 1 data without urea

$>\mathrm{PM}$ retained was calibrated to within $+/-2 \mathrm{gm}$

$>$ Temperature distribution and outlet temperature was calibrated to within +/- $50 \mathrm{CC}$

$>$ Pressure drop was calibrated to within $+/-0.8 \mathrm{kPa}$

$>\mathrm{NO} / \mathrm{NO} 2$ were calibrated to within $+/-20 \mathrm{ppm}$

$>$ Percentage of NO2 oxidation during active regeneration was observed to be $4 \%$ compared to $20 \%$ observed in CPF

$>$ The NO2 assisted PM kinetics are Ea $=116 \mathrm{E6}(\mathrm{J} / \mathrm{kmol}) \mathrm{A}=687(1 / \mathrm{K} \mathrm{s})$ (loading), $\mathrm{A}=164(1 / \mathrm{K} \mathrm{s})$ (oxidation), the $\mathrm{O} 2$ based PM kinetics are Ea $=197 \mathrm{E} 6(\mathrm{~J} / \mathrm{kmol}) \mathrm{A}=$ $374(1 / \mathrm{K} \mathrm{s})$

Configuration 1 data also consists of 7 passive oxidation experiments with urea injection used to study the interaction of the SCR and PM oxidation reactions. In all test cases, an ANR of approximately 1 was used during the passive oxidation stage. It was observed that for all the tests there was a decrease in oxidation rate compared to the same test point without urea injection. Figure 19 shows the Arrhenius plot comparing the passive oxidation kinetics for experiments with and without urea injection from configuration 1 [3].

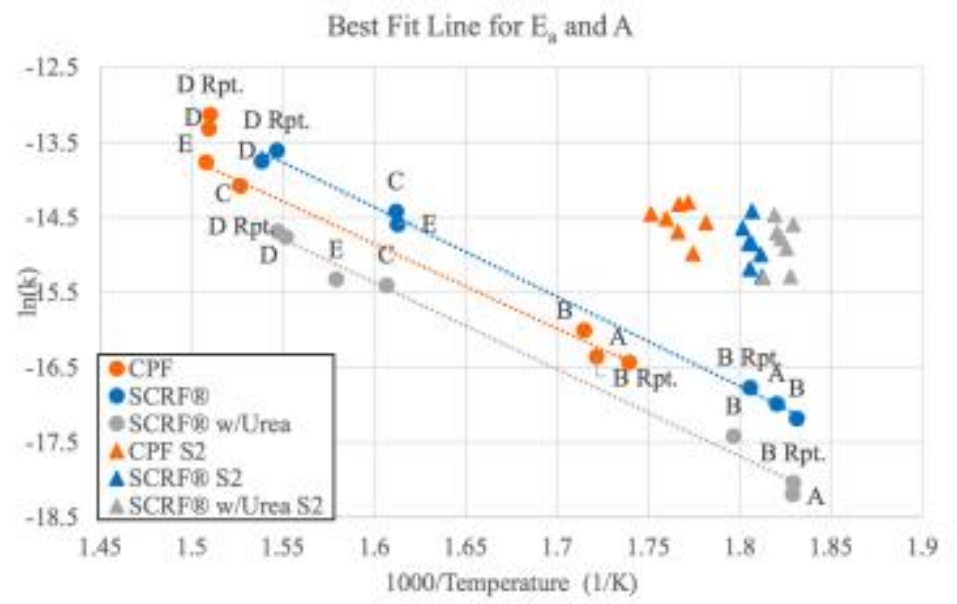

Figure 19 Arrhenius plot for configuration passive oxidation with and without $\mathrm{NH}_{3}$ [3]

The decrease in passive oxidation rate during urea injection is due to decrease in available $\mathrm{NO}_{2}$ in the PM caused by forward diffusion of $\mathrm{NO}_{2}$ which is a result of the concentration gradient caused by the consumption of $\mathrm{NO}$ and $\mathrm{NO}_{2}$ by the SCR reactions in the substrate. The SCR species model in v3.0 has the capability to simulate this phenomenon of forward diffusion between PM 
cake and substrate wall which will be used to calibrate the SCR-F model to the configuration 2 data.

\section{2 $\mathrm{SCRF}^{\circledR}$ configuration 2 experimental data}

Configuration 2 of the $\mathrm{SCRF}^{\circledR}$ experimental data consists of 12 experiments with different PM loading values of 0,2 and $4 \mathrm{~g} / \mathrm{L}$ and ANR values of $0.8,1$ and 1.2. Figure 20 shows the cycle used in the configuration 2 experiments with PM.

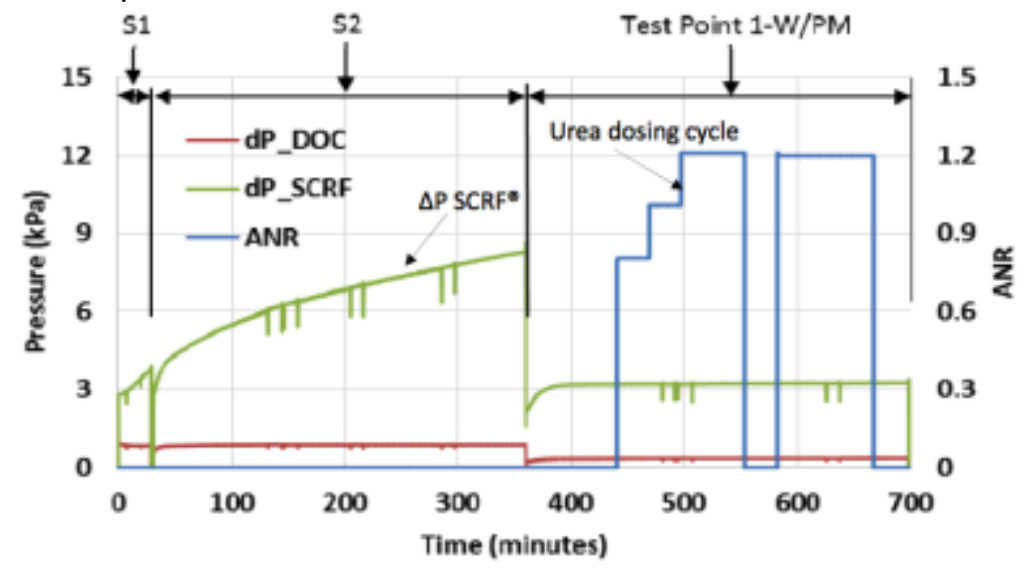

Figure $20 \mathrm{SCRF}^{\circledR}$ configuration 2 experimental test [4]

The loading stages S1, S2 are similar to the stages in configuration with loading values of 0 $\mathrm{g} / \mathrm{l}, 2 \mathrm{~g} / \mathrm{l}$ and $4 \mathrm{~g} / \mathrm{l}$. Instead of PO stage we have urea dosing cycle where the urea is dosed at ANR values of $0.8,1$ and 1.2 to study the NOx reduction performance of the $\mathrm{SCRF}^{\circledR}$ in the presence of different PM loading values. Table B 3 shows the engine conditions used all the 12 experiments in configuration 2.

The configuration 2 data described in Table B 3 shows a wide range of space velocity, inlet NOx and inlet exhaust gas temperatures that have been covered in the 4 test points 1,3,6 and 8 . The primary focus of this dataset is to study the impact of $\mathrm{PM}$ loading on $\mathrm{NH}_{3}$ storage, change in local $\mathrm{NO}_{2} / \mathrm{NO}_{\mathrm{x}}$ ratio in the substrate wall due PM oxidation which effect the SCR reaction rates.

The four experiments with $0 \mathrm{~g} / \mathrm{l}$ will be used to calibrate all the SCR reactions and storage parameters for the SCR-F high fidelity model. Once these values are found the model can be run for $2 \mathrm{~g} / \mathrm{l}$ and $4 \mathrm{~g} / \mathrm{l}$ loading experiments to study the impact of PM loading on the SCR reactions. Further details about these experiments can be found in [3][4].

\section{3 $\mathrm{SCRF}^{\oplus}+\mathrm{SCR}$ system configuration 3 experimental data}

Configuration 3 of the $\mathrm{SCRF}^{\circledR}$ experimental dataset consists of 5 passive oxidation and $1 \mathrm{NO}_{\mathrm{x}}$ reduction experiments with ANR values of 1.05 - 1.1 during oxidation stage described in [41]. The experiments were designed to study the overall $\mathrm{NO}_{x}$ reduction performance and $\mathrm{NH}_{3}$ slip for a system consisting of 17.1 liter $\mathrm{SCRF}^{\circledR}$ and 8.5-liter SCR. Figure 21 describes the cycle used for all the configuration 3 experiments. 


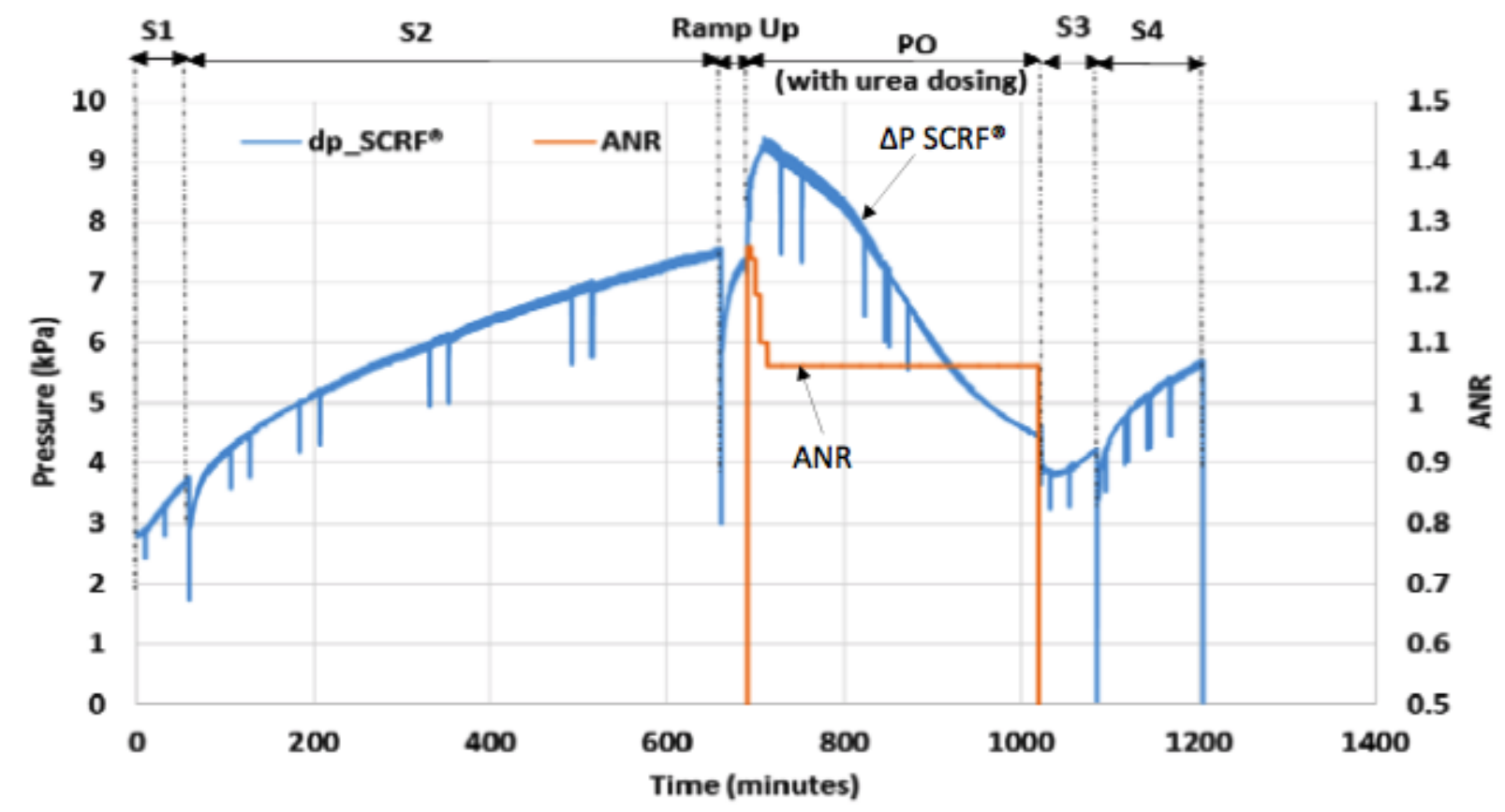

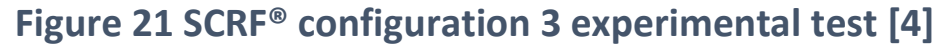

The urea dosing in this case is performed at value of ANR $1.05-1.1$ and the $\mathrm{NH}_{3}$ slip across both $\mathrm{SCRF}^{\circledR}$ and SCR are measured. Table B 4 shows the engine conditions used for all the 7 experiments in the $\mathrm{SCRF}^{\circledR}$ configuration 3 data.

The data from configuration 3 will be used to determine the kinetics for $\mathrm{NO}_{2}$ assisted $\mathrm{PM}$ oxidation of the $\mathrm{SCRF}^{\circledR}$ at constant ANR of 1.05-1.1. NOx reduction and $\mathrm{NH}_{3}$ slip characteristics of the SCRF ${ }^{\circledR}+$ SCR system will be analyzed at ANR 1.0 - 1.1 using the data. In order to perform these studies, a system consisting of the SCR-F and 1D SCR models will be used to simulate the data. Figure 22 shows the system that will be used to simulate the configuration 3 data where outputs of $\mathrm{SCRF}^{\circledR}$ model become inputs of 1D SCR model

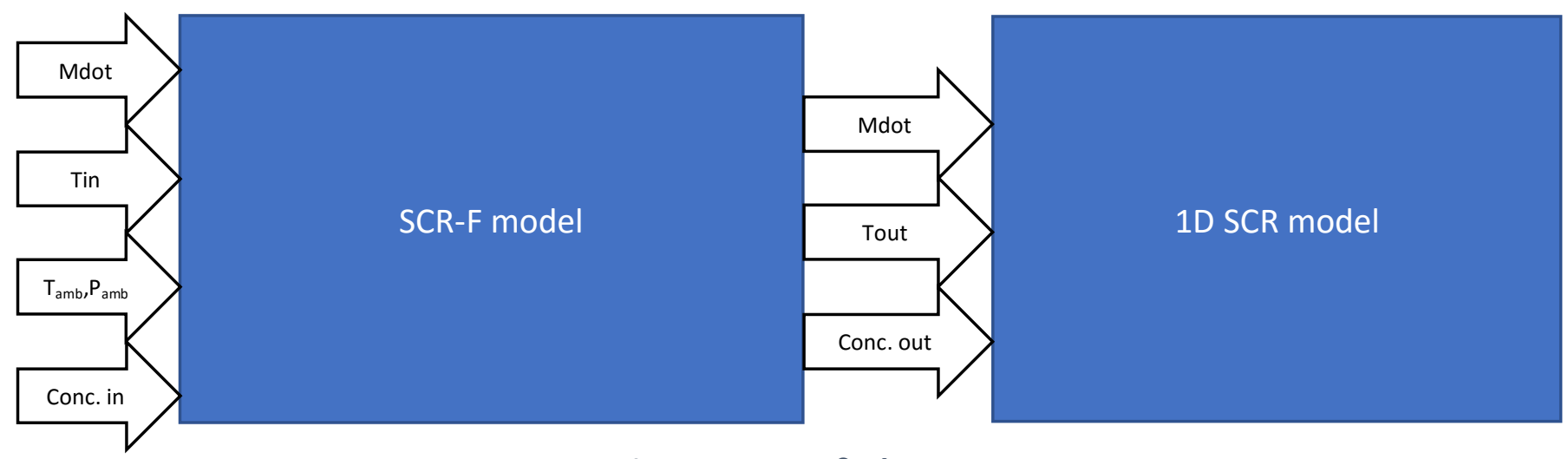

Figure 22 SCRF $^{\circledR}$ plus SCR system 


\section{On-going and Future Research}

The ongoing research described in section 3.5 will be discussed in detail in this section. The major steps for this process include

- Calibration of configuration 2 data without PM

- Calibration of configuration 1 data with urea

- Calibration of configuration 2 data with PM

- Calibration of configuration 3 data

- Reduced order model development

- SCR-F state estimator development

\section{Calibration of configuration 2 data without PM}

The four experiments in the configuration 2 without PM will be used to calibrate the $\mathrm{NH}_{3}$ storage and SCR reactions rate parameters. The main parameters to be found in this stage of the calibration are

1) Maximum storage capacity of the Cu-Ze catalyst

2) Reaction kinetics of standard, fast and slow SCR

3) Reaction kinetics for $\mathrm{NH}_{3}$ oxidation at high temperatures $\left(>350^{\circ} \mathrm{C}\right)$

4) Requirement for a second storage site

5) Energy released by each of the SCR reactions

The completion of this step will lead to a complete set of parameters required to simulate the interaction of the SCR and PM oxidation reactions found in configuration 1 with urea and Configuration 2 with PM datasets.

\section{Calibration of configuration 1 data with urea}

The data from the 7 experiments in the configuration 1 with urea is useful in determining the change in PM oxidation rate during the passive oxidation stage in the presence of urea. The parameters to be found in this stage are as follows

1) The tortuosity of the PM cake layer and substrate wall which controls rate of forward diffusion

2) The change in $\mathrm{NH}_{3}$ storage with change in $\mathrm{PM}$ retained in the substrate wall

In this phase of the calibration, the storage capacity of the model will be converted from a fixed parameter into a variable which is a function of wall PM retained with a maximum capacity equal to the value found in configuration 2 without PM calibration process.

\section{Calibration of configuration 2 data with PM}

The data from the 8 experiments with $2 \mathrm{~g} / \mathrm{l}$ and $4 \mathrm{~g} / \mathrm{I} \mathrm{PM}$ loading will be used to determine the interaction of $\mathrm{NH}_{3}$ with $\mathrm{PM}$ and change in $\mathrm{NO}_{2} / \mathrm{NO}_{x}$ ratio in the substrate wall due to $\mathrm{PM}$ oxidation. The parameters to be found in this stage are 
1) Storage of $\mathrm{NH}_{3}$ on $\mathrm{PM}$ cake if change in $\mathrm{NH}_{3}$ storage at higher $\mathrm{PM}$ loading is found to be significant

2) Change $\mathrm{NO}_{2}$ across the $\mathrm{PM}$ cake due to $\mathrm{PM}$ oxidation and the oxidation of $\mathrm{NO}$ by $\mathrm{Cu}$-Ze Catalyst

\section{Calibration of configuration 3 data}

The configuration 3 data are primarily focused at studying the slip characteristics and NOx reduction performance of a system consisting of $\mathrm{SCRF}^{\circledR}+\mathrm{SCR}$ [41]. The parameters found in configuration 1 and 2 calibration of SCR-F model and SCR model baseline data calibration [4] will be used for this step. Any changes required in the parameters of the SCR-F and SCR model will be performed based on trends observed in the data.

\section{Reduced order model development}

As part of reduced order model development, the following major modifications will be carried out with the high-fidelity SCR-F model

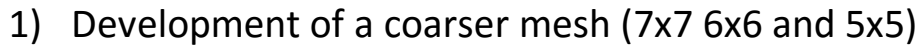

2) Simplification of species concentration equations

3) Lumping the temperature of the inlet and outlet channel exhaust gas

1) Development of coarser mesh

The present version of the SCR-F model consists of 10 axial and 10 radial zones with a simulation speed, 11 times real time. It has been found through study of varying mesh sizes that the model performance increases linearly with decrease in number of mesh elements. The model has been simulated with meshes consisting of $7 \times 7,6 \times 6,5 \times 5$ and $4 \times 4$ elements.

From this study, it was found that the temperature and PM distribution values converge with reasonable accuracy for a mesh size greater than $5 \times 5$ with a change of less than $5 \%$ in model computed values of temperature distribution, pressure drop, PM retained and outlet chemical species concentration values compared to the high-fidelity model. Figure 23 shows the change in model runtime with change in mesh size. 


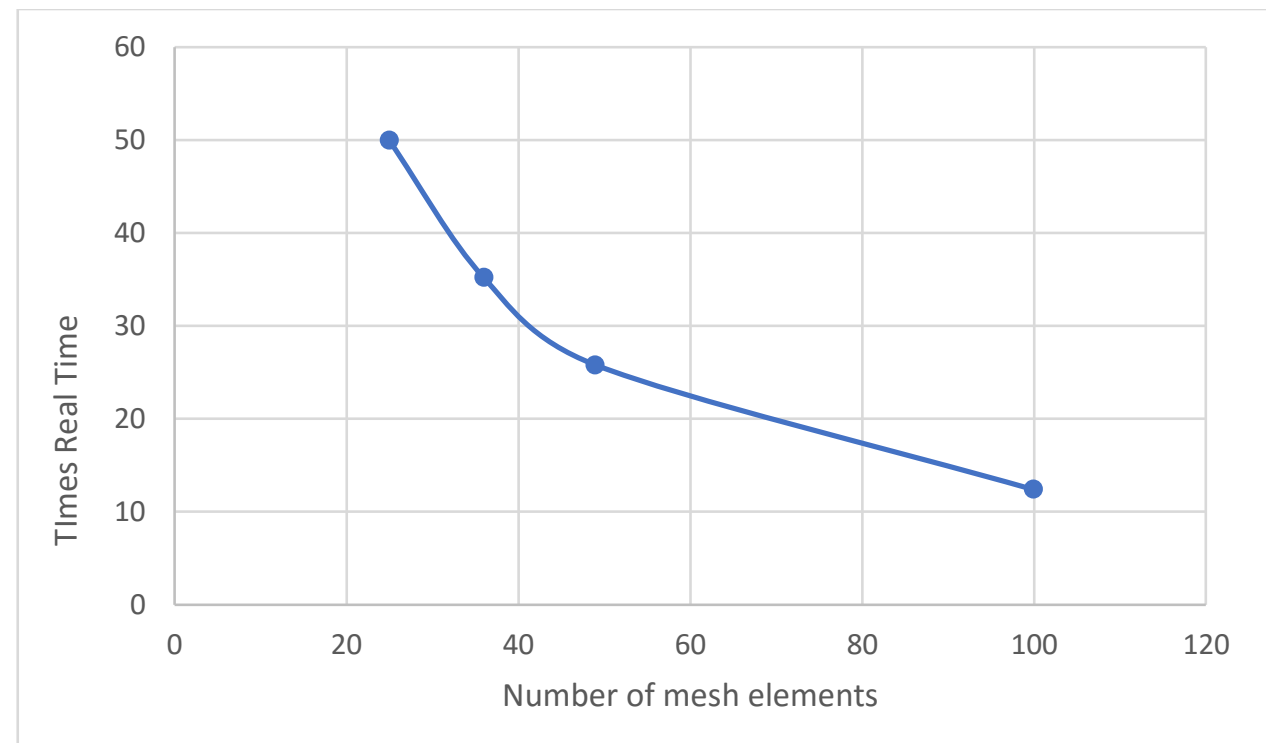

Figure 23 Mesh size vs simulation speedup

2) Simplification of species concentration equations

The present version of the species model uses reaction-diffusion mechanism to simulate the change in chemical species concentration of the chemical species across the SCRF ${ }^{\circledR}$. The model takes into account the change in diffusivity and inhibition caused by each of the chemical species on the other species involved in oxidation reactions. The inhibition term in the model can be simplified to the form show in equation (10)

$$
\mathrm{G}_{\mathrm{i}}=\mathrm{K}_{\mathrm{i}}\left(\frac{\mathrm{T}}{\mathrm{T}_{\mathrm{ref}}}\right)
$$

Where $K_{i}$ is constant for a given species (-)

$\mathrm{G}_{\mathrm{i}}$ is the inhibition factor for given species (-)

T Substrate Temperature (K)

$\mathrm{T}_{\text {ref }}$ Reference temperature $(\mathrm{K})$

Also, the diffusivity equations used in the model can be simplified to the form shown in equations 11 and 12

Where $\mathrm{k}_{\mathrm{mol}, \mathrm{i}, \mathrm{j}}$ and $\mathrm{k}_{\mathrm{kn}, \mathrm{i}}$ are constants

$$
\begin{aligned}
& \mathrm{D}_{\mathrm{mol}, \mathrm{i}}=\frac{1-\mathrm{Y}_{\mathrm{i}}}{\sum_{\mathrm{j} \neq \mathrm{i}} \frac{\mathrm{Y}_{\mathrm{i}}}{\mathrm{k}_{\mathrm{mol}, \mathrm{i}, \mathrm{j}} \mathrm{T}^{\mathrm{b}}}} \\
& \mathrm{D}_{\mathrm{kn}, \mathrm{i}}=\mathrm{k}_{\mathrm{kn}, \mathrm{i}} \sqrt{\mathrm{T}}
\end{aligned}
$$

These modified equations reduce runtime of the model by $10-11 \%$. Detailed description of the process used to derive equations $10-12$ is present in Appendix C. 
3) Lumping the temperature of the inlet and outlet channel exhaust gas

The third modification to the model is lumping of the exhaust gas temperature of inlet and outlet channel. The present version of the model calculates the inlet and outlet channel exhaust gas temperatures as two domains. Equations 13 and 14 replace existing equations with a system of equations that treats exhaust gas in inlet channel and outlet channel as a lump.

$$
\begin{gathered}
\frac{d\left(M_{2} C_{s} T_{w(i, j)}\right)}{d t}=h\left(T_{g a s(i, j)}-T_{w(i, j)}\right) s d x+\frac{\lambda_{s} b s\left(T_{w(i, j+1)}+T_{w(i, j-1)}-2 T_{w(i, j)}\right)}{d x}+ \\
\frac{\lambda_{s} b s\left(T_{w(i+1, j)}+T_{w(i-1, j)}-2 T_{w(i, j)}\right)}{d y}+H_{L}\left(\frac{d m_{p(i, j)}}{d t}\right)(13) \\
\frac{d\left(M_{1} C_{p} T_{\text {gas }(i, j)}\right)}{d t}=u_{\text {out }(i, j-1)} \rho_{g} C_{p} A T_{\text {gas }(i, j-1)}-u_{\text {out }(i, j)} \rho_{g} C_{p} A T_{\text {gas }(i, j)}+h\left(T_{w(i, j)}-T_{\text {gas }(i, j)}\right) s d x
\end{gathered}
$$

This approach reduces runtime of the model by $5-6 \%$. Detailed description of process used for deriving equation 13 and 14 is shown in Appendix B.

\section{SCR-F state estimator development}

In the final phase of the research work a state estimator to estimate the internal states as well as outlet concentrations from the $\mathrm{SCRF}^{\circledR}$ will be developed using the reduced order model developed in the previous phase and an extended Kalman filter. The scope of the estimator is to estimate the states including coverage fraction of $\mathrm{NH}_{3}$ storage inside the $\mathrm{SCRF}{ }^{\circledR}$ along with temperature and PM distribution. Outputs consisting of pressure drop and outlet concentrations of chemical species including $\mathrm{NO}, \mathrm{NO}_{2}$ and $\mathrm{NH}_{3}$ will be estimated based on the values of the states. Equation 15 shows the equations used for the SCR-F state estimator.

$$
\mathrm{f}=\left\{\begin{array}{c}
\theta_{\mathrm{K}-1_{\mathrm{i}, \mathrm{j}}}+\left[\frac{\mathrm{d}\left(\theta_{\mathrm{K}_{\mathrm{i}, \mathrm{j}}}\right)}{\mathrm{dt}}\right]_{\mathrm{k}} \\
\mathrm{M}_{\mathrm{PM}, \mathrm{K}-1_{\mathrm{i}, \mathrm{j}}}+\frac{\mathrm{d}\left(\mathrm{M}_{\mathrm{PM}, \mathrm{L}}\right)}{\mathrm{dt}}+\left[\frac{\mathrm{d}\left(\mathrm{M}_{\mathrm{PM}, \mathrm{K}_{\mathrm{i}, \mathrm{j}}}\right)}{\mathrm{dt}}\right]_{\mathrm{k}} \\
\mathrm{T}_{\mathrm{f}, \mathrm{k}-1_{\mathrm{i}, \mathrm{j}}}+\frac{\left(\dot{\mathrm{Q}}_{\text {cond.axial }}+\dot{\mathrm{Q}}_{\text {cond.radial }}+\dot{\mathrm{Q}}_{\mathrm{conv}}+\dot{\mathrm{Q}}_{\text {reac }}+\dot{\mathrm{Q}}_{\mathrm{rad}}\right)}{\left(\rho_{\mathrm{s}} \mathrm{C}_{\mathrm{s}} \mathrm{V}_{\mathrm{s}, \mathrm{i}, \mathrm{j}}+\rho_{\mathrm{f}} \mathrm{C}_{\mathrm{f}} \mathrm{V}_{\mathrm{f}, \mathrm{i}, \mathrm{j}}\right)} \Delta \mathrm{t}
\end{array}\right\}
$$

Detailed description of the equations used for deriving equation 15 are shown in Appendix D. 
Contributions from the proposed research on the SCR-F high fidelity model and the SCR-F estimator development:

1) Development of a 2D model of SCR-F will be carried out with the ability to simulate temperature and PM distribution in both the radial and axial direction which has not been reported in open literature. Most of the models in the literature are based on Axisute ${ }^{\circledR}$ or 1D models none of which focus on radial temperature variation due to heat loss to the ambient.

- This is the first effort at simulating the 2D temperature distribution in a SCR catalyst on a DPF

- In order to simulate the temperature distribution a 2D energy conservation equation has been implemented with energy release by chemical reactions, radial and axial conduction as well as heat loss to the ambient by convection and radiation terms.

- This part of the model was calibrated using data from the 2007 ISL CPF and the 2013 ISB SCRF ${ }^{\circledR}$ configuration 1 data without urea.

2) Maldistribution of $\mathrm{NH}_{3}$ storage and $\mathrm{NO}_{x}$ reduction due to the temperature gradient in the radial direction will be modeled.

- The literature contains 1D models which do not simulate the variation of radial temperature change. But it has been found from the SCR-F model that there is a significant maldistribution of $\mathrm{NO} / \mathrm{NO}_{2}$ at the outlet of the SCR-F caused by both change in flow rate and temperature in the radial direction. This model will able to predict the temperature part of this maldistribution.

- In order to validate the model in this respect, $\mathrm{NO} / \mathrm{NO}_{2}$ data at the outlet at different radial points is needed. At present, these data are not available but as a work around one other way to validate this data would be to compare the average outlet concentration computed from this radial value against the value obtained from the $\mathrm{NO} / \mathrm{NO}_{2}$ measurement and also compare the trends in $\mathrm{NO} / \mathrm{NO}_{2}$ and $\mathrm{NH}_{3}$ against $\mathrm{SCR}$ data from the literature

- The present version of the model is able to simulate the phenomena mentioned here once the SCR reactions are calibrated using $\mathrm{SCRF}^{\circledR}$ configuration 2 data and the comparisons mentioned above should be able to be performed.

3) Energy release by SCR reactions (axial increase in temperature $5-10^{\circ} \mathrm{C}$ ) will be modeled. A temperature gradient of $5^{\circ} \mathrm{C}$ in axial direction was reported in the experimental literature. A quantitative knowledge of the energy release by each of the SCR reactions can be obtained using the SCR-F high fidelity model. 
- The experimental temperature distribution data from $\mathrm{SCRF}^{\circledR}$ configuration 1 and 2 showed a significant increase in temperature $\left(5-10^{\circ} \mathrm{C}\right)$ in the $\mathrm{SCRF}^{\circledR}$ in the presence of urea.

- In order to simulate this phenomenon, energy release terms for each of the SCR reactions was added to the model.

- The model is able to simulate the temperature rise observed in the experimental data. The calibration of SCR reactions using configuration 2 data without PM should lead to calibration of the temperature distribution

- This is the first study of its kind where this temperature increase phenomenon is being simulated by a model.

4) A quantitative value of diffusivity of $\mathrm{NO} / \mathrm{NO}_{2}$ in the forward direction between $\mathrm{PM}$ cake and substrate wall using the configuration 1 data from $\mathrm{SCRF}^{\circledR}$ experimental dataset will be determined. The present version of model is able to simulate a decrease in available $\mathrm{NO}_{2}$ in the PM cake due to forward diffusion in absence of urea injection, which is going to increase further in the experiments with urea injection and lead to a change in PM oxidation rate thus helping quantify the percentage decrease in available $\mathrm{NO}_{2}$ due to the SCR reactions.

- The forward diffusion of chemical species was reported in the literature. The majority of these models simulate the phenomena but the change in diffusion rate and diffusivity with PM loading were not reported

- This research effort will be able to quantify the change in diffusivity with change in PM loading and SCR reactions rate.

- In order to simulate this phenomenon, the diffusion term in the species conservation reaction was added. In the calibration of the configuration 1 data without urea, the forward diffusion was calibrated. The configuration 1 data with urea should further help in calibration of this phenomenon.

5) $\mathrm{NO}_{x}$ reduction efficiency change with $\mathrm{PM}$ loading $(0 \mathrm{~g} / \mathrm{l}, 2 \mathrm{~g} / \mathrm{l}$, and $4 \mathrm{~g} / \mathrm{l})$ using configuration 2 data will be studied. The change in $\mathrm{NO}_{2}$ across the PM cake due to PM oxidation is being simulated by the SCR-F model which will be used to simulate local $\mathrm{NO}_{2} / \mathrm{NO}_{x}$ ratio in the substrate wall thus enabling prediction of $\mathrm{NO}_{\mathrm{x}}$ reduction as a function of PM loading, ANR etc.

- The models in the literature describe the change in SCR stoichiometry in the substrate wall due to PM loading

- In order to simulate this phenomenon, the change in $\mathrm{NO}_{2}$ due to PM oxidation needs to be simulated. This step has been performed in the calibration of the SCR-F model with configuration 1 data without urea where the outlet $\mathrm{NO} / \mathrm{NO}_{2}$ were simulated to within 20 ppm for all the 11 experiments.

- This is an important contribution since this would be the first time of using this capability to predict the $\mathrm{NO}_{\mathrm{x}}$ reduction performance in a SCR-F state estimator. 
6) System level SCR catalyst on a DPF + SCR studies and the Impact of the downstream SCR on NOx reduction activity and $\mathrm{NH}_{3}$ slip for the entire system will be quantified using configuration $3 \mathrm{SCRF}^{\circledR}$ data which has not been reported in open literature.

- The literature mentions about a few studies where system level simulation of a SCR catalyst on a DPF + SCR have been performed using a 1D model.

- This will be the first study to use a 2D SCR-F model

- In order to achieve this capability, the SCR-F model has to be integrated with the 1D SCR model which is an ongoing work.

7) Change in $\mathrm{NH}_{3}$ storage with $\mathrm{PM}$ oxidation and the impact of wall $\mathrm{PM}$ on the number of active $\mathrm{NH}_{3}$ storage sites will be simulated using the high-fidelity model. This phenomenon has been described in a few papers but the variation in storage rate during passive oxidation condition has not been reported in the literature.

- The literature reports a change in $\mathrm{NH}_{3}$ storage capacity due to PM in the wall. However, the change in $\mathrm{NH}_{3}$ storage capacity during passive oxidation has not been reported.

- This will be the first study of the phenomena of $\mathrm{NH}_{3}$ storage change during passive oxidation.

- In order to simulate this phenomenon, an equation which changes the storage capacity at every time step based on wall PM mass retained needs to be developed. This step is part of the ongoing research.

8) SCR-F estimator for estimating coverage fraction, $\mathrm{PM}$, and temperature distribution will be developed. So far only SCR and CPF estimators have been reported in the literature and this work would be the first effort at designing an estimator for a SCR catalyst on a DPF

- This is the first research at creating a SCR-F estimator

- The approach used for the CPF estimator by Boopathi [3] will be extended to develop a SCR-F estimator. 


\section{$7 \quad$ Timeline and Publication Plan}

\subsection{Timeline}

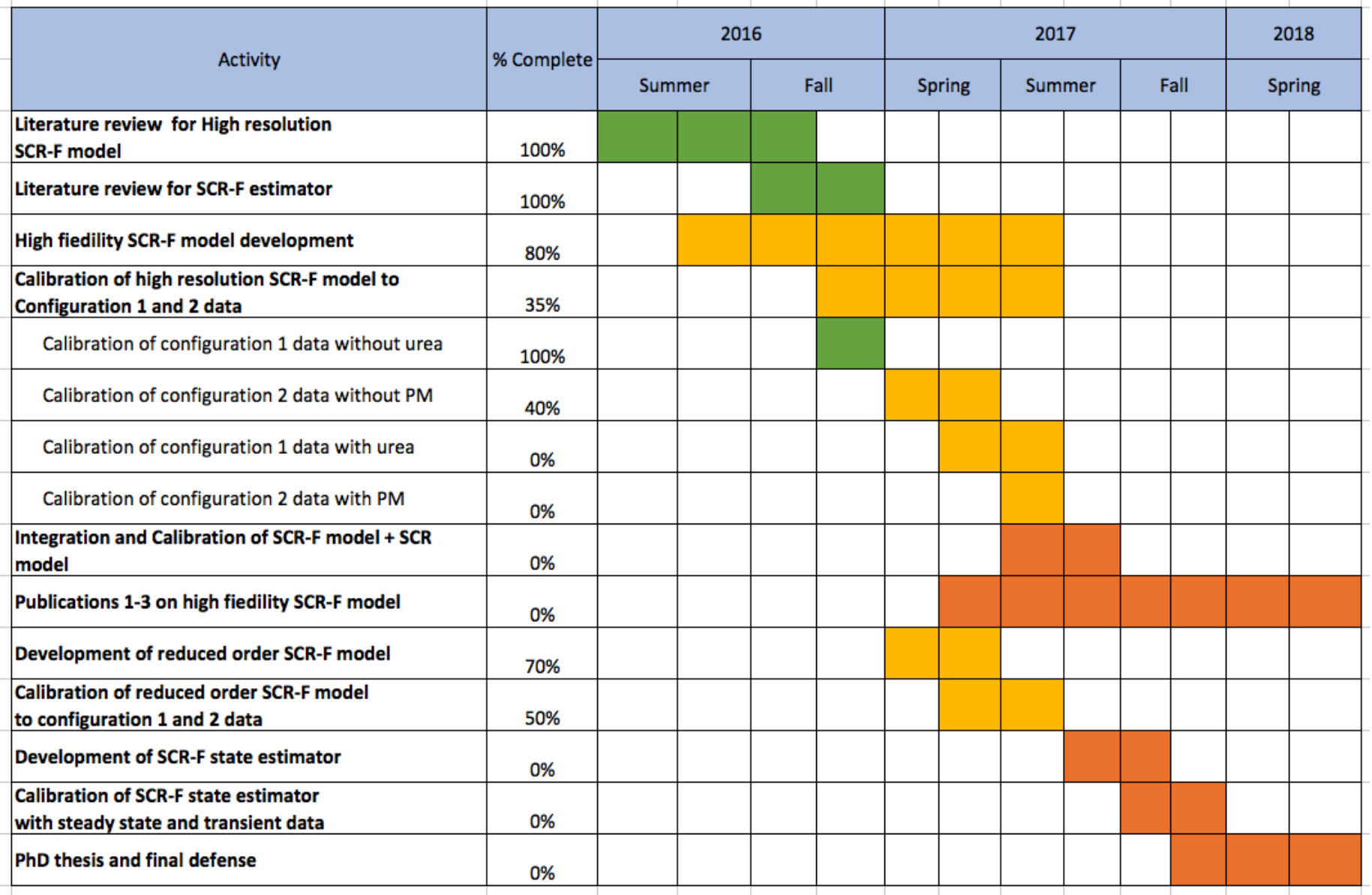

Figure $24:$ PhD degree timeline

\subsection{Publication plan}

Publications based on high resolution SCR-F model with configuration 1,2 and 3 data from Cummins 2013 ISB engine SCRF

$>$ Publication 1 - 2D SCR-F model development - Species model, Temperature model and cake permeability, calibration with 2007 ISL and SCRF ${ }^{\circledR}$ Configuration 1 and 2 data (Boopathi and Venkata)

$>$ Publication 2 - NOx reduction performance, pressure drop and filtration characteristics of the SCRF ${ }^{\oplus}$ based on high fidelity SCR-F model using configuration 1 data

$>$ Publication 3 - Effect of PM mass retained on ammonia storage, NOx reduction performance of the SCRF ${ }^{\oplus}$ and effect of SCR reactions on PM oxidation rate for different PM loading values based on 2D SCR-F model using configuration 2 data

$>$ Publication 4-Impact of downstream SCR on overall NOx emissions and $\mathrm{NH}_{3}$ slip of $\mathrm{SCRF}^{\oplus}+\mathrm{SCR}$ system using configuration 3 data

Publications based on reduced order SCR-F model and SCR-F state estimator with configuration 1 and 2 data from Cummins 2013 ISB engine SCRF ${ }^{\oplus}$ 
> Publication 5 - Reduced order SCR-F model development and calibration with Cummins 2013 ISB engine data for ECU application - a study on model accuracy for various mesh sizes and suitability for ECU application

> Publication 6 - Development and calibration of SCR-F state estimator for ECU application - a study on reduction of urea consumption based on downstream $\mathrm{NO}_{\mathrm{x}}$ emissions estimation

\section{Summary and Conclusions}

The PhD research proposed is to develop a high-fidelity SCR-F model to simulate the $\mathrm{NO}_{\mathrm{x}}$ reduction performance as well as temperature and $\mathrm{PM}$ mass retained distribution and pressure drop across SCRF ${ }^{\circledR}$ followed by development of reduced order SCR-F model and SCR-F estimator. At present the literature review as well as development of the required equations is being carried out.

The initial part of the research consisting of development and calibration of the high-fidelity model is being carried on at the present time with $\mathrm{SCRF}^{\circledR}$ configuration 1 data without urea data calibration completed where the PM retained was simulated to within $2 \mathrm{gm}$, pressure drop to within $0.5 \mathrm{kPa}$ as well as $\mathrm{NO}_{2}$ emissions to within $20 \mathrm{ppm}$ of the experimental data for $7 \mathrm{PO}$ and 4 AR experiments. The calibration of the model with configuration 2 without PM data is being carried out. Following the calibration of configuration 2 data without PM, the high-fidelity model will be calibrated to configuration 1 data with urea and configuration 2 data with PM to study interaction between PM oxidation and SCR reactions. A system consisting of 2D SCR-F model + 1D SCR model will be developed to calibrate the configuration 3 data.

The next phase of the research consists of developing the reduced order model based on simplification of the SCR-F model. Effect of various mesh sizes on accuracy and performance of the model is also being explored. The final stage of the research consisting of SCR-F state estimator will be carried out. 
References

1) https://www.dieselnet.com/standards/us/hd.php

2) Mahadevan, Boopathi. "Development of a Multi-zone Catalyzed Particulate Filter Model and Kalman Filter Estimator for Simulation and Control of Particulate Matter Distribution of a CPF for Engine ECU Applications", PhD Dissertation, 2017.

3) Gustafson, Erik. "An Experimental Investigation into $\mathrm{NO}_{2}$ assisted Passive Oxidation with and without Urea Dosing and Active Regeneration of Particulate Matter for a SCR Catalyst on a DPF." M.S. Thesis, 2016.

4) Kadam, Vaibhav. "An Experimental Investigation of the Effect of Temperature and Space Velocity on the Performance of a Cu-Zeolite Flow-Through SCR And A SCR Catalyst on a DPF with and without PM Loading.", M.S. Thesis 2016.

5) Song, Xiaobo, John H. Johnson, and Jeffrey D. Naber. "A review of the literature of selective catalytic reduction catalysts integrated into diesel particulate filters." International Journal of Engine Research 16.6: 738-749., 2015.

6) Mahadevan, Boopathi, Venkata Chundru, John H. Johnson, Gordon G. Parker, Mahdi Shahbakhti "Development of a High Fidelity 2-D SCR Catalyst on a DPF Model", SAE draft, 2018

7) Figura, Jiri, et al. Automotive Selective Catalytic Reduction System Model-Based Estimators for On-ECU Implementation: A Brief Overview. No. 2016-01-0972. SAE Technical Paper, 2016.

8) Park, S. Y., et al. "Development and validation of a model for wall-flow type selective catalytic reduction system." Proceedings of the Institution of Mechanical Engineers, Part D: Journal of Automobile Engineering 225.12 (2011): 1641-1659. (Modelling), 2011.

9) Park, Soo-Youl, et al. "A model development for evaluating soot-NO $x$ interactions in a blended 2-way diesel particulate filter/selective catalytic reduction." Industrial \& Engineering Chemistry Research 51.48 (2012) (Modelling), 2012.

10) Dosda, Simon, et al. "Modeling of a DOC SCR-F SCR Exhaust Line for Design Optimization Taking into Account Performance Degradation Due to Hydrothermal Aging." SAE International Journal of Fuels and Lubricants 9.2016-01-2281 (2016): 621-632. (Modelling),2016.

11) López, Yaritza M., et al. "NOx and PM Reduction from Diesel Exhaust Using Vanadia SCRF®." SAE International Journal of Engines 9.2016-01-0914:1247-1257., 2016.

12) E. Tronconi, "Interaction of NOx Reduction and Soot Oxidation in a DPF with $\mathrm{Cu}$-Zeolite SCR Coating," Emission Control Science and Technology, DOI 10.1007/s40825-015-0014-y, 2015. 
13) F. Schrade, M. Brammer, J. Schaeffner and K. Langeheinecke, "Physico-Chemical Modeling of an Integrated SCR on DPF (SCR/DPF) System," SAE Int. J. Engines 5(3):958-974, doi:10.4271/2012-01-1083, 2012.

14) T. Watling, "Development, validation and application of a model for an SCR catalyst coated diesel particulate filter," Catalysis Today, doi:10.1016/j.cattod. 2012.02.007, 2012.

15) Konstandopoulos, A. G., et al. "Aspects of multifunctional diesel particulate filters and their efficient simulation." Catalysis today 188.1: 2-13, 2012.

16) Colombo, Massimo, Grigorios Koltsakis, and Ioannis Koutoufaris. A modeling study of soot and de-NOx Reaction Phenomena in SCRF Systems SAE Technical Paper. No. 2011-37-0031., 2011.

17) J. Tan, C. Solbrig and S. Schmieg, "The Development of Advanced 2-Way SCR/DPF Systems to Meet Future Heavy-Duty Diesel Emissions," SAE Technical Paper 2011-01-1140, doi:10.4271/2011-01-1140, 2011.

18) Y. Yang, G. Cho and C. Rutland, "Model Based Study of DeNOx Characteristics for Integrated DPF/SCR System over Cu-Zeolite," SAE Technical Paper 2015-01-1060, doi:10.4271/201501-1060, 2015.

19) V. Strots, A. Kishi, S. Adelberg and L. Kramer, "Application of Integrated SCR/DPF Systems in Commercial Vehicles," JSAE Annual Congress, 454- 20145174, 2014.

20) Mihai, Oana. "Effect of Soot on the SCR Reactions in an Integrated SCR Coated DPF." 24th North American Catalysis Society Meeting. Nam, 2015.

21) Mihai, Oana, et al. "Evaluation of an Integrated Selective Catalytic Reduction-Coated Particulate Filter." Industrial \& Engineering Chemistry Research 54.47,2015.

22) Johansen, Keld, et al. "Passive NO2 Regeneration and NOx Conversion for DPF with an Integrated Vanadium SCR Catalyst. No. SAE Technical Paper, 2016.

23) Cumaranatunge, Lasitha, et al. "A Study of the Soot Combustion Efficiency of an SCRF®

Catalyst vs a CSF During Active Regeneration." Emission Control Science and Technology 3.1: 93-104, 2017.

24) Lee, Jong H., Michael J. Paratore, and David B. Brown. "Evaluation of Cu-based SCR/DPF technology for diesel exhaust emission control." SAE International Journal of Fuels and Lubricants 1.2008-01-0072: 96-101., 2008.

25) Tang, Weiyong, et al. "On-engine investigation of SCR on filters (SCRoF) for HDD passive applications." SAE International Journal of Engines 6.2013-01-1066: 862-872., 2013.

26) Naseri, Mojghan, et al. "Development of SCR on diesel particulate filter system for heavy duty applications." SAE International Journal of Engines 4.2011-01-1312: 1798-1809., 2011. 
27) Mihai, Oana, et al. "The effect of soot on ammonium nitrate species and NO2 selective catalytic reduction over Cu-zeolite catalyst-coated particulate filter." Phil. Trans. R. Soc. A 374.2061: 20150086., 2016.

28) Cavataio, Giovanni, James W. Girard, and Christine K. Lambert. Cu/zeolite SCR on high porosity filters: laboratory and engine performance evaluations. SAE Technical Paper No. 2009-01-0897., 2009.

29) Upadhyay, D, and Van Nieuwstadt, M., "Model Based Analysis and Control Design of a UreaSCR deNOx Aftertreatment System." Journal of Dynamic Systems, Measurement, and Control 128(3):737-741, doi:10.1115/1.2234494., 2006.

30) Devarakonda, M., Parker, G., Johnson, J., Strots, V. et al., "Model-Based Estimation and Control System Development in a Urea-SCR Aftertreatment System," SAE Int. J. Fuels Lubr. 1(1):646-661, doi:10.4271/2008-01-1324., 2009.

31) Hsieh, M., and Wang J., "An Extended Kalman Filter for NOx Sensor Ammonia CrossSensitivity Elimination in Selective Catalytic Reduction Applications," American Control Conference (ACC) 2010, 3033-38, doi:10.1109/ ACC.2010.5531217, 2010.

32) Hsieh, M., and Wang, J., "Design and Experimental Validation of an Extended Kalman FilterBased NOx Concentration Estimator in Selective Catalytic Reduction System Applications," Control Engineering 19.4, 2011.

33) Zhou, G., Jørgensen J., Duwig C., and Huusom J., "State Estimation in the Automotive SCR deNOx Process," Proceedings of 8th IFAC Symposium on Advanced Control of Chemical Processes, 501, 2012.

34) Chen, P., and Wang, J. "Estimation of Automotive Urea-Based Selective Catalytic Reduction Systems during Low Temperature Operations," American Control Conference (ACC), 152328, 2014, doi:10.1109/ACC.2014.6859044., 2014.

35) Surenahalli, H., Parker, G., and Johnson, J., "Extended Kalman Filter Estimator for NH3 Storage, NO, NO2 and NH3 Estimation in a SCR," SAE Technical Paper 2013-01-1581, doi:10.4271/2013-01-1581., 2013.

36) Zhang, H., Wang, J., Wang, Y., "Sensor Reduction in Diesel Engine Two-Cell Selective Catalytic Reduction (SCR) Systems for Automotive Applications," IEEE/ASME Transactions on Mechatronics, 1-12, doi:10.1109/TMECH.2014.2370043., 2014.

37) Mahadevan, Boopathi S., John H. Johnson, and Mahdi Shahbakhti. "Development of a Catalyzed Diesel Particulate filter multi-zone model for simulation of axial and radial substrate temperature and particulate matter distribution." Emission Control Science and Technology 1.2 183-202,2015. 
38) Mahadevan, Boopathi S., John H. Johnson, and Mahdi Shahbakhti. "Experimental and Simulation Analysis of Temperature and Particulate Matter Distribution for a Catalyzed Diesel Particulate Filter." Emission Control Science and Technology 1.4 255-283, 2015.

39) Mahadevan, Boopathi S., John H. Johnson, and Mahdi Shahbakhti. " Predicting Pressure drop, Temperature and particulate matter distribution of a catalyzed diesel particulate filter using a multi-zone model including cake permeability." Emission Control Science and Technology 1.4 255-0062, 2017.

40) Chen, Pingen, and Junmin Wang. "Nonlinear Model Predictive Control of Integrated Diesel Engine and Selective Catalytic Reduction System for Simultaneous Fuel Economy Improvement and Emissions Reduction." Journal of Dynamic Systems, Measurement, and Control 137.8: 081008., 2015.

41) Sharma, Sagar. "The Emission and Particulate Matter Oxidation Performance of a SCR Catalyst on a Diesel Particulate Filter with a Downstream SCR." ,M.S.Report, 2017. 


\section{Appendix A SCR-F configuration 1 results}

Table A1 shows the pressure drop calibration results of SCR-F model with configuration 1 data without urea

Table A 1 Pressure drop model vs experimental SCRF ${ }^{\circledR}$ configuration 1

\begin{tabular}{|c|c|c|c|c|c|c|c|c|c|}
\hline \multirow{3}{*}{ Expt. name } & \multicolumn{9}{|c|}{ Pressure Drop[kPa] } \\
\hline & \multicolumn{3}{|c|}{ End of Loading (Stage 1,2) } & \multicolumn{3}{|c|}{ End of PO/AR } & \multicolumn{3}{|c|}{ End of post loading (Stage 3,4 ) } \\
\hline & Expt. & Model & Diff. & Expt. & Model & Diff. & Expt. & Model & Diff. \\
\hline AR-1 & 7.78 & 7.77 & 0.01 & 5.74 & 5.51 & 0.23 & 6.27 & 6.37 & -0.10 \\
\hline AR-2 & 7.70 & 7.70 & 0.00 & 4.06 & 3.71 & 0.35 & 6.27 & 4.25 & $2.02^{[2]}$ \\
\hline AR-3 & 7.71 & 7.60 & 0.11 & 3.42 & 3.52 & -0.10 & 5.16 & 4.66 & 0.50 \\
\hline AR-2 Repeat & 7.58 & 8.05 & -0.47 & 4.87 & 4.47 & 0.40 & 5.83 & 5.55 & 0.28 \\
\hline PO-A & 8.18 & 8.53 & -0.35 & 1.77 & 1.64 & 0.13 & 6.30 & 6.32 & -0.02 \\
\hline PO-B & 7.10 & 8.54 & $-1.44^{[1]}$ & 1.15 & 0.99 & $-0.16^{[1]}$ & 5.88 & 5.25 & $0.63^{[1]}$ \\
\hline PO-B-Repeat & 8.73 & 8.14 & 0.59 & 0.97 & 1.05 & -0.08 & 6.80 & 5.4 & $1.40^{[2]}$ \\
\hline $\mathrm{PO}-\mathrm{C}$ & 8.02 & 8.23 & -0.21 & 2.13 & 2.25 & -0.12 & 6.01 & 5.49 & 0.52 \\
\hline PO-D & 6.97 & 8.83 & $-1.86^{[1]}$ & 3.30 & 4.99 & $-1.69^{[1]}$ & 4.42 & 5.12 & $-\mathbf{- 0 . 7 0 ^ { [ 1 ] }}$ \\
\hline PO-D- Repeat & 8.44 & 8.34 & 0.10 & 3.52 & 4.00 & -0.48 & 5.25 & 5.10 & 0.15 \\
\hline PO-E & 7.40 & 8.27 & $\mathbf{- 0 . 8 7 ^ { [ 1 ] }}$ & 2.23 & 3.10 & $-1.17^{[1]}$ & 6.22 & 5.30 & $0.92^{[1]}$ \\
\hline $\begin{array}{c}\text { RMS } \\
\text { difference }\end{array}$ & \multicolumn{3}{|c|}{0.3} & \multicolumn{3}{|c|}{0.35} & \multicolumn{3}{|c|}{0.96} \\
\hline
\end{tabular}


Table A2 shows comparison of PM retained values between SCR-F model and experimental data from configuration 1 without urea

Table A 2 PM retained model vs experimental SCRF ${ }^{\circledR}$ configuration 1

\begin{tabular}{|c|c|c|c|c|c|c|c|c|c|c|c|c|}
\hline \multirow{2}{*}{ Expt. Name } & \multicolumn{9}{|c|}{ PM Retained [g] } \\
\cline { 2 - 15 } & \multicolumn{3}{|c|}{ Stage - } & \multicolumn{3}{|c|}{ Stage - } & \multicolumn{3}{c|}{ Stage - 3 } & \multicolumn{3}{c|}{ Stage -4 } \\
\cline { 2 - 15 } & Expt. & Model & Diff. & Expt. & Model & Diff. & Expt. & Model & Diff. & Expt. & Model & Diff. \\
\hline AR-1 & 1.5 & 2.3 & $\mathbf{- 0 . 8}$ & $26.4^{[1]}$ & 28.6 & $\mathbf{- 0 . 9}$ & 18.1 & 18.9 & $\mathbf{- 0 . 8}$ & 24.0 & 24.7 & $\mathbf{- 0 . 7}$ \\
\hline AR-2 & 1.4 & 2.2 & $\mathbf{- 0 . 8}$ & $26.5^{[1]}$ & 28.4 & $\mathbf{- 0 . 7}$ & 5.7 & 7.6 & $\mathbf{- 1 . 9}$ & 11.2 & 12.9 & $\mathbf{- 1 . 7}$ \\
\hline AR-3 & 1.6 & 2.3 & $\mathbf{- 0 . 7}$ & 27.7 & 28.2 & $\mathbf{- 0 . 5}$ & 6.8 & 6.8 & 0.0 & 11.7 & 12.5 & $\mathbf{- 0 . 8}$ \\
\hline AR-2 Repeat & 1.8 & 2.3 & $\mathbf{- 0 . 5}$ & 30.7 & 29.7 & 1.0 & 16.8 & 14.1 & 2.7 & 22.6 & 19.8 & 2.8 \\
\hline PO-A & 4.3 & 4.8 & $\mathbf{- 0 . 6}$ & 35.4 & 34.9 & 0.5 & 29.1 & 31.1 & $\mathbf{- 2 . 0}$ & 35.3 & 36.8 & $\mathbf{- 1 . 4}$ \\
\hline PO-B & 2.5 & 3.8 & $\mathbf{- 1 . 3}$ & 33.6 & 34.8 & $\mathbf{- 1 . 2}$ & 28.9 & 27.5 & 1.4 & 35.4 & 31.5 & 3.8 \\
\hline PO-B-Repeat & 3.1 & 4.0 & $\mathbf{- 0 . 9}$ & 31.7 & 32.9 & $\mathbf{- 1 . 2}$ & 23.0 & 21.7 & 1.3 & 28.6 & 27.4 & 1.2 \\
\hline PO-C & 2.8 & 3.6 & $\mathbf{- 0 . 8}$ & 32.7 & 33.3 & $\mathbf{- 0 . 6}$ & 23.2 & 23.4 & $\mathbf{- 0 . 2}$ & 29.5 & 29.8 & $\mathbf{- 0 . 3}$ \\
\hline PO-D & 2.6 & 3.2 & $\mathbf{- 0 . 6}$ & 32.5 & 34.6 & $\mathbf{- 2 . 2}$ & 18.0 & 17.3 & 0.7 & 24.4 & 23.3 & 1.1 \\
\hline $\begin{array}{c}\text { PO-D- } \\
\text { Repeat }\end{array}$ & 3.2 & 3.7 & $\mathbf{- 0 . 6}$ & $32.5^{[1]}$ & 33.2 & $\mathbf{- 0 . 7}$ & 15.5 & 13.6 & 1.9 & 21.1 & 20.0 & 1.1 \\
\hline $\begin{array}{c}\text { PO-E } \\
\text { RMS }\end{array}$ & 4.6 & 4.7 & $\mathbf{- 0 . 2}$ & 33.5 & 32.6 & 0.9 & 22.9 & 20.4 & 2.5 & 25.9 & 26.2 & $\mathbf{- 0 . 3}$ \\
\hline Difference & & 0.8 & & & 0.8 & & & 1.5 & & & 1.4 & \\
\hline
\end{tabular}


Table A3 compares the experimental and model $\mathrm{NO}_{2}$ outlet values for Configuration 2 without urea

Table A 3 Outlet $\mathrm{NO}_{2}$ concentration model vs experimental SCRF ${ }^{\circledR}$ configuration 1

\begin{tabular}{|c|c|c|c|c|c|c|c|c|c|c|c|c|}
\hline \multicolumn{13}{|c|}{$\mathrm{NO}_{2}$ concentration [ppm] } \\
\hline \multirow{2}{*}{$\begin{array}{c}\text { Run } \\
\text { name }\end{array}$} & \multicolumn{4}{|c|}{ Loading } & \multicolumn{4}{|c|}{ PO/AR } & \multicolumn{4}{|c|}{ Post Loading } \\
\hline & Exp in & Exp & Model & Diff & Exp in & Exp & Model & Diff & Exp in & Exp & Model & Diff \\
\hline AR-1 & 53 & 31 & 44 & -13 & 6 & 1 & 0 & 1 & 52 & 27 & 40 & -13 \\
\hline AR-2 & 61 & 38 & 58 & $-20^{[1]}$ & 16 & 3 & 0 & 3 & 52 & 27 & 43 & -16 \\
\hline AR-3 & 57 & 40 & 57 & -17 & 20 & 6 & 0 & 6 & 59 & 38 & 19 & 19 \\
\hline AR-2 Repeat & 49 & 36 & 50 & -14 & 2 & 7 & 0 & 7 & 46 & 21 & 34 & -13 \\
\hline PO-A & 61 & 41 & 47 & -6 & 263 & 221 & 235 & -14 & 57 & 29 & 43 & -14 \\
\hline PO-B & 39 & 23 & 23 & 0 & 674 & 611 & 602 & 9 & 50 & 22 & 38 & -16 \\
\hline PO-B Repeat & 77 & 45 & 52 & -7 & 792 & 732 & 720 & 12 & 72 & 41 & 62 & $-21^{[1]}$ \\
\hline PO-C & 64 & 48 & 52 & -4 & 228 & 144 & 128 & 16 & 59 & 37 & 46 & -9 \\
\hline PO-D & 52 & 22 & 20 & 2 & 117 & 76 & 81 & -5 & 52 & 36 & 47 & -11 \\
\hline PO-D Repeat & 68 & 38 & 46 & -8 & 147 & 84 & 89 & -5 & 52 & 31 & 41 & -10 \\
\hline PO-E & 66 & 58 & 56 & 2 & 523 & 339 & 330 & 9 & 62 & 36 & 52 & -16 \\
\hline RMS Difference & \multicolumn{4}{|c|}{10} & \multicolumn{4}{|c|}{9} & \multicolumn{4}{|c|}{14} \\
\hline
\end{tabular}


Appendix $\mathrm{B} \mathrm{SCRF}{ }^{\circledR}$ configuration 1,2 and 3 experimental data test points

Table B 1 Engine condition for SCRF ${ }^{\circledR}$ configuration 1 without urea experiments [3]

\begin{tabular}{|c|c|c|c|c|c|c|c|}
\hline Condition & Speed & Load & $\begin{array}{l}\text { Exhaust } \\
\text { Flowrate }\end{array}$ & $\begin{array}{c}\text { SCRF }^{\circledR} \\
\text { Space } \\
\text { Velocity }\end{array}$ & $\begin{array}{l}\text { SCRF }^{\circledR} \text { Inlet } \\
\text { Temperature }\end{array}$ & $\begin{array}{c}\mathrm{NO2} \\
\text { into } \\
\text { SCRF }^{\circledR} \\
\end{array}$ & $\begin{array}{c}\text { NOX into } \\
\text { SCRF }^{\circledR}\end{array}$ \\
\hline$[-]$ & [RPM] & {$[\mathrm{Nm}]$} & {$[\mathrm{kg} / \mathrm{min}]$} & {$[\mathrm{k} / \mathrm{hr}]$} & {$\left[{ }^{\circ} \mathrm{C}\right]$} & [ppm] & [ppm] \\
\hline A & 1300 & 300 & 5.19 & 15.5 & 293 & 241 & 416 \\
\hline B & 900 & 450 & 3.56 & 10.6 & 270 & 651 & 1359 \\
\hline B Rpt. & 900 & 450 & 3.56 & 10.6 & 270 & 651 & 1359 \\
\hline $\mathrm{C}$ & 1400 & 550 & 6.61 & 19.7 & 341 & 205 & 482 \\
\hline $\mathrm{D}$ & 2100 & 600 & 12.07 & 36 & 369 & 132 & 353 \\
\hline D Rpt. & 2100 & 600 & 12.07 & 36 & 369 & 132 & 353 \\
\hline $\mathrm{E}$ & 1200 & 650 & 6.75 & 20.1 & 361 & 515 & 1343 \\
\hline AR-1 & 1900 & 330 & 8.3 & 38.6 & 500 & 5 & 327 \\
\hline AR-2 & 1900 & 330 & 8.4 & 38.7 & 550 & 10 & 361 \\
\hline AR-3 & 1900 & 330 & 8.5 & 38.8 & 600 & 20 & 346 \\
\hline AR-2 Rpt & 1900 & 330 & 8.4 & 38.7 & 500 & 10 & 305 \\
\hline
\end{tabular}


Table B 2 Engine condition for $\mathrm{SCRF}^{\circledR}$ configuration 1 with urea experiments [3]

\begin{tabular}{|c|c|c|c|c|c|c|c|c|}
\hline Condition & Speed & Load & $\begin{array}{l}\text { Exhaust } \\
\text { Flowrate }\end{array}$ & $\begin{array}{c}\text { SCRF }^{\circledR} \\
\text { Space } \\
\text { Velocity }\end{array}$ & $\begin{array}{l}\text { SCRF }^{\circledR} \text { Inlet } \\
\text { Temperature }\end{array}$ & $\begin{array}{l}\text { NO2 } \\
\text { into } \\
\text { SCRF }^{\circledR} \\
\end{array}$ & $\begin{array}{c}\text { NOX } \\
\text { into } \\
\text { SCRF }^{\circledR}\end{array}$ & ANR \\
\hline$[-]$ & [RPM] & {$[\mathrm{Nm}]$} & {$[\mathrm{kg} / \mathrm{min}]$} & [k/hr] & {$\left[{ }^{\circ} \mathrm{C}\right]$} & [ppm] & [ppm] & {$[-]$} \\
\hline$A$ & 1300 & 300 & 5.19 & 15.5 & 293 & 241 & 416 & 1 \\
\hline B & 900 & 450 & 3.56 & 10.6 & 270 & 651 & 1359 & 1 \\
\hline B Rpt & 900 & 450 & 3.56 & 10.6 & 270 & 651 & 1359 & 1 \\
\hline$C$ & 1400 & 550 & 6.61 & 19.7 & 341 & 205 & 482 & 1 \\
\hline D & 2100 & 600 & 12.07 & 36 & 369 & 132 & 353 & 1 \\
\hline D Rpt & 2100 & 600 & 12.07 & 36 & 369 & 132 & 353 & 1 \\
\hline$E$ & 1200 & 650 & 6.75 & 20.1 & 361 & 515 & 1343 & 1 \\
\hline
\end{tabular}


Table B 3 Engine condition for SCRF ${ }^{\circledR}$ configuration 2 experiments [4]

\begin{tabular}{|c|c|c|c|c|c|}
\hline \multirow{2}{*}{ Parameter } & \multirow{2}{*}{ PM Loading } & \multicolumn{4}{|c|}{ Test Point } \\
\hline & & 1 & 3 & 6 & 8 \\
\hline \multirow{3}{*}{$\begin{array}{l}\text { Speed } \\
\text { [RPM] }\end{array}$} & $\mathrm{SCRF}^{\otimes}-0 \mathrm{~g} / \mathrm{L}$ & 1199 & 2200 & 1202 & 2401 \\
\hline & $\mathrm{SCRF}^{\oplus}-2 \mathrm{~g} / \mathrm{L}$ & 1200 & 2101 & 1200 & 2398 \\
\hline & $\mathrm{SCRF}^{\otimes}-4 \mathrm{~g} / \mathrm{L}$ & 1200 & 2203 & 1200 & 2401 \\
\hline \multirow{3}{*}{$\begin{array}{l}\text { Load } \\
{[\mathrm{Nm}]}\end{array}$} & $\mathrm{SCRF}^{\oplus}-0 \mathrm{~g} / \mathrm{L}$ & 201 & 330 & 580 & 826 \\
\hline & $\mathrm{SCRF}^{\otimes}-2 \mathrm{~g} / \mathrm{L}$ & 208 & 329 & 588 & 820 \\
\hline & $\mathrm{SCRF}^{\oplus}-4 \mathrm{~g} / \mathrm{L}$ & 203 & 331 & 587 & 818 \\
\hline \multirow{3}{*}{$\begin{array}{c}\text { Exhaust Flow } \\
{[\mathrm{kg} / \mathrm{min}]}\end{array}$} & $\mathrm{SCRF}^{\otimes}-0 \mathrm{~g} / \mathrm{L}$ & 5 & 10.7 & 6.9 & 17 \\
\hline & $\mathrm{SCRF}^{\oplus}-2 \mathrm{~g} / \mathrm{L}$ & 5 & 9.9 & 6.8 & 17.6 \\
\hline & $\mathrm{SCRF}^{\oplus}-4 \mathrm{~g} / \mathrm{L}$ & 5 & 10.9 & 6.8 & 17.7 \\
\hline \multirow{3}{*}{$\begin{array}{c}\text { SCRF }^{\circledast} \text { Inlet } \\
\text { Temperature }\left[{ }^{\circ} \mathrm{C}\right]\end{array}$} & $\mathrm{SCRF}^{\otimes}-0 \mathrm{~g} / \mathrm{L}$ & 218 & 304 & 345 & 443 \\
\hline & $\mathrm{SCRF}^{\oplus}-2 \mathrm{~g} / \mathrm{L}$ & 206 & 305 & 340 & 438 \\
\hline & $\mathrm{SCRF}^{\oplus}-4 \mathrm{~g} / \mathrm{L}$ & 207 & 302 & 343 & 446 \\
\hline \multirow{3}{*}{$\begin{array}{c}\text { SCRF }^{\circledR} \text { Std. } \\
\text { Space Vel. }[k / h r]\end{array}$} & $\mathrm{SCRF}^{\oplus}-0 \mathrm{~g} / \mathrm{L}$ & 13.7 & 29.1 & 18.8 & 46.3 \\
\hline & $\mathrm{SCRF}^{\oplus}-2 \mathrm{~g} / \mathrm{L}$ & 13.7 & 27 & 18.6 & 48 \\
\hline & $\mathrm{SCRF}^{\oplus}-4 \mathrm{~g} / \mathrm{L}$ & 13.5 & 29.8 & 18.6 & 48.2 \\
\hline \multirow{3}{*}{$\begin{array}{c}\text { SCRF }^{\circledR} \text { Act. } \\
\text { Space Vel. }[k / h r]\end{array}$} & $\mathrm{SCRF}^{\oplus}-0 \mathrm{~g} / \mathrm{L}$ & 24.5 & 60.2 & 42 & 115.2 \\
\hline & $\mathrm{SCRF}^{\oplus}-2 \mathrm{~g} / \mathrm{L}$ & 22.6 & 53.8 & 39.3 & 117.9 \\
\hline & $\mathrm{SCRF}^{\oplus}-4 \mathrm{~g} / \mathrm{L}$ & 22.7 & 56.4 & 35.7 & 99.6 \\
\hline \multirow{3}{*}{$\begin{array}{c}\text { SCRF }^{\circledR} \text { Inlet } \\
\text { NO [ppm] }\end{array}$} & $\mathrm{SCRF}^{\oplus}-0 \mathrm{~g} / \mathrm{L}$ & 345 & 158 & 795 & 411 \\
\hline & $\mathrm{SCRF}^{\oplus}-2 \mathrm{~g} / \mathrm{L}$ & 403 & 161 & 844 & 424 \\
\hline & $\mathrm{SCRF}^{\oplus}-4 \mathrm{~g} / \mathrm{L}$ & 452 & 198 & 793 & 415 \\
\hline \multirow{3}{*}{$\begin{array}{l}\text { SCRF }^{\oplus} \text { Inlet } \\
\text { NO2 [ppm] }\end{array}$} & $\mathrm{SCRF}^{\oplus}-0 \mathrm{~g} / \mathrm{L}$ & 213 & 121 & 674 & 140 \\
\hline & $\mathrm{SCRF}^{\oplus}-2 \mathrm{~g} / \mathrm{L}$ & 203 & 131 & 744 & 125 \\
\hline & $\mathrm{SCRF}^{\oplus}-4 \mathrm{~g} / \mathrm{L}$ & 141 & 143 & 588 & 115 \\
\hline \multirow{3}{*}{$\begin{array}{l}\text { SCRF }^{\oplus} \text { Inlet } \\
\text { NOx [ppm] }\end{array}$} & $\mathrm{SCRF}^{\otimes}-0 \mathrm{~g} / \mathrm{L}$ & 558 & 279 & 1468 & 551 \\
\hline & $\mathrm{SCRF}^{\otimes}-2 \mathrm{~g} / \mathrm{L}$ & 607 & 292 & 1588 & 548 \\
\hline & $\mathrm{SCRF}^{\oplus}-4 \mathrm{~g} / \mathrm{L}$ & 594 & 341 & 1381 & 530 \\
\hline \multirow{3}{*}{$\begin{array}{l}\text { Upstream } \\
\mathrm{NO}_{2} / \mathrm{NO}_{x}\end{array}$} & $\mathrm{SCRF}^{\oplus}-0 \mathrm{~g} / \mathrm{L}$ & 0.38 & 0.43 & 0.46 & 0.25 \\
\hline & $\mathrm{SCRF}^{\circledR}-2 \mathrm{~g} / \mathrm{L}$ & 0.34 & 0.45 & 0.47 & 0.23 \\
\hline & $\mathrm{SCRF}^{\otimes}-4 \mathrm{~g} / \mathrm{L}$ & 0.26 & 0.42 & 0.43 & 0.22 \\
\hline \multirow{3}{*}{$\begin{array}{l}\text { Engine Out PM } \\
{[\mathrm{mg} / \mathrm{scm}]}\end{array}$} & $\mathrm{SCRF}^{\oplus}-0 \mathrm{~g} / \mathrm{L}$ & $\mathrm{N} / \mathrm{A}$ & N/A & $\mathrm{N} / \mathrm{A}$ & $\mathrm{N} / \mathrm{A}$ \\
\hline & $\mathrm{SCRF}^{\circledR}-2 \mathrm{~g} / \mathrm{L}$ & 2.14 & 4.3 & 3.59 & 7.39 \\
\hline & $\mathrm{SCRF}^{\otimes}-4 \mathrm{~g} / \mathrm{L}$ & 1.97 & 4.93 & 2.85 & 4.97 \\
\hline
\end{tabular}


Table B 3 Engine condition for $\mathrm{SCRF}^{\circledR}$ configuration 3 experiments [41]

\begin{tabular}{|c|c|c|c|c|c|c|c|}
\hline $\begin{array}{c}\text { Test } \\
\text { Point }\end{array}$ & Speed & Load & $\begin{array}{c}\text { Exhaust } \\
\text { Flow } \\
\text { Rate }\end{array}$ & $\begin{array}{c}\text { SCRF }^{\circledR} \text { Inlet } \\
\text { Temperature }\end{array}$ & $\begin{array}{c}\text { SCRF } \\
\text { Inlet } \\
\text { NO2 }\end{array}$ & $\begin{array}{c}\text { SCRF } \\
\text { Inlet } \\
\text { NOx }\end{array}$ & $\begin{array}{c}\text { SCRF }^{\circledR} \\
\text { Inlet } \\
\text { NO2/NO } \\
\text { X }\end{array}$ \\
\hline [-] & {$[$ RPM] } & {$[$ N.m] } & {$[\mathrm{kg} / \mathrm{min}]$} & {$\left[{ }^{\circ} \mathrm{C}\right]$} & {$[\mathrm{ppm}]$} & {$[\mathrm{ppm}]$} & {$[-]$} \\
\hline A & 1301 & 303 & 5.6 & 264 & 215 & 590 & 0.44 \\
\hline C & 1399 & 543 & 6.9 & 339 & 290 & 689 & 0.44 \\
\hline E & 1203 & 648 & 7.1 & 342 & 584 & 1450 & 0.37 \\
\hline B & 902 & 449 & 3.7 & 256 & 758 & 1580 & 0.48 \\
\hline D & 2100 & 598 & 12.5 & 366 & 161 & 450 & 0.38 \\
\hline 1 & 1201 & 203 & 5.2 & 203 & 182 & 625 & 0.29 \\
\hline
\end{tabular}




\section{Appendix C Reduced order model equations}

The calculations for the species inhibition and diffusivity terms are performed at every time step which contributes to significant computational time. Equations 1 - 6 show the equations involved in these calculations.

$$
\begin{aligned}
& \mathrm{R}_{\mathrm{HC}}=\frac{\mathrm{A}_{\mathrm{HC}}\left(\mathrm{T}_{\mathrm{W}}\right)^{\mathrm{x}} \mathrm{HC}^{-\frac{\mathrm{E}_{\mathrm{HC}}}{\mathrm{RT}_{\mathrm{W}}}\left[\mathrm{C}_{12} \mathrm{H}_{24}\right]\left[\mathrm{O}_{2}\right]}}{\mathrm{G}_{1}} \\
& \mathrm{R}_{\mathrm{CO}}=\frac{\mathrm{A}_{\mathrm{CO}}\left(\mathrm{T}_{\mathrm{w}}\right)^{\mathrm{x}_{\mathrm{CO}}} \mathrm{e}^{-\frac{\mathrm{E}_{\mathrm{CO}}}{\mathrm{RT}_{\mathrm{w}}}[\mathrm{CO}]\left[\mathrm{O}_{2}\right]}}{\mathrm{G}_{2}}
\end{aligned}
$$

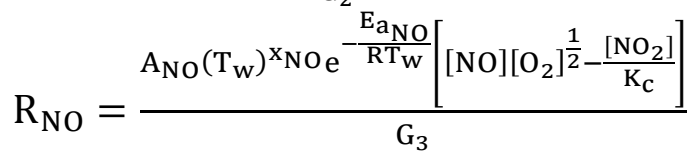

Where $G_{1}, G_{2}$ and $G_{3}$ are the inhibition factors calculated at every time step

$$
\begin{aligned}
& \mathrm{G}_{1}=\left(\frac{\mathrm{T}}{\mathrm{T}_{\mathrm{ref}}}\right)^{\mathrm{x}_{\mathrm{HC}}^{\mathrm{G}}}\left(1+\mathrm{K}_{\mathrm{a}, 1} \mathrm{C}_{\mathrm{CO}}+\mathrm{K}_{\mathrm{a}, 2} \mathrm{C}_{\mathrm{C}_{12} \mathrm{H}_{24}}\right)^{2}\left(1+\mathrm{K}_{\mathrm{a}, 3} \mathrm{C}_{\mathrm{CO}}^{2} \mathrm{C}_{\mathrm{C}_{12} \mathrm{H}_{24}}^{2}\right)\left(1+\mathrm{K}_{\mathrm{a}, 4} \mathrm{C}_{\mathrm{NO}}^{0.7}\right) \\
& \mathrm{G}_{2}=\left(\frac{\mathrm{T}}{\mathrm{T}_{\mathrm{ref}}}\right)^{\mathrm{x}_{\mathrm{CO}}^{\mathrm{G}}}\left(1+\mathrm{K}_{\mathrm{a}, 5} \mathrm{C}_{\mathrm{CO}}+\mathrm{K}_{\mathrm{a}, 6} \mathrm{C}_{\mathrm{C}_{12} \mathrm{H}_{24}}\right)^{2}\left(1+\mathrm{K}_{\mathrm{a}, 7} \mathrm{C}_{\mathrm{CO}}^{2} \mathrm{C}_{\mathrm{C}_{12} \mathrm{H}_{24}}^{2}\right)\left(1+\mathrm{K}_{\mathrm{a}, 8} \mathrm{C}_{\mathrm{NO}}^{0.7}\right) \\
& \mathrm{G}_{3}=\left(\frac{\mathrm{T}}{\mathrm{T}_{\mathrm{ref}}}\right)^{\mathrm{x}_{\mathrm{NO}}^{\mathrm{G}}}\left(1+\mathrm{K}_{\mathrm{a}, 9} \mathrm{C}_{\mathrm{CO}}+\mathrm{K}_{\mathrm{a}, 10} \mathrm{C}_{\mathrm{C}_{12} \mathrm{H}_{24}}\right)^{2}\left(1+\mathrm{K}_{\mathrm{a}, 11} \mathrm{C}_{\mathrm{CO}}^{2} \mathrm{C}_{\mathrm{C}_{12} \mathrm{H}_{24}}^{2}\right)\left(1+\mathrm{K}_{\mathrm{a}, 12} \mathrm{C}_{\mathrm{NO}}^{0.7}\right)
\end{aligned}
$$

The observations made from these equations are as follows:

1) For all the engine, operating conditions used in the study the contribution of $\mathrm{CO}$ and $\mathrm{C}_{12} \mathrm{H}_{24}$ on inhibition factors is low due to small amount of inlet concentrations of these species

2) The inhibition factor is a strong function of substrate temperature and does not vary significantly with variation of NO

3) The values of $x_{H C}^{G}, x_{C O}^{G}$ and $x_{N O}^{G}$ are found to be equal to 1 .

Based on these assumptions the inhibition terms can be reduced to following form

$$
\mathrm{G}_{\mathrm{i}}=\mathrm{K}_{\mathrm{i}}\left(\frac{\mathrm{T}}{\mathrm{T}_{\mathrm{ref}}}\right)
$$

Where $K_{i}$ is constant for a given species (-)

$\mathrm{G}_{\mathrm{i}}$ is the inhibition factor for given species (-)

T Substrate Temperature (K)

$\mathrm{T}_{\text {ref }}$ Reference temperature (K) 
This simplified form of the inhibition factor was tested in the high-fidelity model and found to produce results which were within $6 \%$ of the version with the inhibition factors calculated with the equations $4-6$ with a decrease in compute time by $7 \%$ ( 2500 seconds vs 2325 seconds)

The species conservation equation used in the SCR-F model is of the following form

$$
\mathrm{av}_{\mathrm{w}} \frac{\mathrm{dY_{i }}}{\mathrm{dy}}-\frac{\mathrm{d}}{\mathrm{dy}}\left(\mathrm{D}_{\mathrm{i}} \mathrm{a} \frac{\mathrm{dY_{i }}}{\mathrm{dy}}\right)=-\frac{\overline{\mathrm{a}}}{\left(\bar{\rho}_{\text {exh }}\right)_{\mathrm{w}}} \sum_{\mathrm{j}} \xi_{\mathrm{i}, \mathrm{j}} \mathrm{R}_{\mathrm{j}}
$$

Where $: a=$ Width of inlet channel $(\mathrm{m})$

$V_{w}=$ Exhaust gas velocity through the substrate wall $(\mathrm{m} / \mathrm{s})$

$D_{i}=$ Diffusivity of species $i\left(\mathrm{~m}^{2} / \mathrm{s}\right)$

$\mathrm{dy}=$ Thickness of substrate wall $(\mathrm{m})$

$Y_{i}=$ Concentration of chemical species $i\left(\mathrm{kmol}\right.$ of $\left.\mathrm{I} / \mathrm{m}^{3}\right)$

$\left(\bar{\rho}_{\text {exh }}\right)_{w}=$ Exhaust gas density in the substrate wall $\left(\mathrm{kmol}\right.$ of exhaust $\left./ \mathrm{m}^{3}\right)$

$\xi_{i, j}=$ Stoichiometric coefficient of the species $\mathrm{I}$ in reaction $\mathrm{j}(-)$

$R_{j}=$ Reaction rate of reaction $\mathrm{j}\left(\mathrm{kmol} / \mathrm{m}^{3} \mathrm{~s}\right)$

$\mathrm{i}=$ chemical species $\left(\mathrm{O}_{2}, \mathrm{CO}, \mathrm{CO}_{2}, \mathrm{HC}, \mathrm{NO}, \mathrm{NO}_{2}\right.$ and $\left.\mathrm{NH}_{3}\right)$

$\mathrm{j}=$ Chemical reactions (PM, NO, CO, HC oxidation and SCR reactions)

The diffusivity for each of these chemical species is calculated using the following equations

$$
\begin{gathered}
\mathrm{D}_{\mathrm{eff}, \mathrm{i}}=\frac{1}{\frac{1}{\epsilon}\left[\frac{1}{\mathrm{D}_{\mathrm{mol}, \mathrm{i}}}+\frac{1}{\mathrm{D}_{\mathrm{kn}, \mathrm{i}}}\right]} \\
\mathrm{D}_{\mathrm{i}, \mathrm{j}}=\frac{\mathrm{aT} \mathrm{b}}{\mathrm{P}}\left(\mathrm{T}_{\text {crtical }, \mathrm{i}} \mathrm{T}_{\text {critical }, \mathrm{j}}\right)^{\frac{5}{12}-\frac{\mathrm{b}}{2}}\left(\mathrm{P}_{\text {critical }, \mathrm{i}} \mathrm{P}_{\text {critical }, \mathrm{j}}\right)^{\frac{1}{3}}\left(\frac{1}{\mathrm{MW}_{\mathrm{i}}}+\frac{1}{\mathrm{MW}_{\mathrm{j}}}\right)^{\frac{1}{2}} \\
\mathrm{D}_{\mathrm{mol}, \mathrm{i}}=\frac{1-\mathrm{Y}_{\mathrm{i}}}{\sum_{\mathrm{j} \neq \mathrm{i}} \mathrm{Y}_{\mathrm{i}}} \\
\mathrm{D}_{\mathrm{Kn}, \mathrm{i}}=\frac{\mathrm{d}_{\mathrm{p}}}{3} \sqrt{\frac{8 \mathrm{RT}}{\pi \mathrm{MW}}}
\end{gathered}
$$

The following simplifications can be made to species model based on diffusivity

1) The diffusivity can be calculated only for $\mathrm{NO}, \mathrm{NO}_{2}$ since those are the only species which have a significant variation in concentration across the PM cake and substrate wall

2) The dependence of molecular diffusivity on absolute pressure is negligible since the variation of pressure in the filter is less than $5 \%$

The diffusivity equation can be modified as follows based on these observations

$$
\begin{aligned}
& \mathrm{D}_{\mathrm{mol}, \mathrm{i}}=\frac{1-\mathrm{Y}_{\mathrm{i}}}{\sum_{\mathrm{j} \neq \mathrm{i}} \frac{\mathrm{Y}_{\mathrm{i}}}{\mathrm{k}_{\mathrm{mol}} \mathrm{i}, \mathrm{j}^{\mathrm{T}}}} \\
& \mathrm{D}_{\mathrm{kn}, \mathrm{i}}=\mathrm{k}_{\mathrm{kn}, \mathrm{i}} \sqrt{\mathrm{T}}
\end{aligned}
$$


Where $\mathrm{k}_{\mathrm{mol}, \mathrm{i}, \mathrm{j}}$ and $\mathrm{k}_{\mathrm{kn}, \mathrm{i}}$ are constants

3) Lumping the Temperature of inlet and outlet channel gas temperature

The present version of the model is using the following equations to compute the temperature of exhaust gas in the inlet and outlet channel along with substrate wall

$$
\begin{aligned}
& \frac{d\left(M_{1} C_{p} T_{i n(i, j)}\right)}{d t}=u_{i n(i, j-1)} \rho_{g} C_{p} A T_{i n(i, j-1)}-u_{i n(i, j)} \rho_{g} C_{p} A T_{i n(i, j)}-v_{i} \rho_{g} C_{p} A T_{i n(i, j)}+h\left(T_{w(i, j)}-\right. \\
& \left.\mathrm{T}_{\mathrm{in}(\mathrm{i}, \mathrm{j})}\right) \operatorname{sdx} \quad(24) \\
& \frac{d\left(M_{2} C_{s} T_{w(i, j)}\right)}{d t}=v_{i} \rho_{g} C_{p} A T_{i n(i, j)}+h\left(T_{w(i, j)}-T_{i n(i, j)}\right) s d x+h\left(T_{\text {out }(i, j)}-T_{w(i, j)}\right) s d x- \\
& v_{i} \rho_{g} C_{p} A_{w}(i, j)+\frac{\lambda_{s} b s\left(T_{w(i, j+1)}+T_{w(i, j-1)}-2 T_{w(i, j)}\right)}{d x}+\frac{\lambda_{s} b s\left(T_{w(i+1, j)}+T_{w(i-1, j)}-2 T_{w(i, j)}\right)}{d y}+H_{L}\left(\frac{d_{p(i, j)}}{d t}\right) \\
& \frac{d\left(M_{3} C_{p} T_{\text {out }(i, j)}\right)}{d t}=u_{\text {out }(i, j-1)} \rho_{g} C_{p} A T_{\text {out }(i, j-1)}-u_{\text {out }(i, j)} \rho_{g} C_{p} A T_{\text {out }(i, j)}-v_{i} \rho_{g} C_{p} A T_{\text {out }(i, j)}+ \\
& h\left(T_{w(i, j)}-T_{\text {out }(i, j)}\right) s d x
\end{aligned}
$$

On applying the simplification this system gets reduced to 2 equations

$$
\begin{gathered}
\frac{d\left(M_{2} C_{s} T_{w(i, j)}\right)}{d t}=h\left(T_{g a s(i, j)}-T_{w(i, j)}\right) s d x+\frac{\lambda_{s} b s\left(T_{w(i, j+1)}+T_{w(i, j-1)}-2 T_{w(i, j)}\right)}{d x}+ \\
\frac{\lambda_{s} b s\left(T_{w(i+1, j)}+T_{w(i-1, j)}-2 T_{w(i, j)}\right)}{d y}+H_{L}\left(\frac{d m_{p(i, j)}}{d t}\right)(17) \\
\frac{d\left(M_{1} C_{p} T_{g a s(i, j)}\right)}{d t}=u_{\text {out }(i, j-1)} \rho_{g} C_{p} A T_{\text {gas }(i, j-1)}-u_{\text {out }(i, j)} \rho_{g} C_{p} A T_{\text {gas }(i, j)}+h\left(T_{w(i, j)}-T_{\text {gas }(i, j)}\right) s d x
\end{gathered}
$$

This approach will reduce the accuracy of the exhaust gas temperature by $4-5 \%$ with speedup of $5 \%$ compared to the previous set of equations. 


\section{Appendix D State estimator equations}

The scope of the estimator is to estimate the states including coverage fraction of $\mathrm{NH}_{3}$ storage inside the $\mathrm{SCRF}{ }^{\circledR}$ along with temperature, $\mathrm{PM}$ loading distribution. Outputs consisting of Pressure drop and outlet concentrations of chemical species including $\mathrm{NO}, \mathrm{NO}_{2}$ and $\mathrm{NH}_{3}$ will be estimated based on the values of the states.

The nonlinear system present in a problem solved by EKF is of general form described below

$$
\begin{gathered}
\mathrm{x}(\mathrm{k})=\mathrm{f}(\mathrm{x}(\mathrm{k}-1), \mathrm{u}(\mathrm{k}))+\mathrm{w}(\mathrm{k}) \\
\mathrm{z}(\mathrm{k})=\mathrm{h}(\mathrm{x}(\mathrm{k}))+\mathrm{v}(\mathrm{k})
\end{gathered}
$$

Where $w(k)$ and $v(k)$ are process and observation noises with zero mean multi variate Gaussian noise with covariance of $Q(k)$ and $R(k)$. The EFK estimates in two steps: 1) Prediction 2) Update.

In prediction step, the state vector $\mathrm{x}$ and the error covariance matrix $\mathrm{p}$ are predicted

$$
\begin{gathered}
x(k \mid k-1)=f(x(k-1 \mid k-1), u(k)) \\
P(k \mid k-1)=F(k) P(k-1 \mid k-1) F(K)^{T}+Q(K)
\end{gathered}
$$

Where $F$ is the Jacobian matrix of the state function $f$.

In update step, the predicted system states $\mathrm{x}(\mathrm{k} \mid \mathrm{k}-1)$ and error covariance matrix $\mathrm{P}(\mathrm{k} \mid \mathrm{k}-1)$ are updated by comparing them to measurement $z(k)$. Based on the assumption that the noises are zero mean Gaussian distribution, the optimal Kalman gain $\mathrm{K}(\mathrm{k})$ and the estimated value $\mathrm{x}(\mathrm{k})$ can be calculated by following equations

$$
\begin{aligned}
& \mathrm{y}(\mathrm{k})=\mathrm{z}(\mathrm{k})-\mathrm{h}(\mathrm{x}(\mathrm{k} \mid \mathrm{k}-1)) \\
& \mathrm{S}(\mathrm{k})=\mathrm{H}(\mathrm{k}) \mathrm{P}(\mathrm{k} \mid \mathrm{k}-1) \mathrm{H}(\mathrm{k})^{\mathrm{T}}+\mathrm{R}(\mathrm{k}) \\
& \mathrm{K}(\mathrm{k})=\mathrm{P}(\mathrm{k} \mid \mathrm{k}-1) \mathrm{H}(\mathrm{k})^{\mathrm{T}} \mathrm{S}(\mathrm{k})^{-1} \\
& \mathrm{x}(\mathrm{k} \mid \mathrm{k})=\mathrm{x}(\mathrm{k} \mid \mathrm{k}-1)+\mathrm{K}(\mathrm{k}) \mathrm{y}(\mathrm{k}) \\
& \mathrm{P}(\mathrm{k} \mid \mathrm{k})=(\mathrm{I}-\mathrm{K}(\mathrm{k}) \mathrm{H}(\mathrm{k})) \mathrm{P}(\mathrm{k} \mid \mathrm{k}-1)
\end{aligned}
$$

Where $\mathrm{H}$ is Jacobian function of output function $\mathrm{h}$.

The proposed states for the SCR-F estimator are as follows

$$
\mathrm{x}_{\mathrm{k}_{\mathrm{i}, \mathrm{j}}}=\left[\begin{array}{c}
\theta_{\mathrm{K}_{\mathrm{i}, \mathrm{j}}} \\
\mathrm{M}_{\mathrm{PM}, \mathrm{K}_{\mathrm{i}, \mathrm{j}}} \\
\mathrm{T}_{\mathrm{f}, \mathrm{K}_{\mathrm{i}, \mathrm{j}}}
\end{array}\right]
$$


Where subscripts $\mathrm{i}$ and $\mathrm{j}$ represent indexes for radial and axial zones respectively. $\theta_{i, k}=$ coverage fraction of $\mathrm{NH}_{3}$ storage in each of the radial and axial zone $(\mathrm{i}, j)$ at time step $\mathrm{k}, M_{P M, K_{i, j}}$ $=$ PM loading in each axial and radial zone at time step $\mathrm{k}, \mathrm{T}_{\mathrm{f}, \mathrm{K}_{\mathrm{i}, \mathrm{j}}}=$ temperature of the filter substrate at each axial and radial zone at time step $k$. The function $f$ represents the equations used for each of these calculations

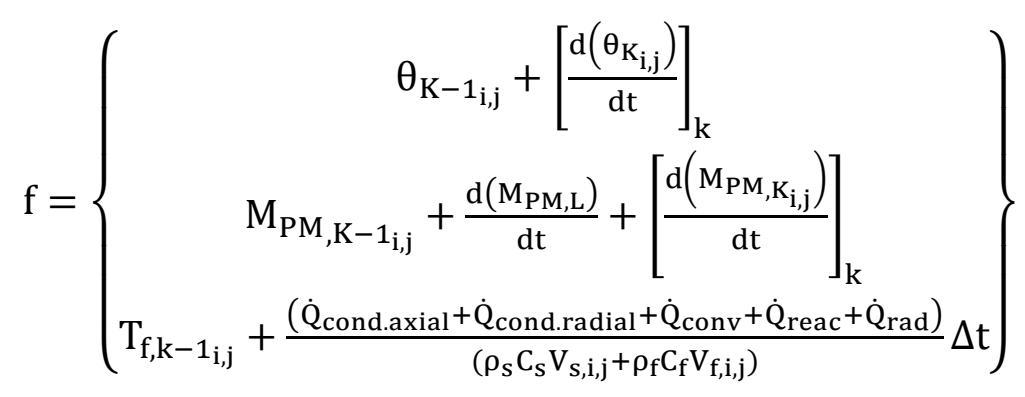

